\title{
Butadiyne-Bridged (Porphinato)Zinc(II) Chromophores Assemble into Free-Standing Nanosheets
}

Chuan Liu, ${ }^{\mathrm{a}}$ Kaixuan Liu, ${ }^{\mathrm{a}}$ Arindam Mukhopadhyay, ${ }^{\mathrm{a}}$ Victor Paulino, ${ }^{\mathrm{a}}$ Brianna Bernard, ${ }^{\mathrm{a}}$ and JeanHubert Olivier ${ }^{\mathrm{a}^{*}}$

aDepartment of Chemistry, University of Miami, Coral Gables, FL 33146, USA

*To whom correspondence may be sent: Jean-Hubert Olivier (jh.olivier@miami.edu)

\section{Table of Contents:}

1) Materials and Methods (p.2-3)

2) Synthetic Procedures (p.4-9)

3) DFT and TD-TDFT Calculation (p.10-12)

4) Variable-Temperature Electronic Absorption Spectra of MPZnE 2 PZnM (p.13-17)

5) Additional Ground-State Electronic Absorption Spectra (p.18-23)

6) Finke-Watzky Model (p.24)

7) Atomic Force Microscopy Images (p.25-27)

8) NMR and MS Spectra (p.28-64)

9) References (p.65) 


\section{Materials and Methods}

Materials and Instrumentation. All water-sensitive and oxygen-sensitive compounds were stored and handled in a Braun Labmaster DP glovebox. Standard Schlenk techniques were employed to manipulate water-sensitive and oxygen-sensitive reactions. Only ultrapure argon purchased from Airgas was used. All water used is DI water. All non-distilled dry solvents were prepared by molecular sieves (type 3A). Distilled tetrahydrofuran (THF) was prepared under argon using a sodium/benzophenone distillation device. Methanol, ethanol, THF, hexane, diethylether, pyridine, acetone, chloroform, dichloromethane, $N, N$-dimethylformamide (DMF), potassium hydroxide, sodium chloride, hydrochloric acid, and silica gel (70 90 $\mu \mathrm{m})$ were purchased from VWR International. Trimethylsilylacetylene and 4-iodoaniline were purchased from Matrix Scientific. Sodium sulfate, potassium carbonate, diisopropylamine, tetrabutylammonium fluoride (1 M solution in THF), and pyridinium chloride were purchased from MilliporeSigma. Copper(I) iodide, sodium, benzophenone, triisopropylsilylacetylene, copper(II) acetate, 4-(dimethylamino)butyric acid hydrochloride, and methyl iodide were purchased from Alfa Aesar. Sodium tetrafluoroborate, $N, N$-dimethylpyridin-4-amine, and $N$-(3-dimethylaminopropyl)- $N$ 'ethylcarbodiimide hydrochloride were purchased from Tokyo Chemical Industry Co., Ltd. Tetrakis(triphenylphosphine)palladium(0) was purchased from Strem Chemicals, Inc. Size exclusion chromatography was performed using Bio-Beads S-X1 Support purchased from Bio-Rad Laboratories, Inc. Nuclear magnetic resonance (NMR) spectroscopy was performed on a Bruker Avance NMR spectrometer. All deuterated solvents were purchased from Cambridge Isotope Laboratories, Inc. Groundstate electronic absorption spectrophotometry was performed on a Cary 5000 UV-Vis-NIR spectrophotometer equipped with a Peltier cooling and heating stage. Spectroscopic cells/cuvets were purchased from Starna Cells, Inc. Quartz plates used for solid-state electronic absorption spectrophotometry were purchased from Ted Pella, Inc. Fourier-transform infrared (FTIR) spectroscopy was performed on a PerkinElmer Frontier FTIR spectrometer. Electrospray ionization mass spectrometry (ESI-MS) was performed on a Bruker MicroQ-TOF III ESI mass spectrometer. Matrix-assisted laser desorption/ionization mass spectrometry (MALDI-MS) was performed on a Bruker Autoflex III MALDI mass spectrometer. Atomic force microscopy (AFM) was performed on a Dimension 3100 Scanning Probe Microscope. Silicon wafers $(<111>$, p-type with boron as dopant, $0.5 \mathrm{~mm}$ thick) used to prepare AFM samples were purchased from UniversityWafer, Inc. DFT and TDDFT calculations have been performed using Gaussian 09 hosted on the University of Miami Supercomputer Pegasus. ${ }^{1}$ 
Solid-State Electronic Absorption Spectrophotometry Sample Preparation. Quartz plates were cleaned by Piranha solution and air-dried. Porphyrin solutions were dropcasted onto the quartz plates. When there was no visible liquid left, the quartz plates were dried under vacuum.

AFM Sample Preparation. Silicon wafers were soaked in ethanol for $1 \mathrm{~h}$ and washed with acetone. Porphyrin solutions that had undergone the corresponding experiments were then dropcasted onto the wafers. When a coffee ring was formed, the remaining liquid was removed by an air stream carefully. The wafers were dried under vacuum before AFM experiments. 


\section{Synthetic Procedures}

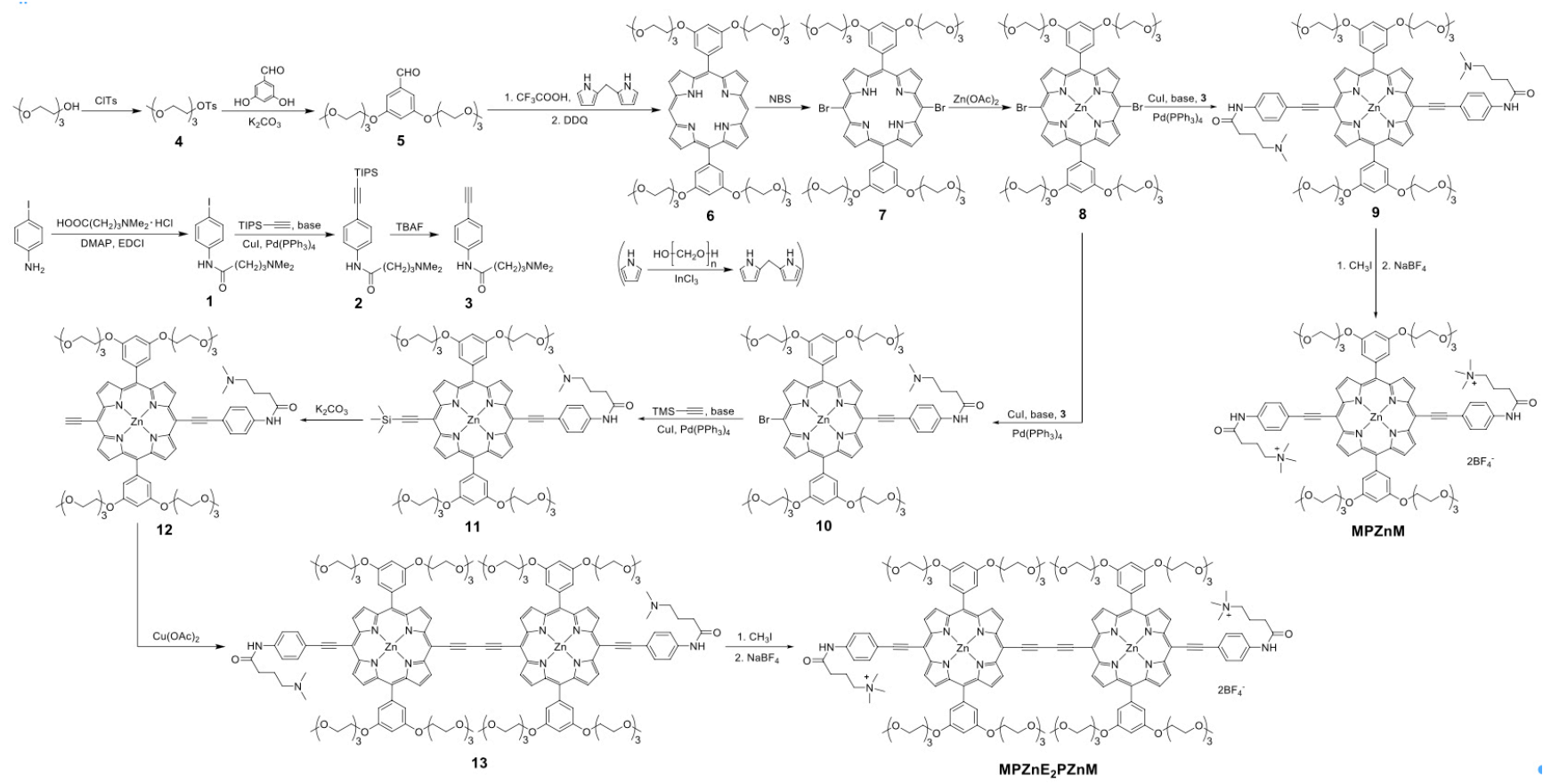

Scheme S1: Synthetic scheme for the (porphinato)zinc(II) building blocks involved in this study. Compounds $\mathbf{4} \sim \mathbf{8}$ and dipyrromethane were synthesized according to previously reported procedures. ${ }^{2,3}$

Compound 1. 4-Iodoaniline (5.00 g, $\left.2.28 \times 10^{-2} \mathrm{~mol}\right)$, 4-(dimethylamino)butyric acid hydrochloride $(3.83$ g, $\left.2.28 \times 10^{-2} \mathrm{~mol}\right), \quad N, N$-dimethylpyridin-4-amine $\left(6.96 \mathrm{~g}, 5.70 \times 10^{-2} \mathrm{~mol}\right)$ and $N$-(3dimethylaminopropyl)- $N$ '-ethylcarbodiimide hydrochloride $\left(8.74 \mathrm{~g}, 4.56 \times 10^{-2} \mathrm{~mol}\right)$ were dissolved in $100 \mathrm{~mL}$ of dry DMF, and the solution was purged with Ar for $15 \mathrm{~min}$. The reaction mixture was stirred at room temperature under $\mathrm{Ar}$ for $18 \mathrm{~h}$, and $500 \mathrm{~mL}$ of $\mathrm{H}_{2} \mathrm{O}$ was added. The mixture was extracted using $\mathrm{CH}_{2} \mathrm{Cl}_{2}$, and the organic layer was washed with $50 \mathrm{~mL}$ brine twice and dried over $\mathrm{Na}_{2} \mathrm{SO}_{4}$. After solvent removal, the residue was chromatographed on silica using 100:5:2 $\mathrm{CH}_{2} \mathrm{Cl}_{2}: \mathrm{CH}_{3} \mathrm{OH}: \mathrm{Et}_{3} \mathrm{~N}$ as the eluent. The collected solid was dried under vacuum to give the desired product as a white solid (7.13 $\mathrm{g}, 94 \%)$. ${ }^{1} \mathrm{H}$ NMR $\left(400 \mathrm{MHz}, \mathrm{CDCl}_{3}\right) \delta=10.20(\mathrm{~s}, 1 \mathrm{H}), 7.49$ (d, 2H, J=8.8 Hz), 7.27 (d, 2H, J=8.8 Hz), 2.39 (t, $2 \mathrm{H}, J=6.6 \mathrm{~Hz}), 2.32(\mathrm{t}, 2 \mathrm{H}, J=6.4 \mathrm{~Hz}), 2.20(\mathrm{~s}, 6 \mathrm{H}), 1.76(\mathrm{~m}, 2 \mathrm{H}) \mathrm{ppm} .{ }^{13} \mathrm{C} \mathrm{NMR}\left(101 \mathrm{MHz}, \mathrm{CD}_{3} \mathrm{OD}\right)$ $\delta=172.6,139.7,138.9,123.0,87.8,58.6,43.5,34.2,21.2$ ppm. ESI-MS m/z: $333.05\left([\mathrm{M}+\mathrm{H}]^{+}\right.$, calcd for 333.05). FTIR: $\bar{v}=3355,3100,3057,2917,2851,1702,1661,1623,1540 \mathrm{~cm}^{-1}$. 
Compound 2. Compound 1 (1.00 g, $\left.3.01 \times 10^{-3} \mathrm{~mol}\right), \mathrm{CuI}\left(57.0 \mathrm{mg}, 2.99 \times 10^{-4} \mathrm{~mol}\right)$ and $\mathrm{Pd}\left(\mathrm{PPh}_{3}\right)_{4}(348$ $\left.\mathrm{mg}, 3.01 \times 10^{-4} \mathrm{~mol}\right)$ were added into a Schlenk flask in a glove box. After triisopropylsilylacetylene (1.35 $\left.\mathrm{mL}, 6.02 \times 10^{-3} \mathrm{~mol}\right), 50 \mathrm{~mL}$ of distilled THF and $10 \mathrm{~mL}$ of dry $\left(\mathrm{Me}_{2} \mathrm{CH}\right)_{2} \mathrm{NH}$ were mixed, freeze-pumpthawed and cannulated into the Schlenk flask, the reaction mixture was stirred at $60{ }^{\circ} \mathrm{C}$ for $12 \mathrm{~h}$ under $\mathrm{Ar}$ and passed through a silica plug using THF as the eluent. The solvent was evaporated, and the solid was dissolved in $50 \mathrm{~mL}$ of $\mathrm{CHCl}_{3}$, washed with $50 \mathrm{~mL}$ of brine twice and dried over $\mathrm{Na}_{2} \mathrm{SO}_{4}$. After solvent removal, the residue was chromatographed on silica using 100:5:2 $\mathrm{CH}_{2} \mathrm{Cl}_{2}: \mathrm{CH}_{3} \mathrm{OH}: \mathrm{Et}_{3} \mathrm{~N}$ as the eluent. The collected solid was dried under vacuum to give the desired product as a white solid (1.00 g, 86\%). ${ }^{1} \mathrm{H} \mathrm{NMR}\left(400 \mathrm{MHz}, \mathrm{CDCl}_{3}\right) \delta=10.14(\mathrm{~s}, 1 \mathrm{H}), 7.47(\mathrm{~d}, 2 \mathrm{H}, J=8.4 \mathrm{~Hz}), 7.41(\mathrm{~d}, 2 \mathrm{H}, J=8.4 \mathrm{~Hz}), 2.50$ (t, $2 \mathrm{H}, J=6.4 \mathrm{~Hz}), 2.44(\mathrm{t}, 2 \mathrm{H}, J=6.0 \mathrm{~Hz}), 2.30(\mathrm{~s}, 6 \mathrm{H}), 1.85(\mathrm{~m}, 2 \mathrm{H}), 1.12(\mathrm{~m}, 21 \mathrm{H}) \mathrm{ppm} .{ }^{13} \mathrm{C} \mathrm{NMR}(101$ $\left.\mathrm{MHz}_{2} \mathrm{CDCl}_{3}\right) \delta=171.5,139.0,132.8,118.7,118.4,107.1,89.5,59.0,45.0,37.2,22.6,18.7,11.3 \mathrm{ppm}$. ESI-MS m/z: $387.28\left([\mathrm{M}+\mathrm{H}]^{+}\right.$, calcd for 387.28). FTIR: $\bar{v}=3397,3269,3145,2928,2875,2159,1709$, $1635,1570 \mathrm{~cm}^{-1}$.

Compound 3. Compound $2\left(0.500 \mathrm{~g}, 1.29 \times 10^{-3} \mathrm{~mol}\right)$ was dissolved in $20 \mathrm{~mL}$ of distilled THF, and the solution was stirred at $273 \mathrm{~K}$ under Ar, followed by dropwise addition of a $1 \mathrm{M}$ THF solution of tetrabutylammonium fluoride $\left(2.00 \mathrm{~mL}, 2.00 \times 10^{-3} \mathrm{~mol}\right)$ to the reaction. After $20 \mathrm{~min}$, a drop of $\mathrm{H}_{2} \mathrm{O}$ was added, and the solvent was evaporated. The resulting solid was dissolved in $50 \mathrm{~mL}$ of $\mathrm{CHCl}_{3}$, washed with $50 \mathrm{~mL}$ of brine twice and dried over $\mathrm{Na}_{2} \mathrm{SO}_{4}$. After solvent removal, the residue was chromatographed on silica using 100:5:2 $\mathrm{CH}_{2} \mathrm{Cl}_{2}: \mathrm{CH}_{3} \mathrm{OH}: \mathrm{Et}_{3} \mathrm{~N}$ as the eluent. The collected solid was dried under vacuum to give the desired product as a white solid $(0.24 \mathrm{~g}, 80 \%) .{ }^{1} \mathrm{H} \mathrm{NMR}\left(500 \mathrm{MHz}, \mathrm{CDCl}_{3}\right)$ $\delta=10.17(\mathrm{~s}, 1 \mathrm{H}), 7.50(\mathrm{~d}, 2 \mathrm{H}, J=9.0 \mathrm{~Hz}), 7.40(\mathrm{~d}, 2 \mathrm{H}, J=9.0 \mathrm{~Hz}), 3.01(\mathrm{~s}, 1 \mathrm{H}), 2.48(\mathrm{t}, 2 \mathrm{H}, J=6.5 \mathrm{~Hz})$, $2.43(\mathrm{t}, 2 \mathrm{H}, J=6.0 \mathrm{~Hz}), 2.30(\mathrm{~s}, 6 \mathrm{H}), 1.85(\mathrm{~m}, 2 \mathrm{H}) \mathrm{ppm} .{ }^{13} \mathrm{C} \mathrm{NMR}\left(101 \mathrm{MHz}, \mathrm{CDCl}_{3}\right) \delta=171.8,139.4$, 132.8, 119.0, 116.8, 83.6, 76.5, 59.0, 45.0, 36.9, $22.6 \mathrm{ppm}$. ESI-MS m/z: $231.15\left([\mathrm{M}+\mathrm{H}]^{+}\right.$, calcd for 231.15). FTIR: $\bar{v}=3478,3305,3041,2921,2250,1704,1635,1545 \mathrm{~cm}^{-1}$.

Compound 9 and 10. Compound $8\left(0.100 \mathrm{~g}, 7.51 \times 10^{-4} \mathrm{~mol}\right)$, Compound $3\left(0.0173 \mathrm{~g}, 7.51 \times 10^{-4} \mathrm{~mol}\right)$, $\mathrm{CuI}\left(14.3 \mathrm{mg}, 7.51 \times 10^{-5} \mathrm{~mol}\right)$ and $\mathrm{Pd}\left(\mathrm{PPh}_{3}\right)_{4}\left(133 \mathrm{mg}, 1.13 \times 10^{-4} \mathrm{~mol}\right)$ were added into a Schlenk flask in a glove box. After $50 \mathrm{~mL}$ of distilled THF and $10 \mathrm{~mL}$ of dry $\left(\mathrm{Me}_{2} \mathrm{CH}\right)_{2} \mathrm{NH}$ were mixed, freeze-pumpthawed and cannulated into the Schlenk flask, the reaction mixture was stirred at $60{ }^{\circ} \mathrm{C}$ for $12 \mathrm{~h}$ under $\mathrm{Ar}$ and passed through a silica plug using THF as the eluent. After solvent removal, the residue was chromatographed on silica using 100:5:2 $\mathrm{CH}_{2} \mathrm{Cl}_{2}: \mathrm{CH}_{3} \mathrm{OH}: \mathrm{Et}_{3} \mathrm{~N}$ as the eluent. Three colorful bands eluded 
out from the column. The first band (puce) was the starting material (Compound 8), so it was collected and reused for future reactions. The second band (green) was Compound 10, and the third band (green) was Compound 9. Both Compound 9 and Compound $\mathbf{1 0}$ were then purified by size exclusion chromatography (Compound 9 and Compound 10 separately) using THF as the eluent. The collected solids were both washed with 10:1 hexane: $\mathrm{CH}_{2} \mathrm{Cl}_{2}$ and dried under vacuum to give the desired products. Compound 9: green solid, $0.025 \mathrm{~g}, 21 \%$ (based off of the amount of Compound 8 used). Compound 10: green solid, $0.059 \mathrm{~g}, 53 \%$ (based off of the amount of Compound 8 used).

Compound 9: ${ }^{1} \mathrm{H}$ NMR $\left(500 \mathrm{MHz}, \mathrm{CDCl}_{3}\right.$ with $1 \%$ deuterated pyridine) $\delta=10.14(\mathrm{~s}, 2 \mathrm{H}), 9.66(\mathrm{~d}, 4 \mathrm{H}, J$ $=4.5 \mathrm{~Hz}), 8.91(\mathrm{~d}, 4 \mathrm{H}, J=4.5 \mathrm{~Hz}), 7.94(\mathrm{~d}, 4 \mathrm{H}, J=8.5 \mathrm{~Hz}), 7.78(\mathrm{~d}, 4 \mathrm{H}, J=8.5 \mathrm{~Hz}), 7.37$ (d, 4H, $J=2.0$ $\mathrm{Hz}), 6.93(\mathrm{t}, 2 \mathrm{H}, J=2.0 \mathrm{~Hz}), 4.32(\mathrm{t}, 8 \mathrm{H}, J=4.8 \mathrm{~Hz}), 3.94(\mathrm{t}, 8 \mathrm{H}, J=4.8 \mathrm{~Hz}), 3.78(\mathrm{~m}, 8 \mathrm{H}), 3.69$ (m, $8 \mathrm{H}), 3.63(\mathrm{~m}, 8 \mathrm{H}), 3.50(\mathrm{~m}, 8 \mathrm{H}), 3.31(\mathrm{~s}, 12 \mathrm{H}), 2.60(\mathrm{t}, 4 \mathrm{H}, J=6.3 \mathrm{~Hz}), 2.55(\mathrm{t}, 4 \mathrm{H}, J=6.3 \mathrm{~Hz}), 2.38$ (s, 12H), $1.92(\mathrm{~m}, 4 \mathrm{H})$ ppm. ${ }^{13} \mathrm{C}$ NMR (101 MHz, $\mathrm{CDCl}_{3}$ with $1 \%$ deuterated pyridine) $\delta=171.1,157.8$, 152.0, 149.6, 144.6, 138.9, 132.4, 132.3, 130.6, 122.1, 119.4, 119.3, 114.8, 101.2 , 101.0, 96.3, 92.8, 71.9, 70.9, 70.7, 70.6, 69.8, 67.8, 59.0, 44.4, 31.6, 22.6, 14.1 ppm. MALDI-MS m/z: 1629.70 ([M+H] $]^{+}$, calcd for 1629.72). FTIR: $\bar{v}=3378,3030,2938,2710,2511,1639,1544,1500 \mathrm{~cm}^{-1}$.

Compound 10: ${ }^{1} \mathrm{H} \mathrm{NMR}\left(400 \mathrm{MHz}, \mathrm{CDCl}_{3}\right.$ with $1 \%$ deuterated pyridine) $\delta=10.21(\mathrm{~s}, 1 \mathrm{H}), 9.68(\mathrm{~d}, 2 \mathrm{H}$, $J=4.4 \mathrm{~Hz}), 9.59$ (d, 2H, $J=4.8 \mathrm{~Hz}), 8.94(\mathrm{~d}, 2 \mathrm{H}, J=4.4 \mathrm{~Hz}), 8.90$ (d, 2H, $J=4.4 \mathrm{~Hz}), 7.94$ (d, 2H, $J=$ $8.4 \mathrm{~Hz}), 7.74(\mathrm{~d}, 2 \mathrm{H}, J=8.4 \mathrm{~Hz}), 7.35(\mathrm{~d}, 4 \mathrm{H}, J=1.6 \mathrm{~Hz}), 6.93(\mathrm{~s}, 2 \mathrm{H}), 4.31(\mathrm{t}, 8 \mathrm{H}, J=4.6 \mathrm{~Hz}), 3.94(\mathrm{t}$, $8 \mathrm{H}, J=4.6 \mathrm{~Hz}), 3.78(\mathrm{~m}, 8 \mathrm{H}), 3.69(\mathrm{~m}, 8 \mathrm{H}), 3.63(\mathrm{~m}, 8 \mathrm{H}), 3.50(\mathrm{~m}, 8 \mathrm{H}), 3.32(\mathrm{~s}, 12 \mathrm{H}), 2.49(\mathrm{t}, 2 \mathrm{H}, J=$ $6.2 \mathrm{~Hz}), 2.30(\mathrm{~m}, 2 \mathrm{H}), 2.16(\mathrm{~s}, 6 \mathrm{H}), 1.75(\mathrm{~m}, 2 \mathrm{H}) \mathrm{ppm} .{ }^{13} \mathrm{C} \mathrm{NMR}\left(101 \mathrm{MHz}, \mathrm{CDCl}_{3}\right.$ with 1\% deuterated pyridine) $\delta=171.6,157.8,152.7,150.5,149.6,149.5,144.5,139.1,132.8,132.8,132.6,132.3,130.8$, $121.7,119.4,119.2,114.8,105.8,100.9,100.4,96.1,92.6,71.9,70.9,70.7,70.6,69.8,67.8,59.0,44.8$, 29.7, 22.4, $13.6 \mathrm{ppm}$. MALDI-MS m/z: $1479.47\left([\mathrm{M}+\mathrm{H}]^{+}\right.$, calcd for 1479.50). FTIR: $\bar{v}=3399,3041$, $2939,2799,1715,1644,1545 \mathrm{~cm}^{-1}$.

MPZnM. Compound $9\left(0.0500 \mathrm{~g}, 3.07 \times 10^{-5} \mathrm{~mol}\right)$ was dissolved in $20 \mathrm{~mL}$ of dry DMF, and the solution was purged with Ar for $30 \mathrm{~min}$. After the solution was cooled to $273 \mathrm{~K}, \mathrm{CH}_{3} \mathrm{I}\left(0.010 \mathrm{~mL}, 1.61 \times 10^{-4} \mathrm{~mol}\right)$ was added. The reaction mixture was stirred at room temperature under Ar for $4 \mathrm{~h}$ and added dropwise into $100 \mathrm{~mL}$ of saturated $\mathrm{NaBF}_{4}$ solution in $\mathrm{H}_{2} \mathrm{O}$. A precipitate was collected via centrifugation and washed with THF to yield the desired product as a green solid (0.054 g, 97\%). ${ }^{1} \mathrm{H} \mathrm{NMR} \mathrm{(400} \mathrm{MHz,}$ $\left(\mathrm{CD}_{3}\right)_{2} \mathrm{SO}$ with $1 \%$ deuterated pyridine) $\delta=9.72(\mathrm{~d}, 4 \mathrm{H}, J=4.8 \mathrm{~Hz}), 9.58(\mathrm{~s}, 2 \mathrm{H}), 8.99(\mathrm{~d}, 4 \mathrm{H}, J=4.8$ Hz), $7.99(\mathrm{~d}, 4 \mathrm{H}, J=8.4 \mathrm{~Hz}), 7.92(\mathrm{~d}, 4 \mathrm{H}, J=8.0 \mathrm{~Hz}), 7.41(\mathrm{~s}, 4 \mathrm{H}), 7.03(\mathrm{~s}, 2 \mathrm{H}), 4.34(\mathrm{t}, 8 \mathrm{H}, J=4.8 \mathrm{~Hz})$, 
$3.92(\mathrm{t}, 8 \mathrm{H}, J=4.6 \mathrm{~Hz}), 3.70(\mathrm{~m}, 8 \mathrm{H}), 3.61(\mathrm{~m}, 8 \mathrm{H}), 3.58(\mathrm{~m}, 8 \mathrm{H}), 3.45(\mathrm{~m}, 8 \mathrm{H}), 3.26(\mathrm{~s}, 12 \mathrm{H}), 2.68(\mathrm{~m}$, $4 \mathrm{H}, J=6.4 \mathrm{~Hz}), 2.45(\mathrm{~s}, 18 \mathrm{H}), 2.31(\mathrm{~m}, 8 \mathrm{H}) \mathrm{ppm}$. Unfortunately, no resolved ${ }^{13} \mathrm{C}$ NMR spectrum with a considerable signal-to-noise ratio was successfully obtained because of the poor solubility of this compound. ESI-MS m/z: $829.38\left(\mathrm{M}^{2+}\right.$, calcd for 829.38); $560.58\left([\mathrm{M}+\mathrm{Na}]^{3+}\right.$, calcd for 560.58). Note: here "M" refers to the cation in this ionic compound.

Compound 11. Compound $10\left(0.250 \mathrm{~g}, 1.69 \times 10^{-4} \mathrm{~mol}\right)$, CuI $\left(3.20 \mathrm{mg}, 1.68 \times 10^{-5} \mathrm{~mol}\right)$ and $\mathrm{Pd}\left(\mathrm{PPh}_{3}\right)_{4}$ $\left(19.5 \mathrm{mg}, 1.69 \times 10^{-5} \mathrm{~mol}\right)$ were added into a Schlenk flask in a glove box. After trimethylsilylacetylene $\left(0.48 \mathrm{~mL}, 3.37 \times 10^{-3} \mathrm{~mol}\right), 40 \mathrm{~mL}$ of distilled THF and $10 \mathrm{~mL}$ of dry $\left(\mathrm{Me}_{2} \mathrm{CH}\right)_{2} \mathrm{NH}$ were mixed, freezepump-thawed and cannulated into the Schlenk flask, the reaction mixture was stirred at $60{ }^{\circ} \mathrm{C}$ for $12 \mathrm{~h}$ under Ar and passed through a silica plug using THF as the eluent. The solvent was evaporated, and the solid was dissolved in $50 \mathrm{~mL}$ of $\mathrm{CHCl}_{3}$, washed with $50 \mathrm{~mL}$ of brine twice and dried over $\mathrm{Na}_{2} \mathrm{SO}_{4}$. After solvent removal, the residue was first chromatographed on silica using 100:5:2 $\mathrm{CH}_{2} \mathrm{Cl}_{2}: \mathrm{CH}_{3} \mathrm{OH}: \mathrm{Et}_{3} \mathrm{~N}$ as the eluent and then purified by size exclusion chromatography using THF as the eluent. The collected solid was washed with 10:1 hexane: $\mathrm{CH}_{2} \mathrm{Cl}_{2}$ and dried under vacuum to give the desired product as a green solid (0.201 g, 79\%). ${ }^{1} \mathrm{H} \mathrm{NMR}\left(400 \mathrm{MHz}, \mathrm{CDCl}_{3}\right.$ with $1 \%$ deuterated pyridine) $\delta=10.04(\mathrm{~s}, 1 \mathrm{H}), 9.67$ $(\mathrm{d}, 2 \mathrm{H}, J=4.4 \mathrm{~Hz}), 9.59(\mathrm{~d}, 2 \mathrm{H}, J=4.8 \mathrm{~Hz}), 8.91(\mathrm{~m}, 4 \mathrm{H}), 7.93(\mathrm{~d}, 2 \mathrm{H}, J=8.4 \mathrm{~Hz}), 7.77(\mathrm{~d}, 2 \mathrm{H}, J=8.4$ $\mathrm{Hz}), 7.36(\mathrm{~d}, 4 \mathrm{H}, J=2.0 \mathrm{~Hz}), 6.93(\mathrm{~s}, 2 \mathrm{H}), 4.32(\mathrm{t}, 8 \mathrm{H}, J=4.6 \mathrm{~Hz}), 3.94(\mathrm{t}, 8 \mathrm{H}, J=4.6 \mathrm{~Hz}), 3.78(\mathrm{~m}, 8 \mathrm{H})$, $3.69(\mathrm{~m}, 8 \mathrm{H}), 3.63(\mathrm{~m}, 8 \mathrm{H}), 3.49(\mathrm{~m}, 8 \mathrm{H}), 3.32(\mathrm{~s}, 12 \mathrm{H}), 2.47(\mathrm{~m}, 2 \mathrm{H}), 2.33(\mathrm{~m}, 2 \mathrm{H}), 2.17(\mathrm{~s}, 6 \mathrm{H}), 1.75$ $(\mathrm{m}, 2 \mathrm{H}) \mathrm{ppm} .{ }^{13} \mathrm{C} \mathrm{NMR}\left(101 \mathrm{MHz}, \mathrm{CDCl}_{3}\right.$ with $1 \%$ deuterated pyridine) $\delta=171.0,157.8,152.4,151.8$, $149.8,149.7,144.5,139.0,132.5,132.3,132.3,130.8,130.7,122.0,119.5,119.2,114.8,108.4,101.6$, 100.9, 100.8, 100.2, 96.4, 92.7, 71.9, 70.9, 70.7, 70.6, 69.8, 67.8, 59.0, 44.2, 31.6, 22.6, 14.1, 0.4 ppm. MALDI-MS m/z: $1497.67\left([\mathrm{M}+\mathrm{H}]^{+}\right.$, calcd for 1497.63). FTIR: $\bar{v}=3490,2919,2178,1714,1636,1538$ $\mathrm{cm}^{-1}$.

Compound 12. Compound $11\left(0.200 \mathrm{~g}, 1.33 \times 10^{-4} \mathrm{~mol}\right)$ was dissolved in a mixture of $100 \mathrm{~mL}$ of $\mathrm{MeOH}$ and $1 \mathrm{~mL} \mathrm{H} \mathrm{H}_{2} \mathrm{O}$, and the solution was purged with Ar for $15 \mathrm{~min} . \mathrm{K}_{2} \mathrm{CO}_{3}\left(1.890 \mathrm{~g}, 1.37 \times 10^{-2}\right.$ mol) was added, and the suspension was stirred vigorously at room temperature under Ar for $16 \mathrm{~h}$. After solvent removal, $100 \mathrm{~mL}$ of $\mathrm{CH}_{2} \mathrm{Cl}_{2}$ and $100 \mathrm{~mL}$ of $\mathrm{H}_{2} \mathrm{O}$ were added to the solid, and a classic extraction was performed with the mixture. The organic layer was dried over $\mathrm{Na}_{2} \mathrm{SO}_{4}$ and passed through a silica plug using 100:5:2 $\mathrm{CH}_{2} \mathrm{Cl}_{2}: \mathrm{CH}_{3} \mathrm{OH}: \mathrm{Et}_{3} \mathrm{~N}$ as the eluent. The collected green solid was dried under vacuum and directly applied to the next synthetic step without further purification. Only MS was used to characterize 
this compound because of its instability and the importance of participating in the next reaction step with its freshness kept. MALDI-MS m/z: $1464.51\left([\mathrm{M}+\mathrm{K}]^{+}\right.$, calcd for 1464.55).

Compound 13. Compound 12 (around $0.2 \mathrm{~g}$, the resulting green solid described in the last paragraph) was dissolved in $20 \mathrm{~mL}$ of dry pyridine, and the solution was purged with Ar for $15 \mathrm{~min}$. Copper(II) acetate $\left(19.1 \mathrm{mg}, 1.05 \times 10^{-4} \mathrm{~mol}\right)$ in $2 \mathrm{~mL}$ of pyridine was heated to $333 \mathrm{~K}$ under $\mathrm{Ar}$ and added to the porphyrin solution. The mixture was then stirred at $363 \mathrm{~K}$ under $\mathrm{Ar}$ for $1 \mathrm{~h}$. A drop of $\mathrm{H}_{2} \mathrm{O}$ was added, and the solvent was evaporated. The residue was first chromatographed on silica using 100:5:2 $\mathrm{CH}_{2} \mathrm{Cl}_{2}: \mathrm{CH}_{3} \mathrm{OH}: \mathrm{Et}_{3} \mathrm{~N}$ as the eluent and then purified by size exclusion chromatography using THF as the eluent. The collected solid was washed with 10:1 hexane: $\mathrm{CH}_{2} \mathrm{Cl}_{2}$ and dried under vacuum to give the desired product as a yellowish green solid (0.150 g). ${ }^{1} \mathrm{H}$ NMR (400 $\mathrm{MHz}, \mathrm{CDCl}_{3}$ with $1 \%$ deuterated pyridine) $\delta=9.85(\mathrm{~d}, 4 \mathrm{H}, J=4.4 \mathrm{~Hz}), 9.68(\mathrm{~d}, 4 \mathrm{H}, J=4.4 \mathrm{~Hz}), 9.47(\mathrm{~s}, 2 \mathrm{H}), 9.01(\mathrm{~d}, 4 \mathrm{H}, J=4.8 \mathrm{~Hz})$, $8.92(\mathrm{~d}, 4 \mathrm{H}, J=4.4 \mathrm{~Hz}), 7.95(\mathrm{~d}, 4 \mathrm{H}, J=8.0 \mathrm{~Hz}), 7.79(\mathrm{~d}, 4 \mathrm{H}, J=7.6 \mathrm{~Hz}), 7.40$ (d, 8H, $J=1.5 \mathrm{~Hz}), 6.95$ $(\mathrm{s}, 4 \mathrm{H}), 4.34(\mathrm{t}, 16 \mathrm{H}, J=4.6 \mathrm{~Hz}), 3.96(\mathrm{t}, 16 \mathrm{H}, J=4.6 \mathrm{~Hz}), 3.78(\mathrm{~m}, 16 \mathrm{H}), 3.70(\mathrm{~m}, 16 \mathrm{H}), 3.63(\mathrm{~m}, 16 \mathrm{H})$, $3.50(\mathrm{~m}, 16 \mathrm{H}), 3.31(\mathrm{~s}, 24 \mathrm{H}), 2.97(\mathrm{~m}, 4 \mathrm{H}), 2.72(\mathrm{~s}, 12 \mathrm{H}), 2.60(\mathrm{~m}, 4 \mathrm{H}), 2.13(\mathrm{~m}, 4 \mathrm{H}) \mathrm{ppm} .{ }^{13} \mathrm{C}$ NMR (101 MHz, $\mathrm{CDCl}_{3}$ with $1 \%$ deuterated pyridine) $\delta=170.6,157.9,153.3,153.1,152.1,151.9,150.0,150.0$, $149.6,149.5,144.5,133.0,132.3,130.7,127.8,119.7,119.5,114.8,113.9,101.0,92.8,88.3,82.2,71.9$, 70.9, 70.7, 70.6, 69.9, 67.8, 59.0, 44.0, 31.6, 22.6, 14.1 ppm. MALDI-MS m/z: 2848.15 ([M+H] $]^{+}, \mathrm{calcd}$ for 2848.11). FTIR: $\bar{v}=3497,3251,2918,2886,2155,1709,1635,1540 \mathrm{~cm}^{-1}$.

MPZnE 2 PZnM. Compound $13\left(0.0750 \mathrm{~g}, 2.63 \times 10^{-5} \mathrm{~mol}\right)$ was dissolved in $20 \mathrm{~mL}$ of dry DMF, and the solution was purged with Ar for $30 \mathrm{~min}$. After the solution was cooled to $273 \mathrm{~K}, \mathrm{CH}_{3} \mathrm{I}(0.016 \mathrm{~mL}, 2.57 \times$ $10^{-4} \mathrm{~mol}$ ) was added. The reaction mixture was stirred at room temperature under Ar for $4 \mathrm{~h}$ and added dropwise into $100 \mathrm{~mL}$ of saturated $\mathrm{NaBF}_{4}$ solution in $\mathrm{H}_{2} \mathrm{O}$. A precipitate was collected via centrifugation and dried under vacuum to give the desired product as a green solid (0.077 g, 97\%). ${ }^{1} \mathrm{H} \mathrm{NMR}(400 \mathrm{MHz}$, $\left(\mathrm{CD}_{3}\right)_{2} \mathrm{SO}$ with $1 \%$ deuterated pyridine) $\delta=10.14(\mathrm{~s}, 2 \mathrm{H}), 9.83(\mathrm{~d}, 4 \mathrm{H}, J=4.4 \mathrm{~Hz}), 9.71(\mathrm{~d}, 4 \mathrm{H}, J=4.4$ Hz), $9.03(\mathrm{~d}, 4 \mathrm{H}, J=4.8 \mathrm{~Hz}), 8.94$ (d, 4H, $J=4.4 \mathrm{~Hz}), 8.09$ (d, 4H, $J=8.0 \mathrm{~Hz}), 7.92$ (d, 4H, J=8.4 Hz), $7.42(\mathrm{~s}, 8 \mathrm{H}), 7.09(\mathrm{~s}, 4 \mathrm{H}), 4.42(\mathrm{t}, 16 \mathrm{H}, J=4.6 \mathrm{~Hz}), 3.93(\mathrm{t}, 16 \mathrm{H}, J=4.6 \mathrm{~Hz}), 3.71(\mathrm{~m}, 16 \mathrm{H}), 3.63(\mathrm{~m}$, $16 \mathrm{H}), 3.58(\mathrm{~m}, 16 \mathrm{H}), 3.46(\mathrm{~m}, 16 \mathrm{H}), 3.24(\mathrm{~s}, 24 \mathrm{H}), 3.05(\mathrm{~s}, 18 \mathrm{H}$, covered by solvent peak), $2.8 \sim 1.8(\mathrm{~m}$, 12H) ppm. Unfortunately, no resolved ${ }^{13} \mathrm{C}$ NMR spectrum with a considerable signal-to-noise ratio was successfully obtained because of the poor solubility of this compound. ESI-MS m/z: $1438.58\left(\mathrm{M}^{2+}\right.$, calcd 
for 1438.58); $966.73\left([\mathrm{M}+\mathrm{Na}]^{3+}\right.$, calcd for 966.73); $730.79\left([\mathrm{M}+2 \mathrm{Na}]^{4+}\right.$, calcd for 730.79$) ; 1155.47$ $\left([2 \mathrm{M}+\mathrm{Na}]^{5+}\right.$, calcd for 1155.47). Note: here "M" refers to the cation in this ionic compound. 


\section{DFT and TDDFT Calculation}

Structure optimizations and time-dependent (TD) calculations were performed using density functional theory (DFT) in the Gaussian 09.D01 software package. All calculations were conducted using the truncated molecular structure shown in Figure S1A where: 1) the aryl groups are unsubstituted phenyl groups, and 2) pendant ammonium side chains have been removed.

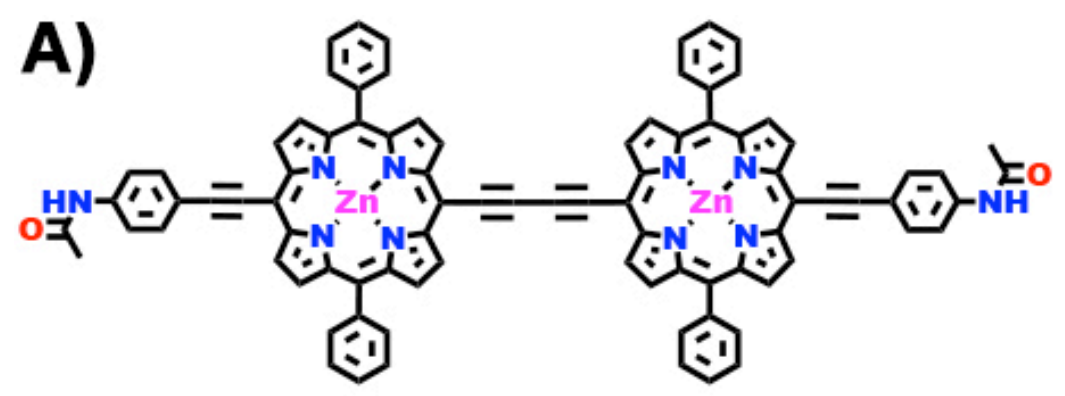

B)
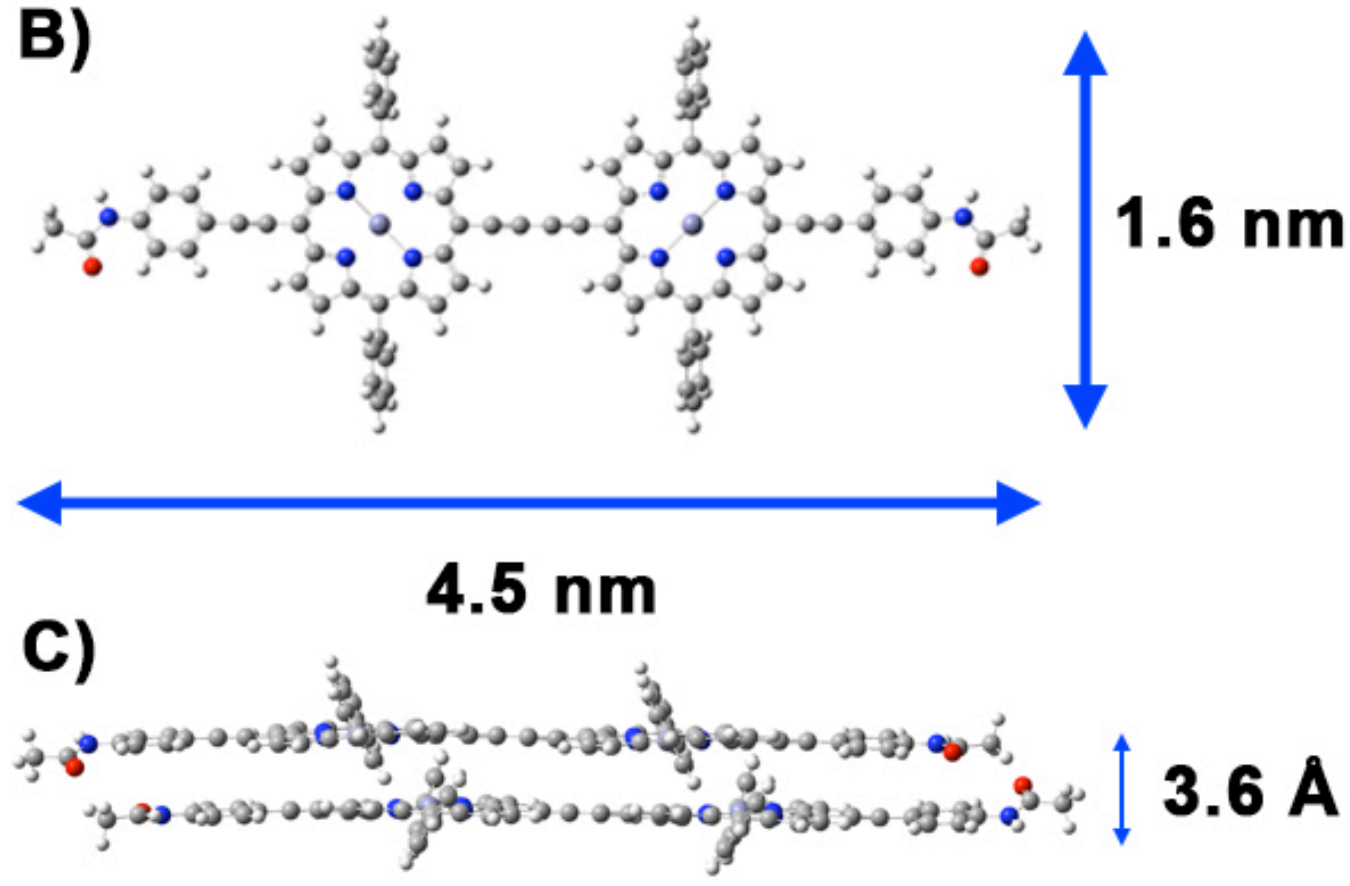

Figure S1. (A) Truncated $\mathrm{MPZnE}_{2} \mathbf{P Z n M}$ structure used for DFT and TDDFT calculation. (B) energy minimized structure of $\mathbf{M P Z n E}_{2} \mathbf{P Z n M}$ (C) Energy minimized structure of a non-covalent dimer that features two $\mathbf{M P Z n E}_{2} \mathbf{P Z n M}$ building blocks.

To compute vertical excitation energies for torsion conformers, dihedral angles between the (porphinato)Zn(II) rings were frozen allowing the rest of the structure to relax towards its energy minimum. Ten conformers, starting from the planar conformer with an increment of $10^{\circ}$ have been 
minimized using the Becke three-parameters hybrid and the Lee-Yang-Parr correlation functional (B3LYP). All calculations were conducted using the Dunning's correlation consistent double zeta basis set (cc-pvdz). Please note that this basis set includes valence polarization functions. For calculation of the vertical excitation energies in DMF solvent, a polarized continuum solvation model (SCRF = IEF PCM) with DMF as the solvent was used. Frequency calculations have been performed on each conformer to confirm the validity of the minimized structure.

Figure S2A-B shows the vertical electronic excitation of $\mathbf{M P Z n E}_{2} \mathbf{P Z M}$ as a function of the dihedral angles delineated by the two porphyrin cores in the gas phase and in DMF solvent, respectively. Unexpectedly, the Q-type transitions for all the computed conformers are polarized along the molecular long axis (x-axis). An unambiguous decrease of ground to excited state energy along with a decrease of computed oscillator strength accompanies the increase of dihedral angles further underscoring an attenuation of $\pi$-electron delocalization as structures deviate from planarity. Identical observations have been reported by Anderson and Albinssson. ${ }^{4,5}$ While calculations performed in DMF solvent deliver ground to excited state transitions that are lower in energy when compared to those computed in the gas phase, similar hypsochromic shifts and a decrease of oscillator strengths that characterize the Q-type transitions are evidenced as a function of dihedral angles (Figure S2B).

For the $0^{\circ}$ and $90^{\circ}$ rotational conformers, the molecular orbital configuration and percentage contribution characterizing the Q-type transitions are shown in Figure S2C and S2D. In the case of the perpendicular conformer (Figure S2C), emphasis should not be placed on the helical molecular orbital that best describes the degenerate HOMO and LUMO. As unambiguously demonstrated by Anderson, these seemingly delocalized, helical MO are equivalent to $2 \mathrm{MO}$ localized on each of the two (porphinato)Zn(II) cores. Disordered side groups such as the phenyl fragments on the truncated $\mathbf{M P Z n E}_{2} \mathbf{P Z M}$ cores may enforce deviation from $D_{2 d}$ symmetry and cause emergence of helical orbitals. In sharp contrast, the planar conformer features a HOMO and LUMO that are delocalized on the two PZn cores due to the butadiyne-bridged connectivity. Consequently, the low-lying excited state has principally $\mathrm{HOMO} \rightarrow$ LUMO character. 

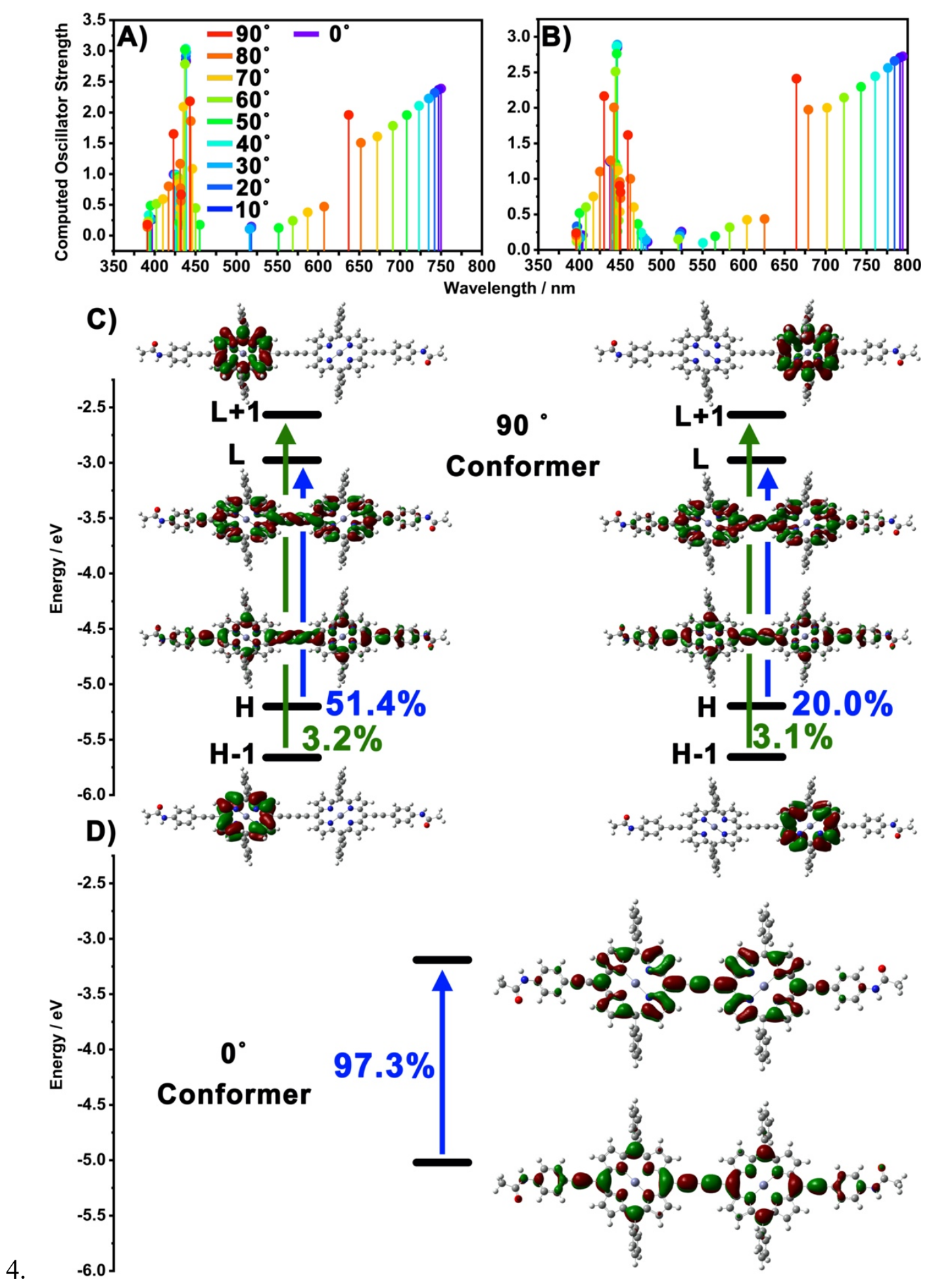

Figure S2. Calculated vertical excitation transitions in the UV-vis-NIR spectral window (350 to $850 \mathrm{~nm}$ ) as a function of torsional angles using the truncated $\mathbf{M P Z n E}_{2} \mathbf{P Z n M}$ model in the gas phase (A) and in DMF solvent (B). (C-D) Energy level diagram that highlights the molecular orbitals contributing to the Q-type transitions for the $0^{\circ}$ and $90^{\circ}$ conformers. 
4. Variable-Temperature Electronic Absorption Spectra of $\mathrm{MPZnE}_{2} \mathrm{PZnM}$

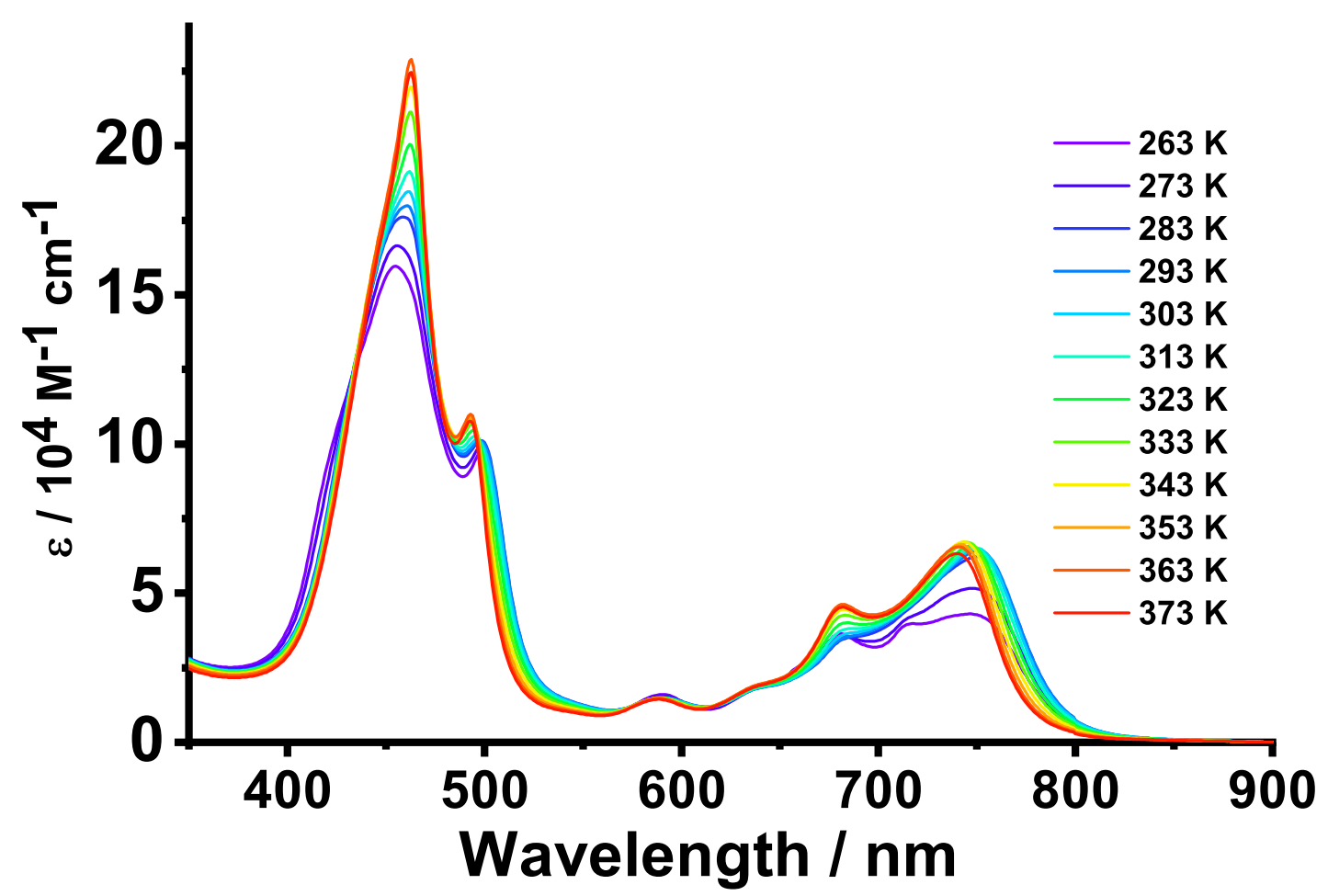

Figure S3. Variable-temperature electronic absorption spectra recorded for $\mathbf{M P Z n E} \mathbf{E}_{\mathbf{2}} \mathbf{P Z n M}$ in DMF: $\mathrm{H}_{2} \mathrm{O} 1: 1$ aqueous medium from $263 \mathrm{~K}$ to $373 \mathrm{~K}$. 


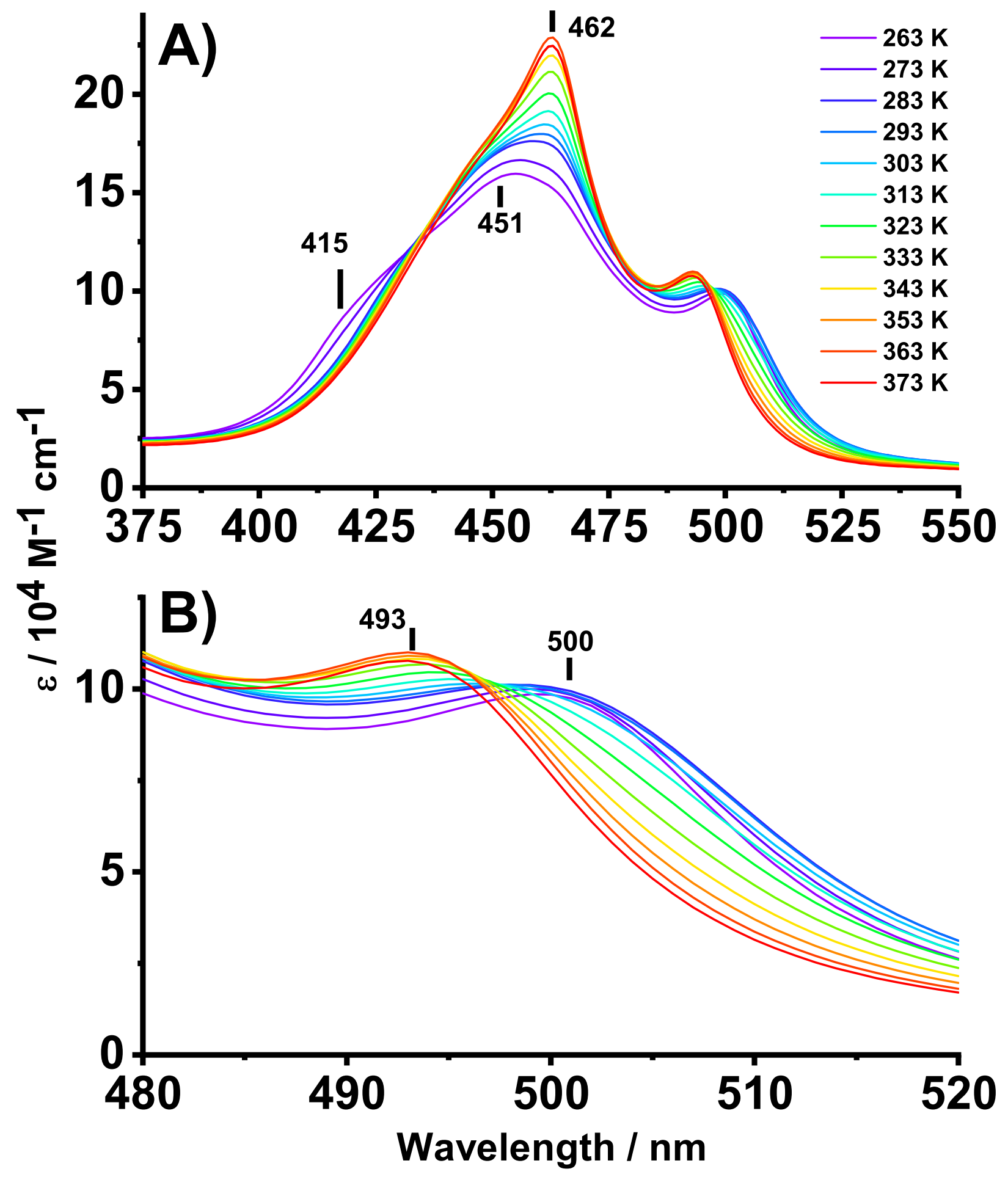

Figure S4. Zoom-in from Figure S4 that chronicles the evolution of the absorptive features of the Btype transitions in the 263-to-373-K temperature range. 


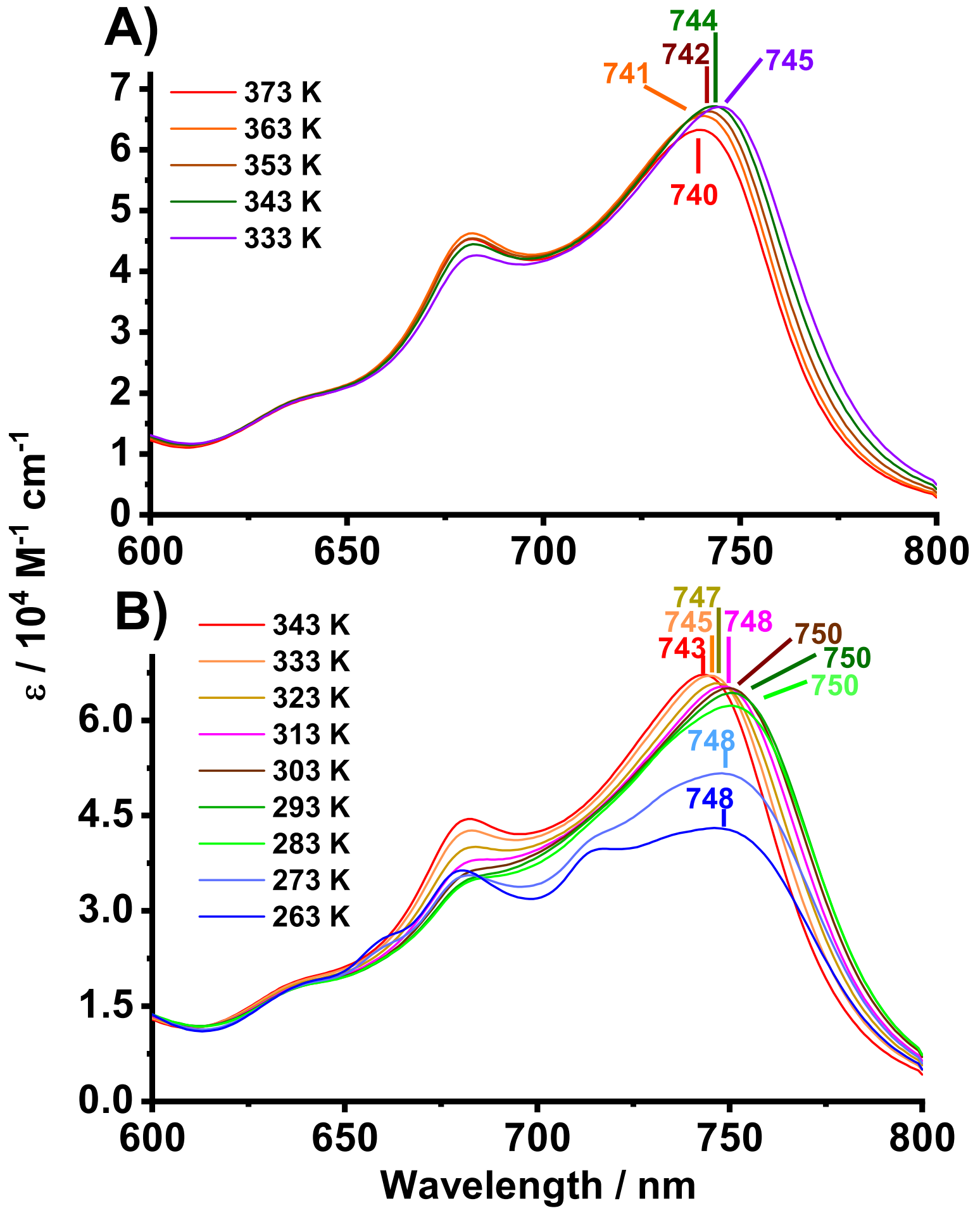

Figure S5. Zoom-in from Figure S3 that chronicles the evolution of the absorptive features of the Qtype transitions in the 343 -to-373K (A) and in the 343-to-263K (B) temperature range. 
Figure S5A highlights that the descent from $373 \mathrm{~K}$ to $333 \mathrm{~K}$ is accompanied by a bathochromic $\operatorname{shift}(\Delta \mathrm{E}=11 \mathrm{meV})$ of the transition initially centered at $740 \mathrm{~nm}$. Based on our DFT calculations (section $\mathrm{S} 3$ ), it is fair to assume that the $740 \mathrm{~nm}$ transitions characterized a conformer population that features a dihedral angle close to $0^{\circ}$. As the temperature decreases, a pool of conformer characterized by lower dihedral angles is favored, explaining the apparent bathochromic shift and increase of extinction coefficient. It is well established that, due to an increase of $\pi$-electron delocalization, conformer potential energies decrease as the dihedral angle decreases. Furthermore, the modest decrease of the extinction coefficient of the absorptive feature centered at $682 \mathrm{~nm}$ suggests that populating the perpendicular conformer is less favored at lower temperature.

The gradual bathochromic shift observed from $745 \mathrm{~nm}$ to $750 \mathrm{~nm}$ when cooling the solution from $333 \mathrm{~K}$ to $293 \mathrm{~K}$ diagnoses the formation of conformers characterized with a lower dihedral angle than those at the origin of the $740 \mathrm{~nm}$ transitions $(373 \mathrm{~K})$. To further validate this assignment, the decrease of extinction coefficient associated with the transitions at $680 \mathrm{~nm}$ indicates an overall decrease of the perpendicular conformer population. As established by Anderson and by our DFT calculation (Section S3), planarization of the two (porphinato)zinc(II) rings is accompanied with a decrease of $\mathrm{S}_{0} \rightarrow \mathrm{S}_{1}$ transition energy and a concomitant rise of the oscillator strength (Figure S2A and S2B). It is worth noting that the apparent attenuation of extinction coefficients as the temperature is lowered may indicate the existence of an underlying process other than a decrease of dihedral angle. Further decreasing the temperature from $296 \mathrm{~K}$ to $263 \mathrm{~K}$ engenders a drastic decrease of the extinction coefficient of the transition centered at $750 \mathrm{~nm}$ and the apparition of the 718-nm transition. Analysis of the spectroscopic features that characterize the Q-type transitions as a function of temperature suggests the formation of aggregate species.

Evaluation of the absorptive features characterizing the B-type transitions as a function of temperature further validates the conclusion established upon interpretation of the Q-type transitions. As shown in Figure S4A and S4B, the descent from $373 \mathrm{~K}$ to $263 \mathrm{~K}$ is accompanied with: 1) a hypochromic shift of the absorption centered at $462 \mathrm{~nm}, 2$ ) a bathochromic shift of the transition initially centered at $493 \mathrm{~nm}$ to $500 \mathrm{~nm}$, and 3) rise of a new absorptive feature at $415 \mathrm{~nm}$. The hypochromic shift at $462 \mathrm{~nm}$ is unambiguously rationalized by a decrease of the perpendicular conformer population. Meanwhile, the bathochromic shift of the shoulder initially centered at $493 \mathrm{~nm}$ and the more pronounced transition at 451 $\mathrm{nm}$ indicate an increase of excitonic coupling between (porphinato)zinc(II) units enforced by 
planarization of the molecular arrays. Similar to the rise of the $718 \mathrm{~nm}$ transition, the continuous rise of the transition at $415 \mathrm{~nm}$ below $283 \mathrm{~K}$ further indicates the formation of aggregate species. While a matter of speculation at this time, these absorptive signatures may diagnose the formation of an $\mathrm{H}$-like aggregates. 


\section{Additional Ground-State Electronic Absorption Spectra}

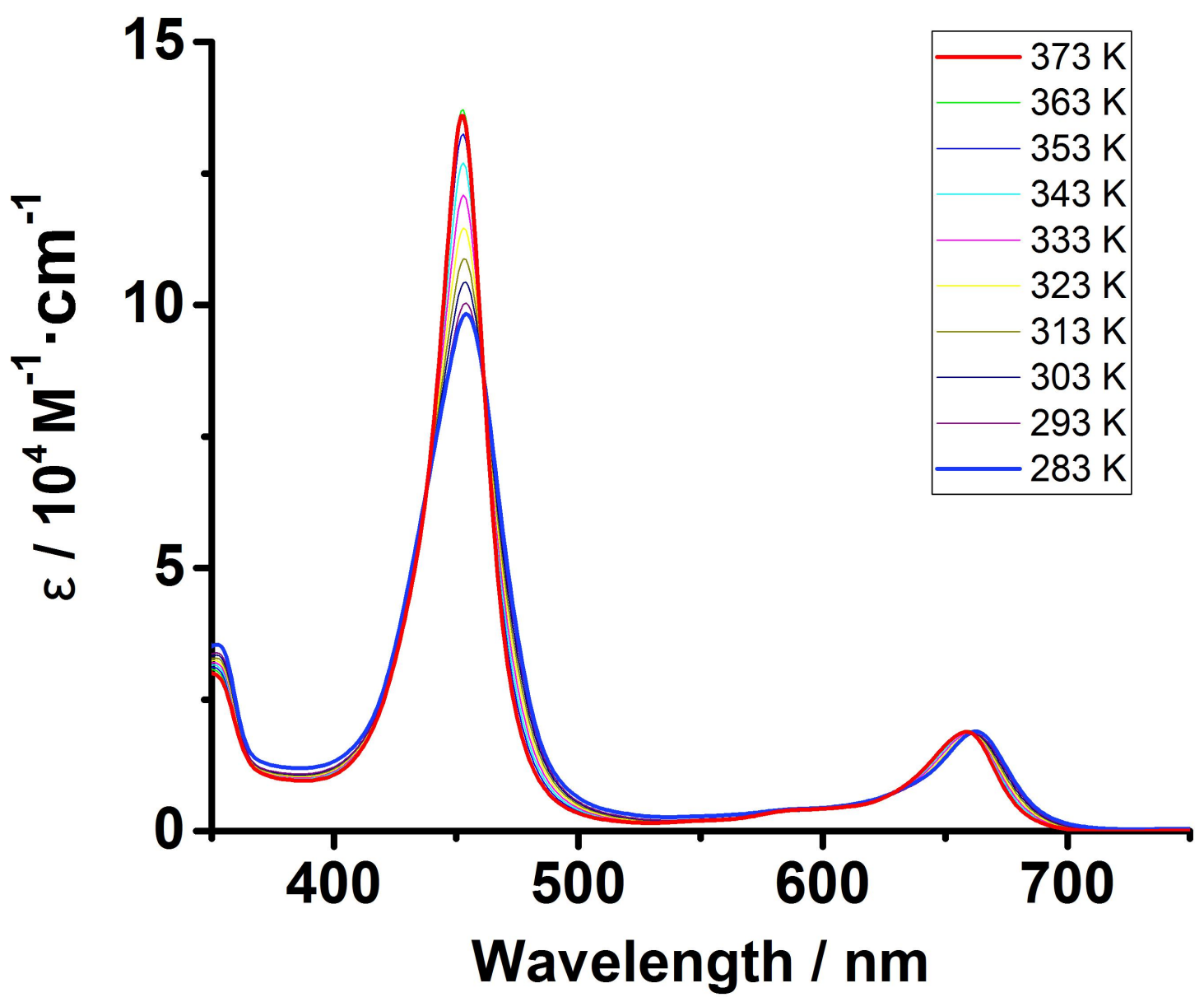

Figure S6: Temperature-dependent electronic absorption spectra of MPZnM (A) in 7\% DMF in $\mathrm{H}_{2} \mathrm{O}$ (c $=3.8 \times 10^{-5} \mathrm{M}$ ). Optical pathlength: $2 \mathrm{~mm}$. Samples were heated to $373 \mathrm{~K}$ and then cooled down at 1 $\mathrm{K} \cdot \min ^{-1}$. 


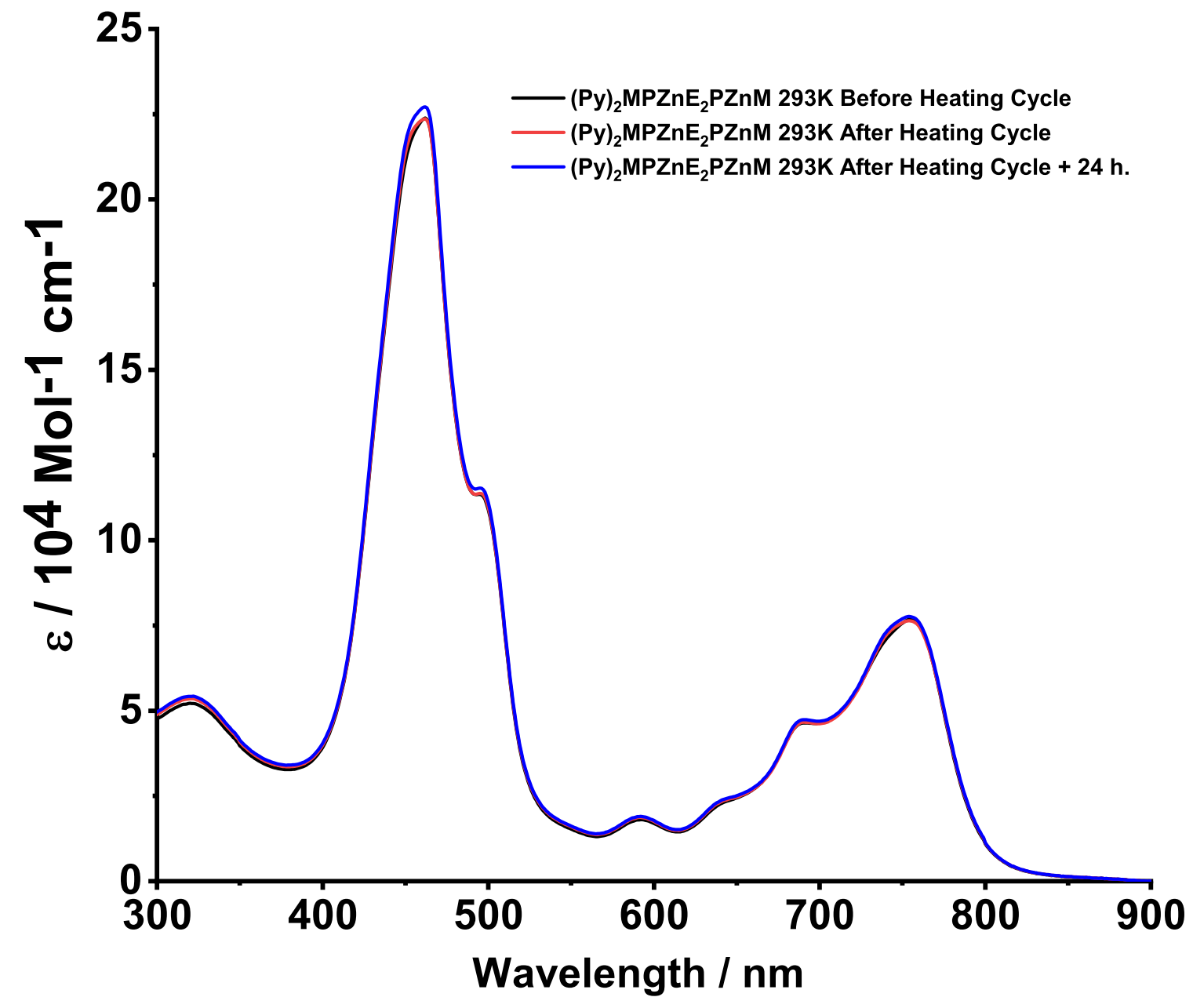

Figure S7. Electronic absorption spectra of $\mathbf{M P Z n E}_{2} \mathbf{P Z n M}$ in DMF- $\mathrm{H}_{2} \mathrm{O}(1: 1)$ with $0.2 \%$ pyridine added $\left(\mathrm{c}=2.3 \times 10^{-5} \mathrm{M}\right)$. Optical pathlength: $2 \mathrm{~mm}$.

The addition of pyridine to a solution of $\mathbf{M P Z n E}_{2} \mathbf{P Z n M}$ in DMF- $\mathrm{H}_{2} \mathrm{O}$ (1:1) solution promotes the formation of the individualized building blocks $(\mathbf{P y})_{2} \mathbf{M P Z n E}_{2} \mathbf{P Z n M}$ by coordination of the $\mathrm{Zn}$ metal complex. As can be seen in Figure S7, the spectroscopic signatures resemble those recorded in DMF solvent (Figure 1A in the main text). In addition, in contrast to the absorptive features of $\mathbf{M P Z n E} \mathbf{F}_{2} \mathbf{P Z n M}$ building blocks that indicate formation of H-like aggregates as a function of time (Figure 1B in the main text), no apparent change of optical properties is evidenced for $(\mathbf{P y})_{2} \mathbf{M P Z n E} \mathbf{E}_{2} \mathbf{P Z n M}$ after 24 hours which further indicates the stability of the coordinated species. 


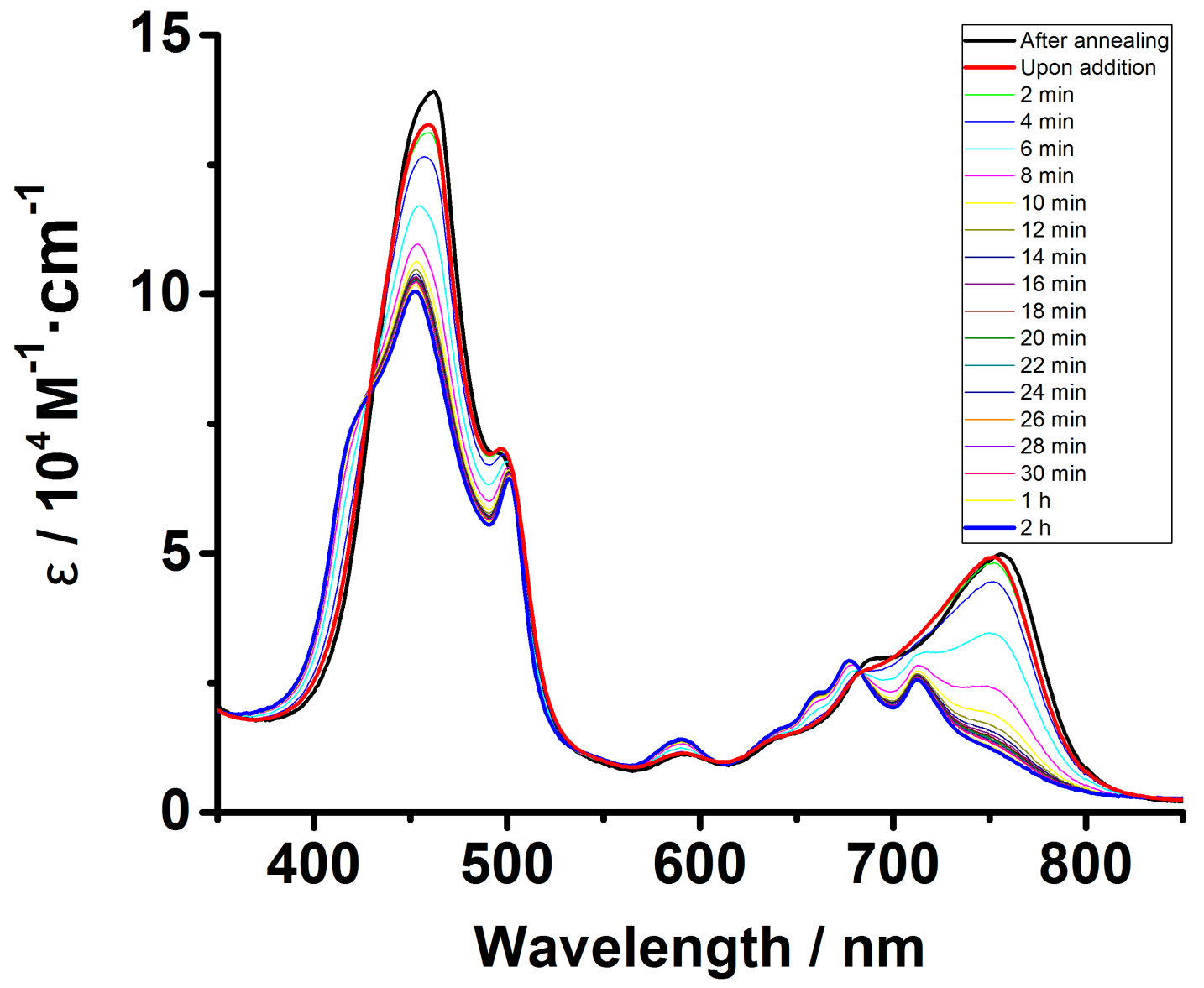

Figure S8: Electronic absorption spectra of $\mathbf{M P Z n E}_{2} P Z n M\left(c=2.3 \times 10^{-5} \mathrm{M}\right)$ in $\mathrm{DMF}_{2} \mathrm{H}_{2} \mathrm{O}$-pyridine (250:250:1) treated with $0.87 \mathrm{M} \mathrm{HCl}$ (1.5 eq with respect to the amount of pyridine) over time. Optical pathlength: $2 \mathrm{~mm}$. The sample was heated to $373 \mathrm{~K}$ and then cooled down to $293 \mathrm{~K}$ at $1 \mathrm{~K} \cdot \mathrm{min}^{-1}$ before $\mathrm{HCl}$ addition. The sample temperature was constantly kept at $293 \mathrm{~K}$ throughout the whole aging period. 


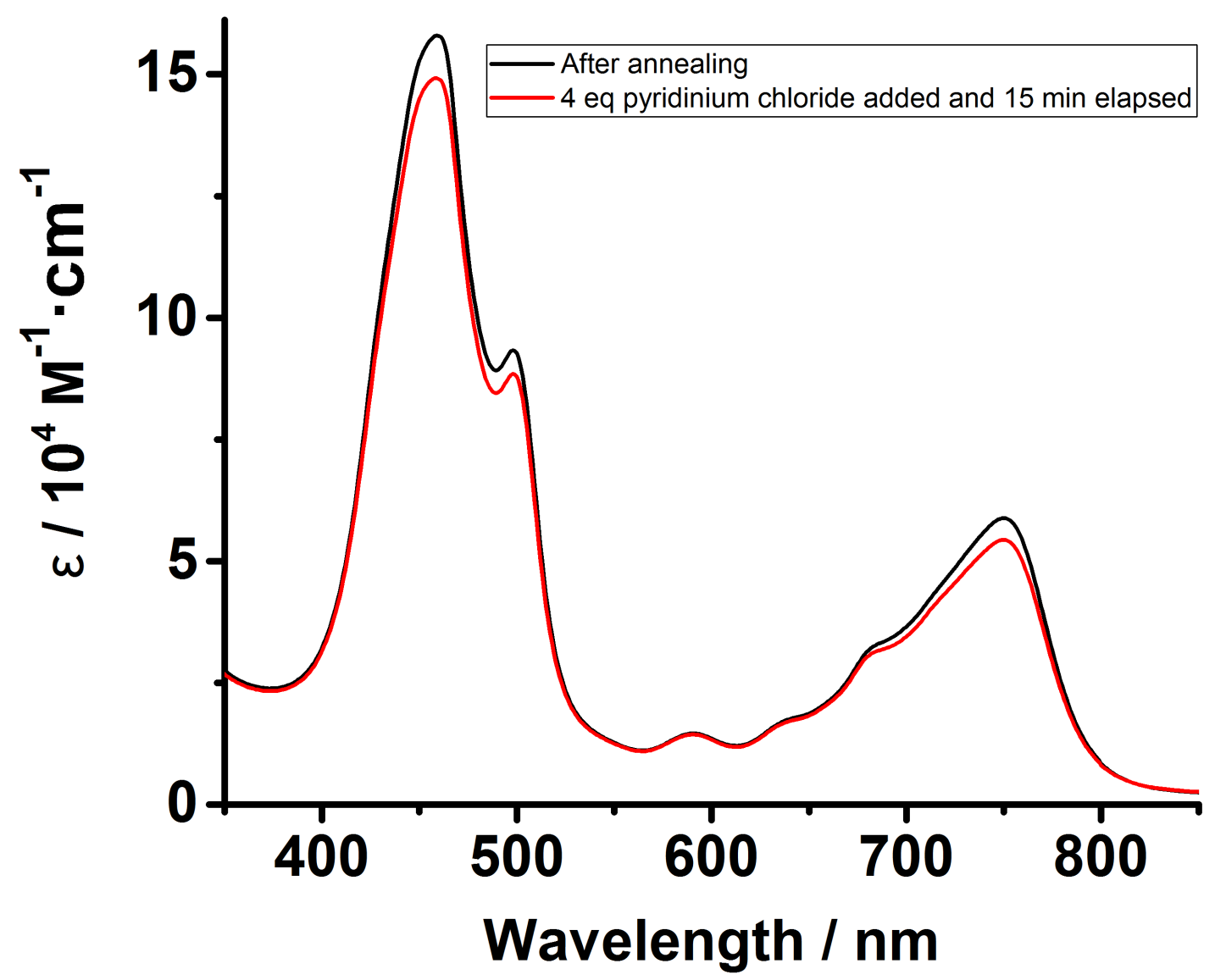

Figure S9: Electronic absorption spectrum of $\mathbf{M P Z n E}_{2} \mathbf{P Z n M}\left(\mathrm{c}=2.3 \times 10^{-5} \mathrm{M}\right)$ in DMF- $\mathrm{H}_{2} \mathrm{O}(1: 1)$ treated with 4 eq pyridinium chloride. Optical pathlength: $2 \mathrm{~mm}$. Please note that the number of equivalents of pyridinium chloride in this experiment is with respect to the amount of the $0.2 \%$ pyridine used in the other experiments, not with respect to the amount of porphyrin building blocks. The sample was heated to 373 $\mathrm{K}$ and then cooled down to $293 \mathrm{~K}$ at $1 \mathrm{~K} \cdot \mathrm{min}^{-1}$ before pyridinium chloride addition. The sample temperature was constantly kept at $293 \mathrm{~K}$ throughout the whole experiment. 


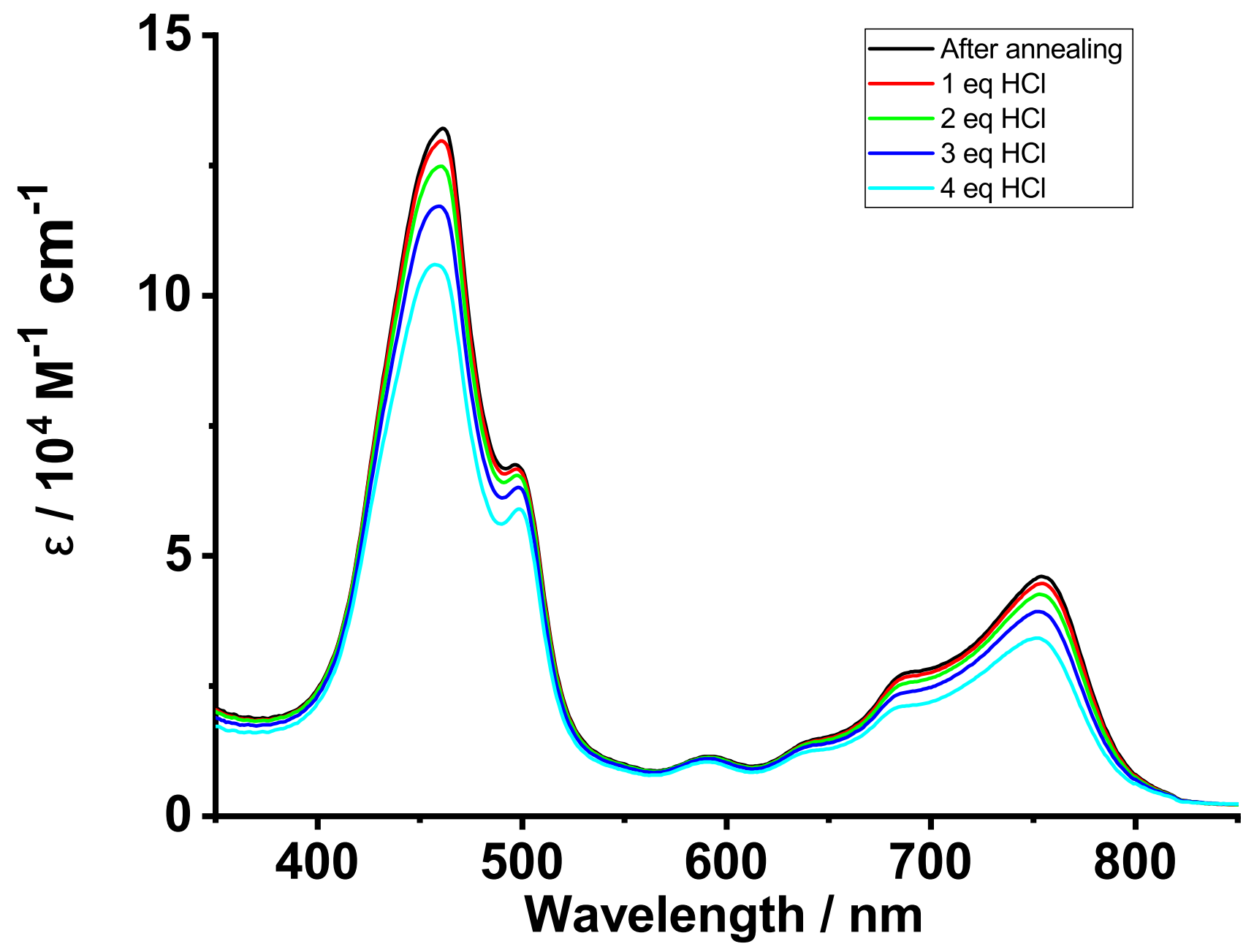

Figure S10: Electronic absorption spectrum of $\mathbf{M P Z n E}_{2} \mathbf{P Z n M}\left(\mathrm{c}=2.3 \times 10^{-5} \mathrm{M}\right)$ in DMF- $\mathrm{H}_{2} \mathrm{O}(1: 1)$ treated with hydrochloric acid. Optical pathlength: $2 \mathrm{~mm}$. The sample was heated to $373 \mathrm{~K}$ and then cooled down to $293 \mathrm{~K}$ at $1 \mathrm{~K} \cdot \mathrm{min}^{-1}$ right before hydrochloric acid was added. The numbers of equivalents of hydrochloric acid in this experiment are with respect to the amount of the $0.2 \%$ pyridine used in the $\mathrm{pH}$-triggered experiments, not with respect to the amount of porphyrin building blocks. In the experiments where pyridine was added, there is $500 \mu \mathrm{L}$ of PZn solution in the spectroscopic cell and $0.2 \%$ pyridine which corresponds to $1 \mu \mathrm{L}$ of pyridine $(0.012 \mathrm{mmol})$. Therefore, in this control experiment, 1 eq of $\mathrm{HCl}$ corresponds to $0.012 \mathrm{mmol}$ of $\mathrm{HCl}$ in $500 \mu \mathrm{L}$ of the solution and was added in the form of $14 \mu \mathrm{L}$ of 0.87 $\mathrm{M} \mathrm{HCl}$. If converted to molarities of $\mathrm{HCl}$ in the whole solution, 1 eq of $\mathrm{HCl}$ corresponds to $0.024 \mathrm{M}, 2 \mathrm{eq}$ of $\mathrm{HCl}$ corresponds to $0.048 \mathrm{M}, 3$ eq of $\mathrm{HCl}$ corresponds to $0.072 \mathrm{M}$, and 4 eq of $\mathrm{HCl}$ corresponds to $0.096 \mathrm{M}$. After adding $4 \mathrm{eq} \mathrm{HCl}$, the concentration of $\mathrm{H}_{3} \mathrm{O}^{+}$is $0.096 \mathrm{M}$, which corresponds to a $\mathrm{pH}$ value 
of around 1. The overall decreased of extinction coefficient may be diagnostic of aggregation processes enforced by an increase of ionic strength. 


\section{Finke-Watzky Model}

$$
\begin{aligned}
& A \stackrel{k_{1}}{\rightarrow} B \quad \text { (Nucleation Step) } \\
& A+B \stackrel{k_{2}}{\rightarrow} 2 B \text { (Growth Step) }
\end{aligned}
$$

Scheme S2. The Finke-Watzky mechanism

$$
B=\left(A_{0}-\frac{\frac{k_{1}}{k_{2}}+A_{0}}{1+\frac{k_{1}}{k_{1} A_{0}} e^{\left(k_{1}+k_{2} A_{0}\right) t}}\right)
$$

The degree of aggregation of activated MPZnE 2 PZnM building blocks as a function of time has been fitted using the minimal 2-step autocatalytic model introduced by Finke and Watzky. ${ }^{6-8}$ This model consists of two steps shown in Scheme S2, namely nucleation of the precatalytic species A followed by the growth of aggregated species (B). The rate constant $\mathrm{k}_{1}$ and $\mathrm{k}_{2}$ are average rate constants that characterize the nucleation and growth step reactions respectively. It is important to mention that the FW mechanism is considered minimal because: 1) the steps describing nucleation and growth are considered pseudo-elementary and encompass a plethora of steps, 2) all types of growing aggregates can compose species B that describe the catalytic active form of aggregated monomers.

$$
\begin{gathered}
\alpha_{a g g}=1-\left(\frac{\varepsilon(t)-\varepsilon(a g g)}{\varepsilon(\text { mono })-\varepsilon(a g g)}\right)(\text { eq. S2) } \\
\alpha_{a g g}=\frac{B}{A_{0}}(\text { eq. S3) }
\end{gathered}
$$

The fraction of aggregated $\mathbf{M P Z n E _ { 2 }} \mathbf{P Z n M}$ building blocks at a given time can be calculated from equation $\mathrm{S} 1$ and relates to the concentration of aggregated species using eq. S3. $\mathrm{A}_{0}$ corresponds to the total concentration of activated monomer. In our study, $A_{0}$ delineates activated $\mathbf{M P Z n} \mathbf{E}_{2} \mathbf{P Z n} \mathbf{M}$ building blocks formed after decoordination of the Pyridine ligands. 


\section{Atomic Force Microscopy Images}
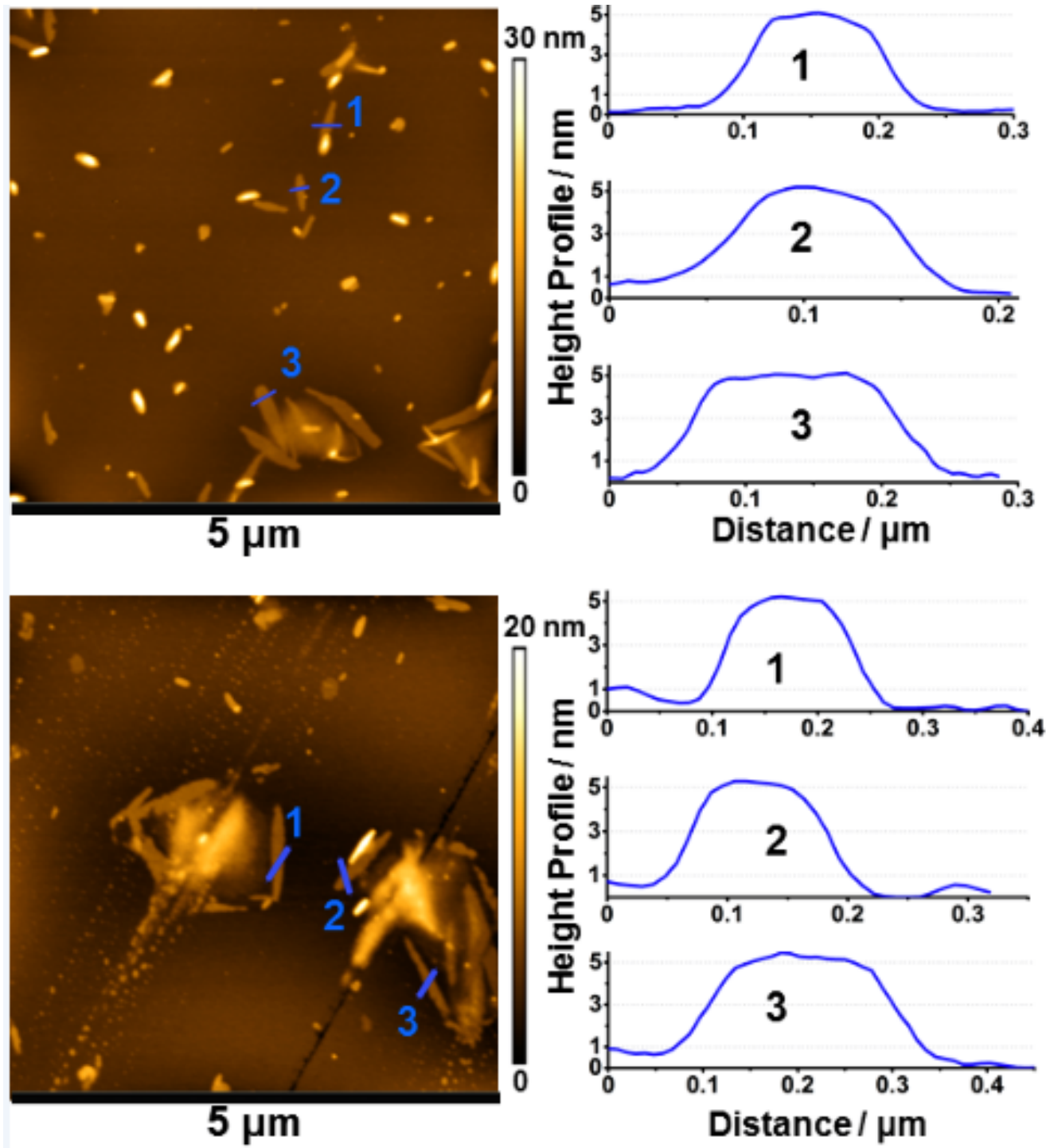

Figure S11: Additional topographic intermittent contact mode AFM images of $\mathbf{M P Z n E}_{2} \mathbf{P Z n M}$ dropcasted from its annealed DMF solution on silicon. 

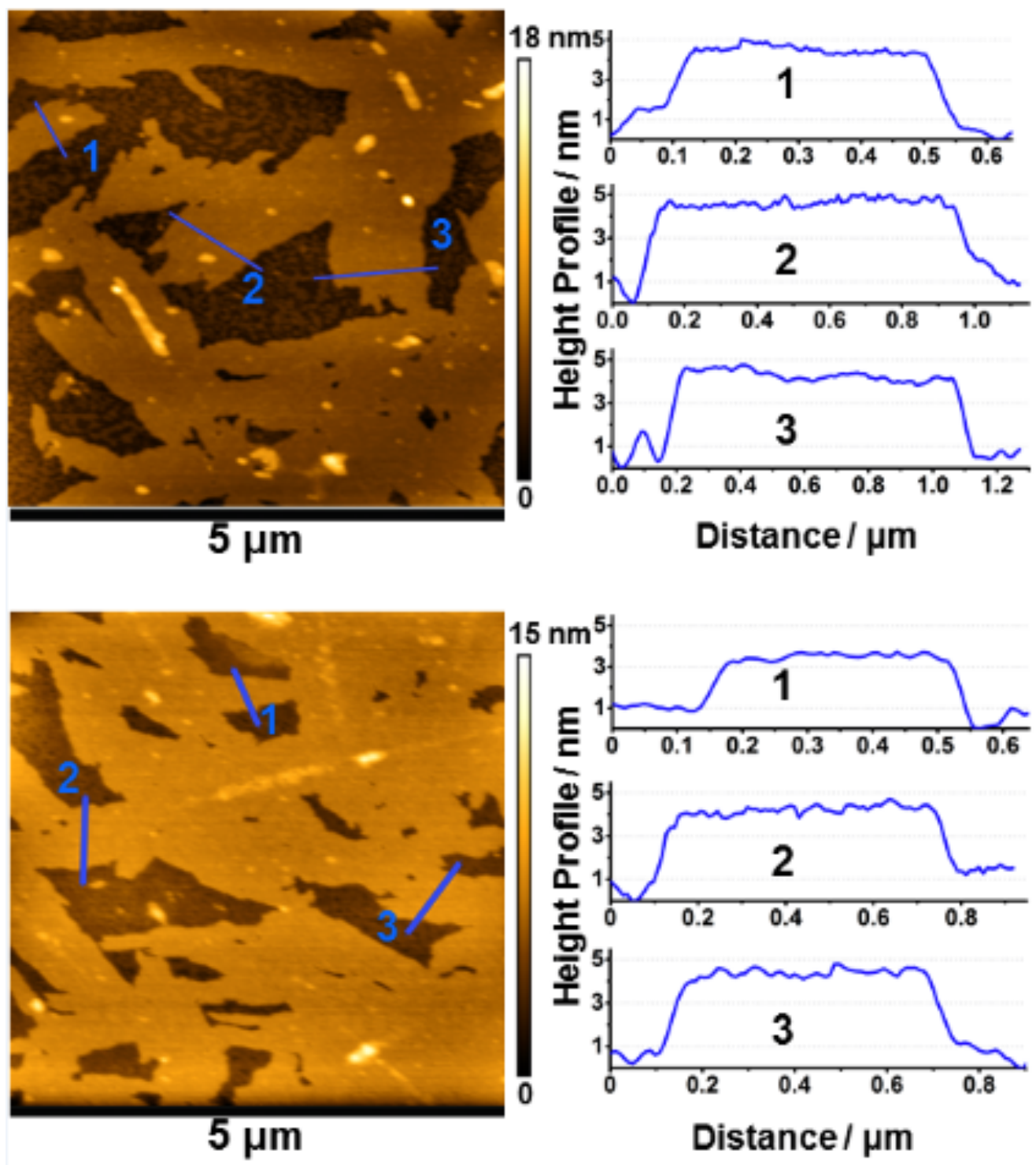

Figure S12: Additional topographic intermittent contact mode AFM images of $\mathbf{M P Z n E}_{2} \mathbf{P Z n M}$ dropcasted from its annealed DMF- $\mathrm{H}_{2} \mathrm{O}(1: 1)$ solution on silicon. 

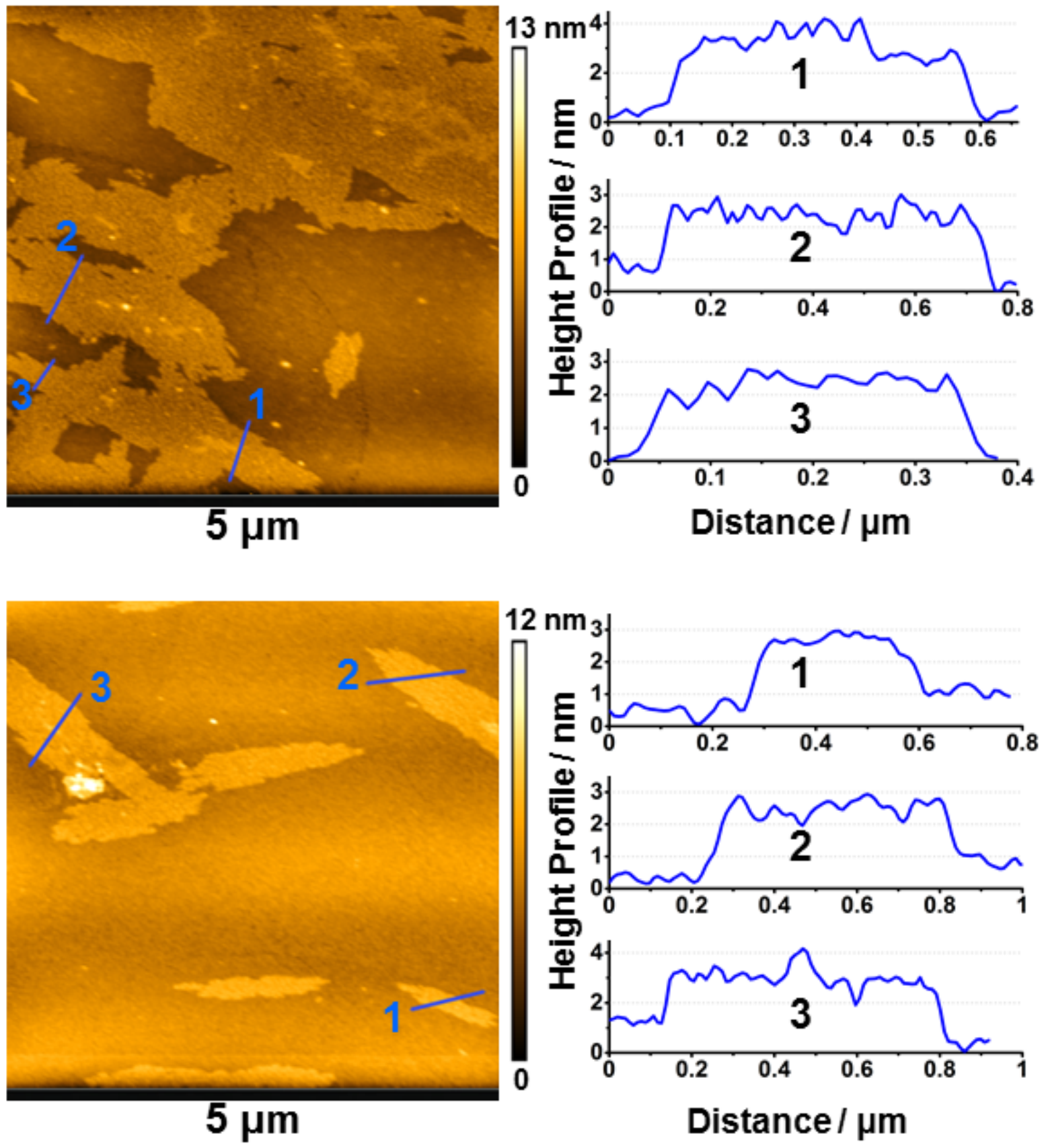

Figure S13: Topographic intermittent contact mode AFM images of $\mathrm{pH}$-triggered $\mathbf{M P Z n E} \mathbf{E}_{2} \mathbf{P Z n M}$ aggregate dropcasted on silicon wafer from a DMF- $\mathrm{H}_{2} \mathrm{O}-$ pyridine (250:250:1) solvent mixture after treatment with 1.25 eq $\mathrm{HCl}$. 


\section{NMR and MS Spectra}
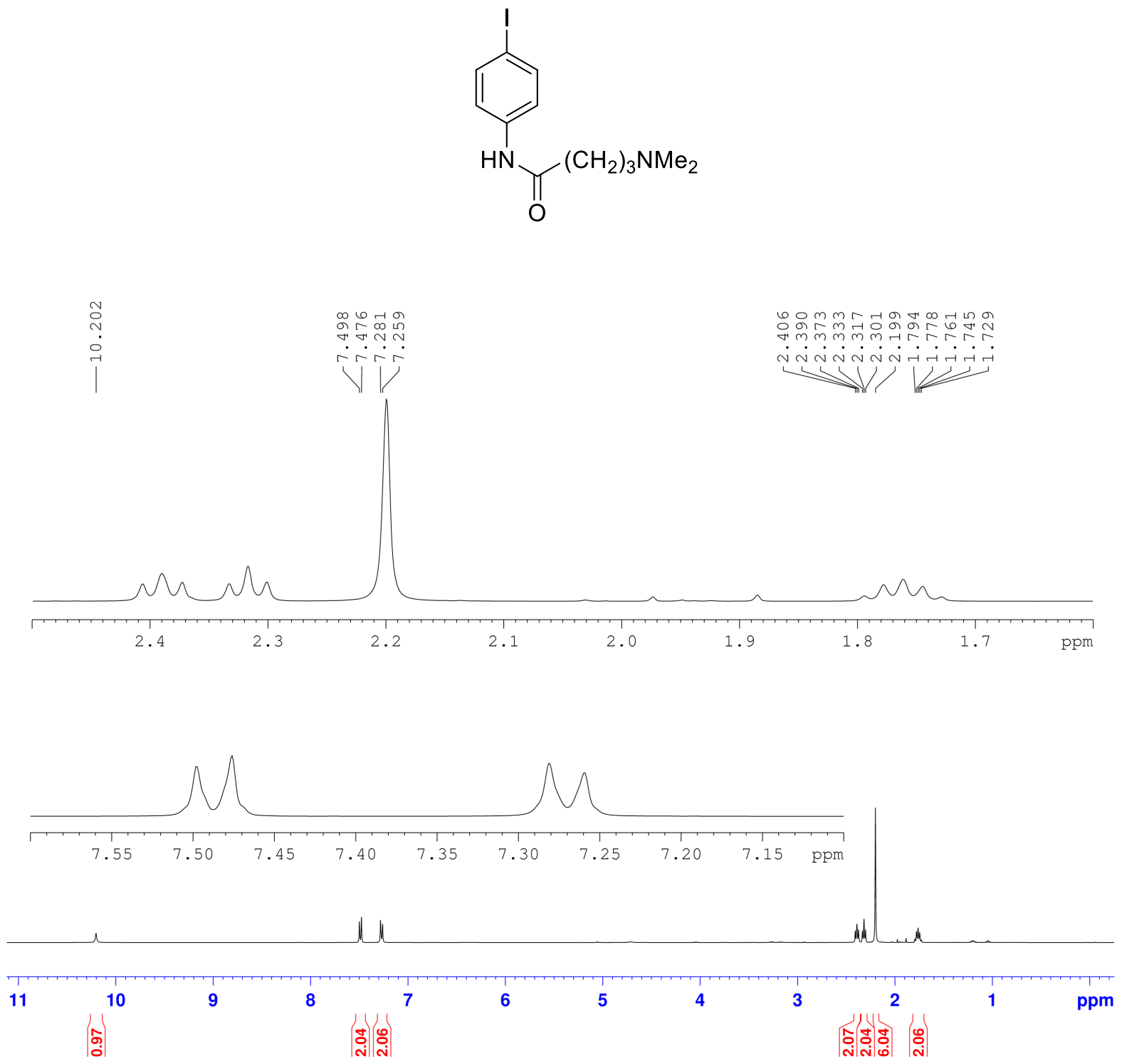

Figure S14. ${ }^{1} \mathrm{H}$ NMR spectrum of Compound 1. 

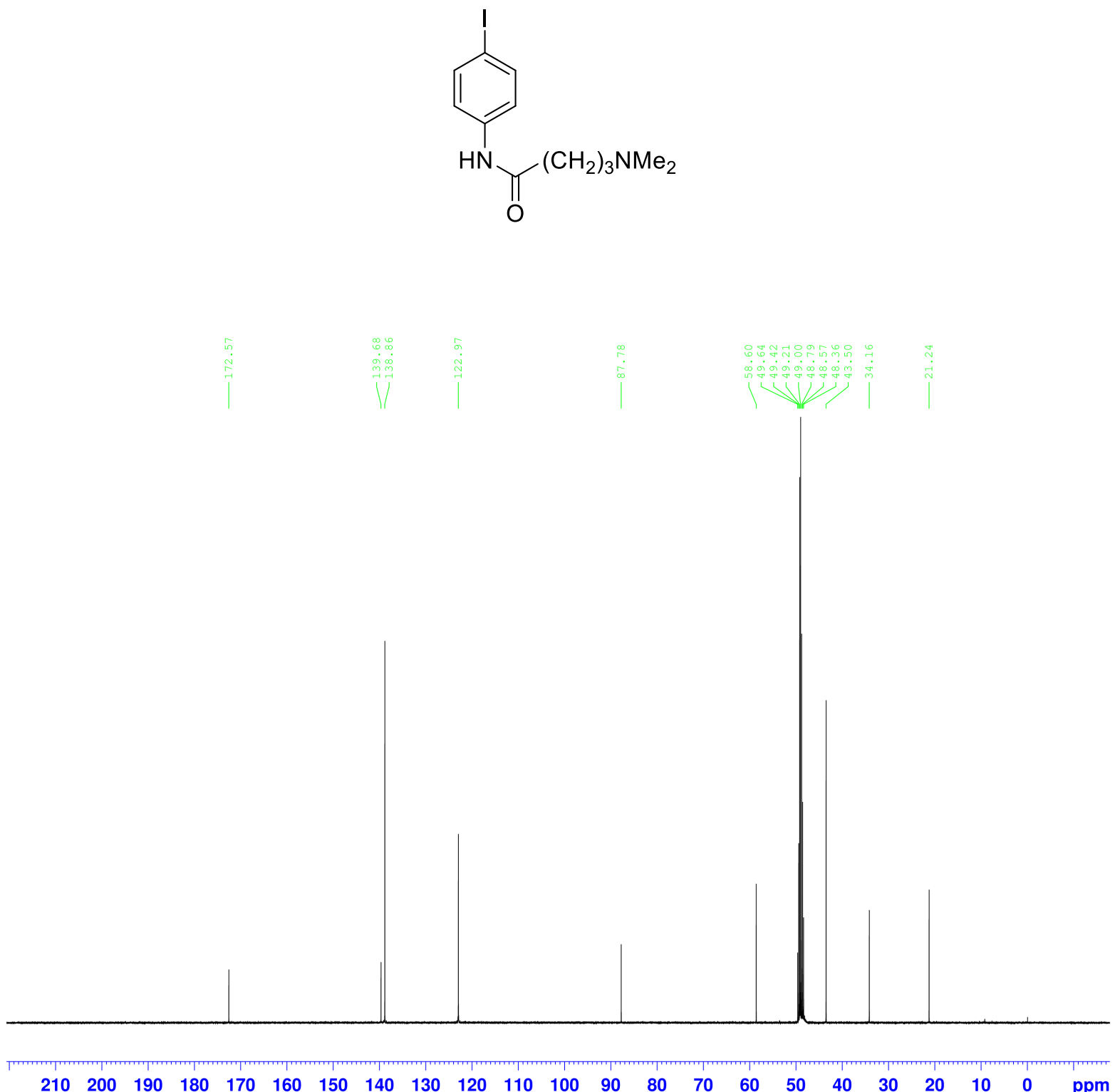

Figure S15. ${ }^{13} \mathrm{C}$ NMR spectrum of Compound 1. 
ESI-TOF Mass Spectrum Report

$\begin{array}{ll}\text { Analysis Name } & \text { D:IDatalUMiamil0518ChLi02_LOW_MEOH_CHCL3_woFA_POS.d } \\ \text { Sample Name } & \text { CL159 } \\ \text { Comment } & \text { MEOH_CHCL3 }(50: 500.0 \% \text { FA) }\end{array}$

Comment

MEOH_CHCL3 $(50: 500.0 \%$ FA)

Intens.
$\times 10^{5}$

105
Acquisition Date 5/18/2018 1:51:49 PM

Instrument micrOTOF-Q II

Method tune_low_Bruker_Calibration.m

+ MS, $0.2-0.4 \min \#(12-23)$ 

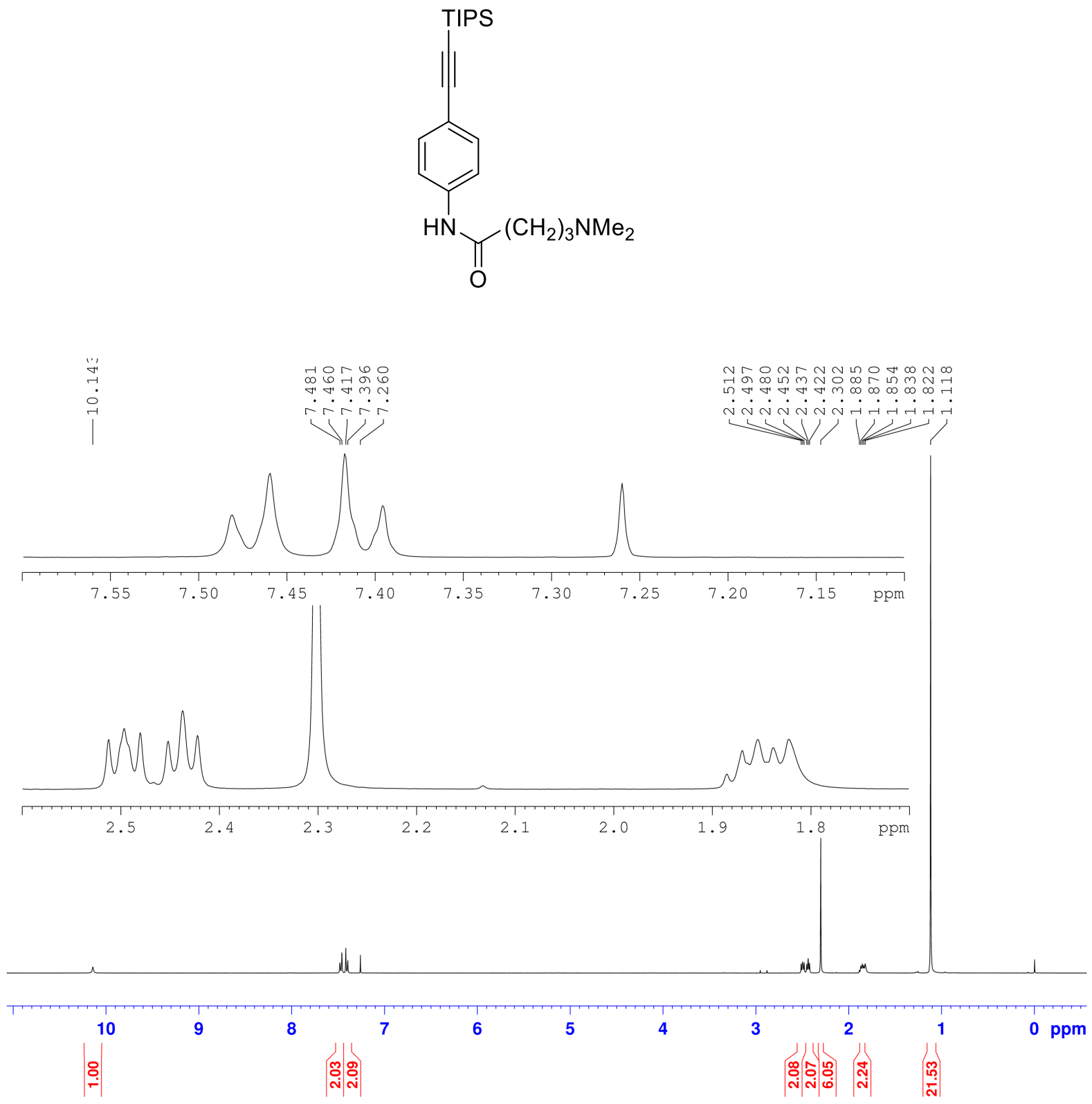

Figure S17. ${ }^{1} \mathrm{H}$ NMR spectrum of Compound 2. 

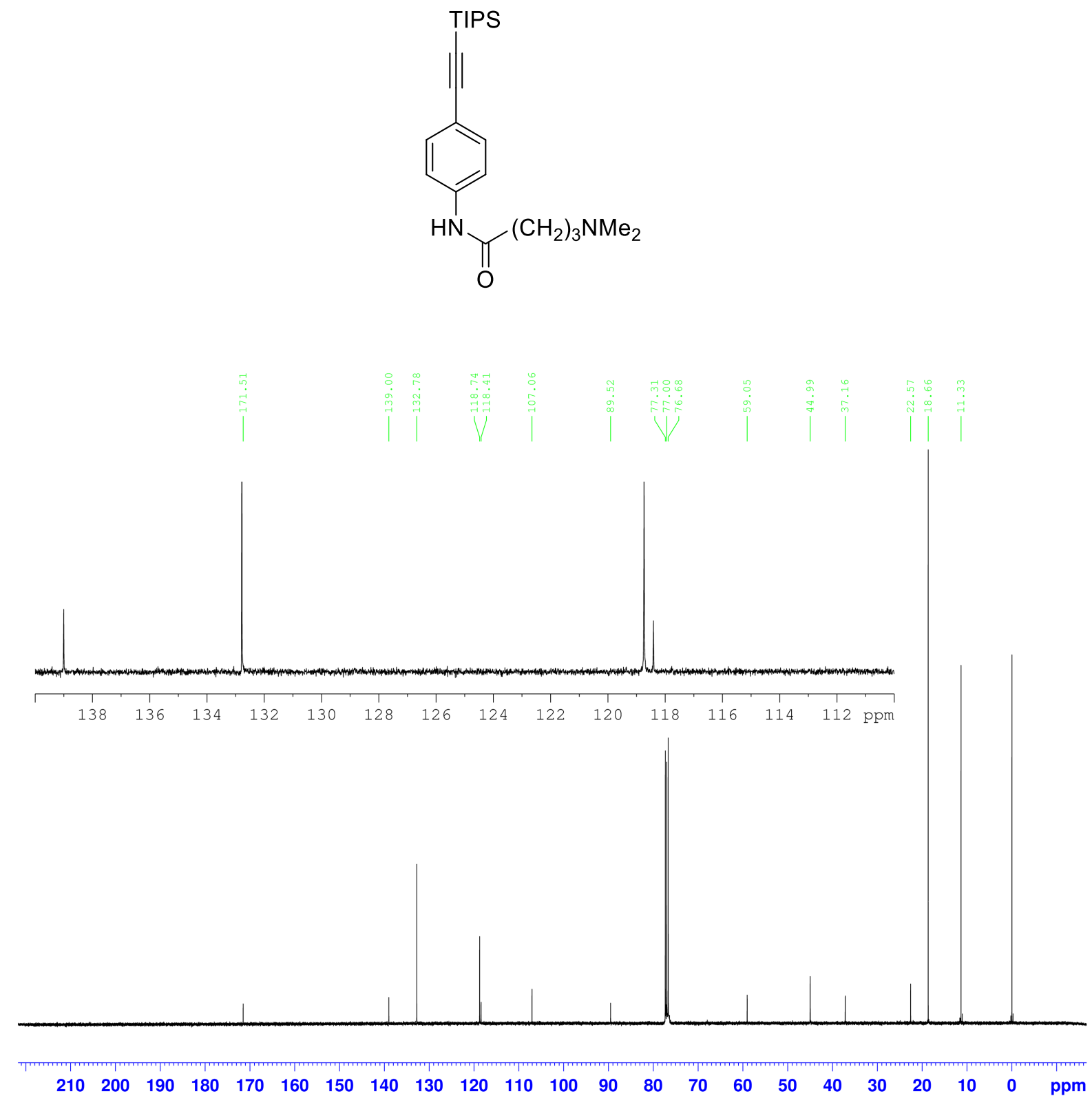

Figure S18. ${ }^{13} \mathrm{C}$ NMR spectrum of Compound 2. 


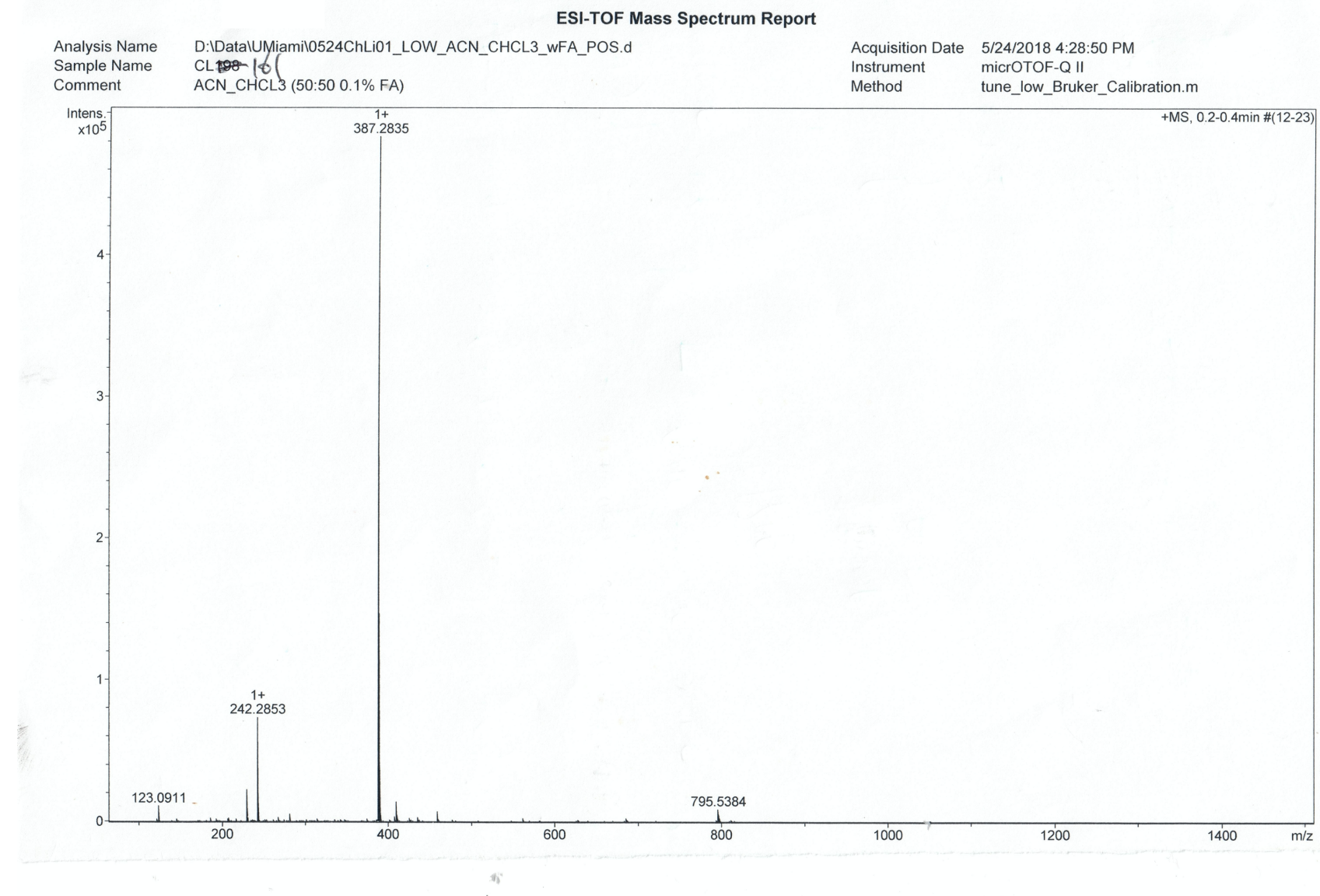

Figure S19. ESI-MS of Compound 2. 

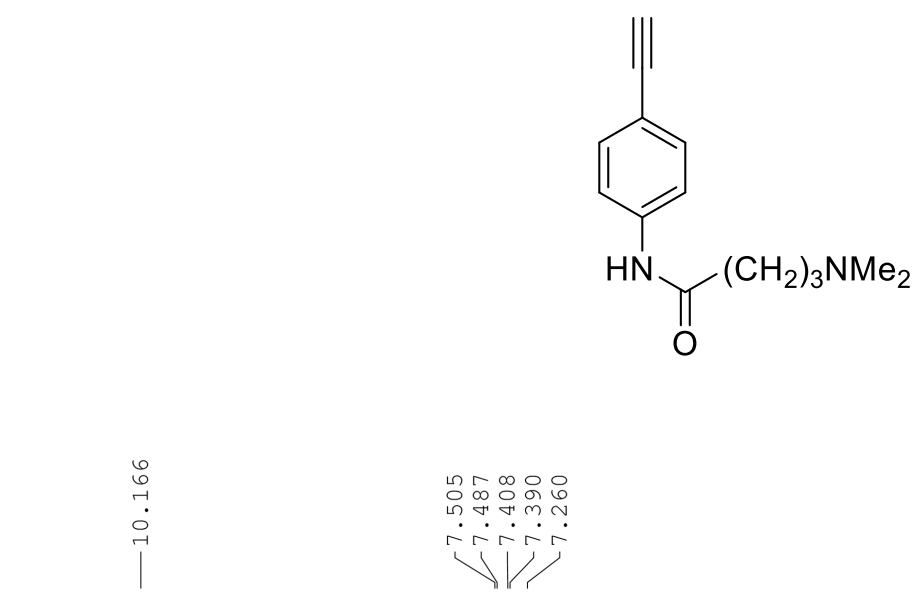

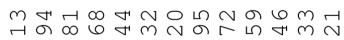

$\dot{M} \sim \dot{N} \sim \vec{N} \sim N H-H$
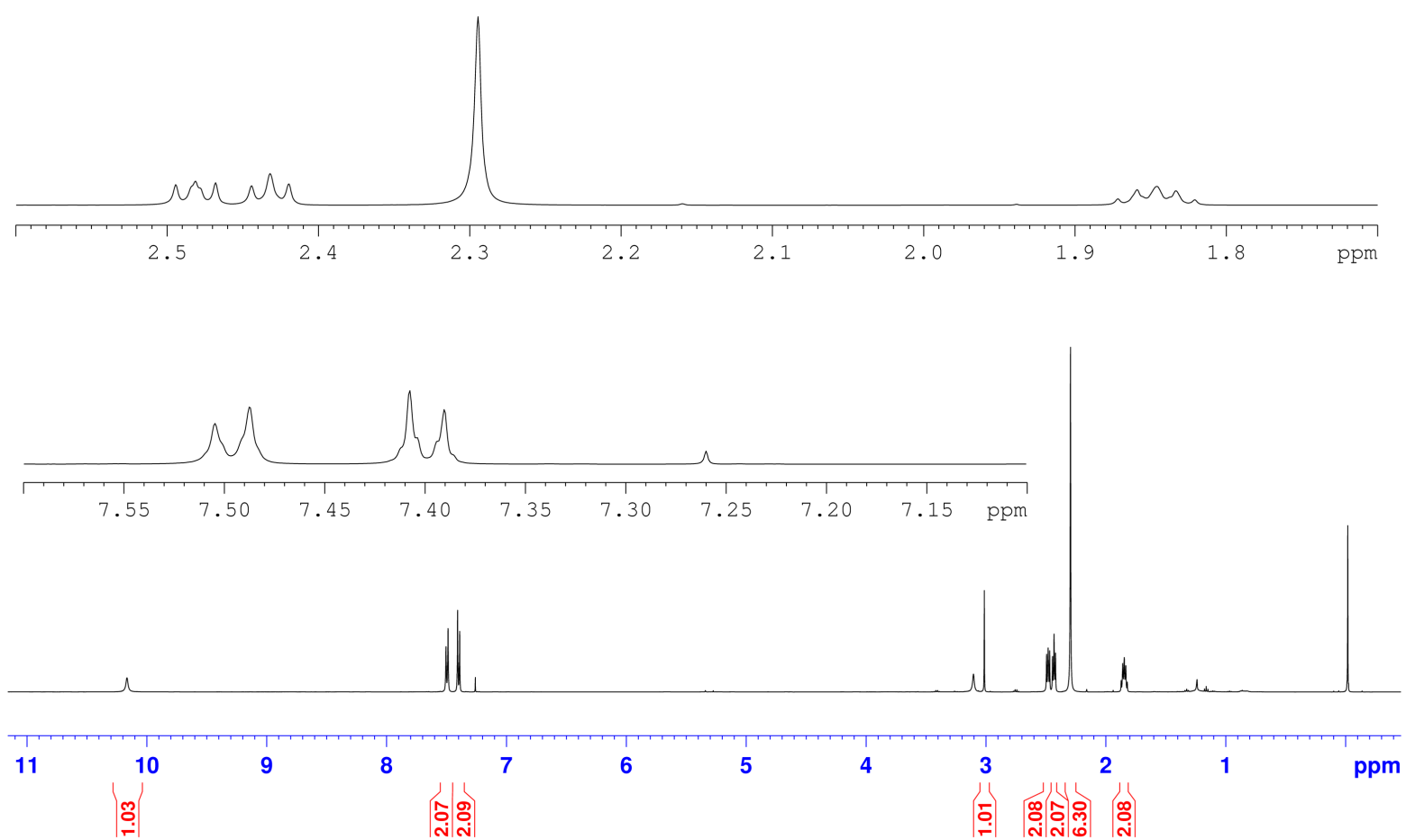

Figure S20. ${ }^{1} \mathrm{H}$ NMR spectrum of Compound 3. 

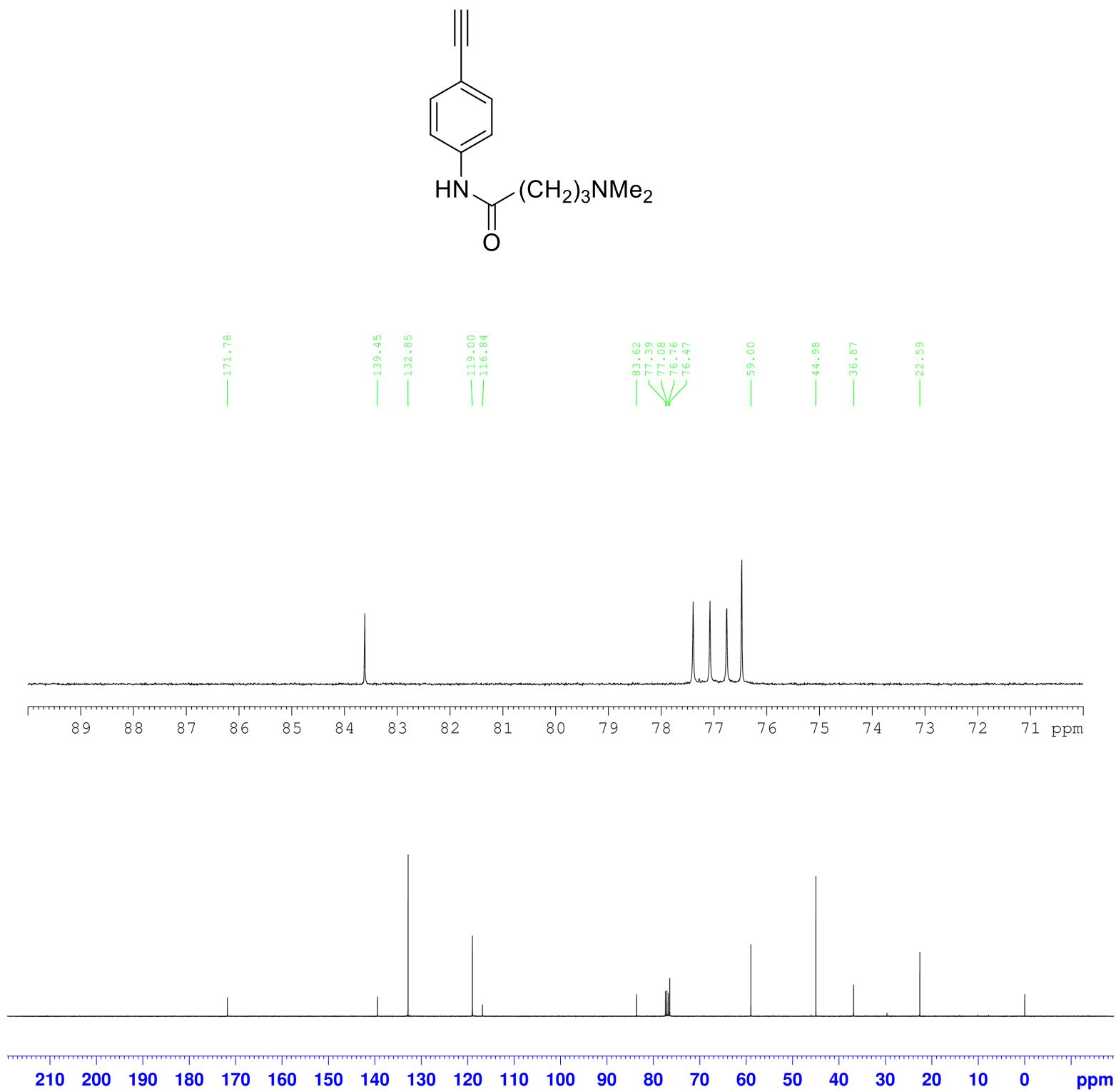

Figure S21. ${ }^{13} \mathrm{C}$ NMR spectrum of Compound 3. 
ESI-TOF Mass Spectrum Report

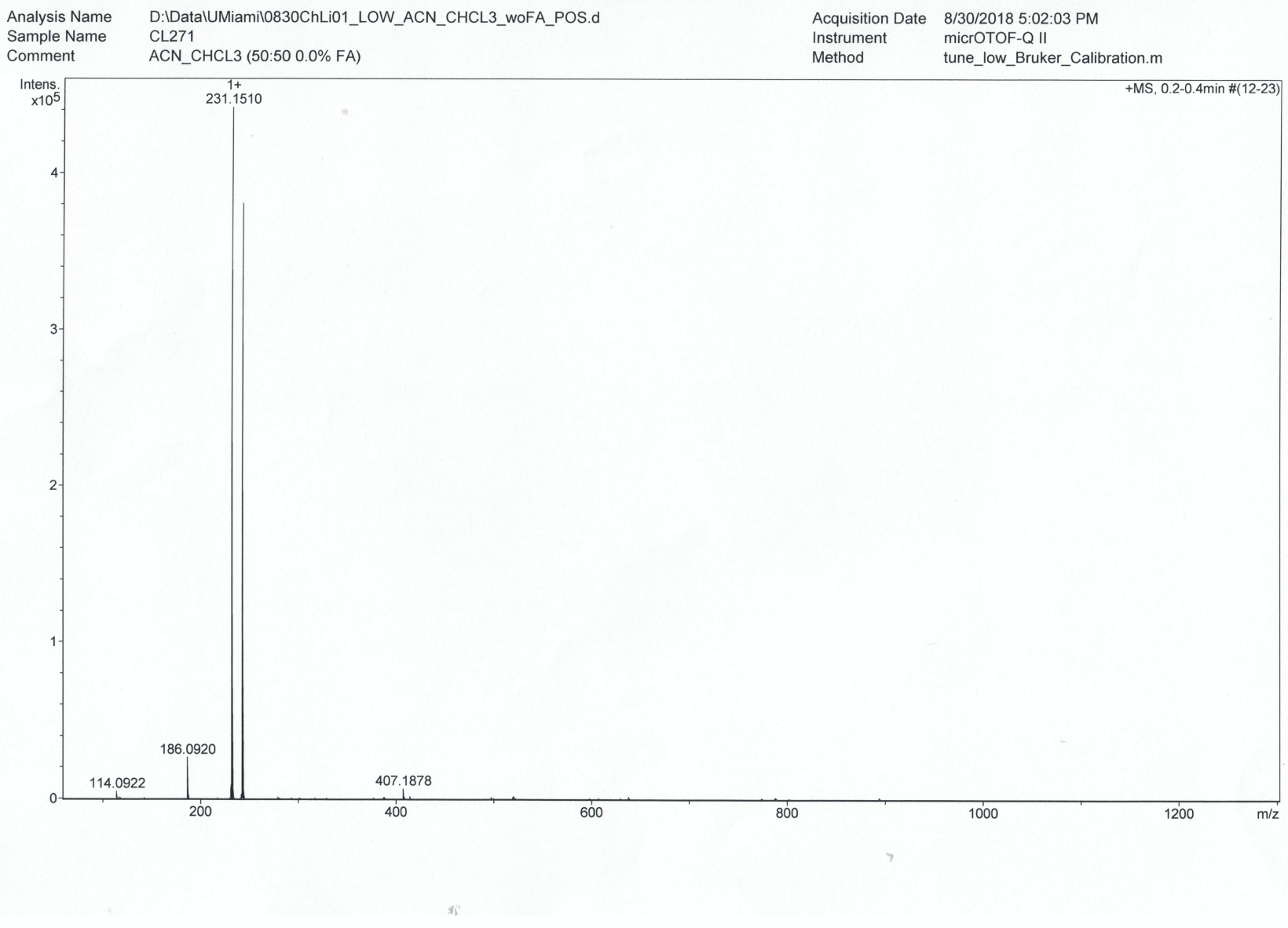

Figure S22. ESI-MS of Compound 3. 

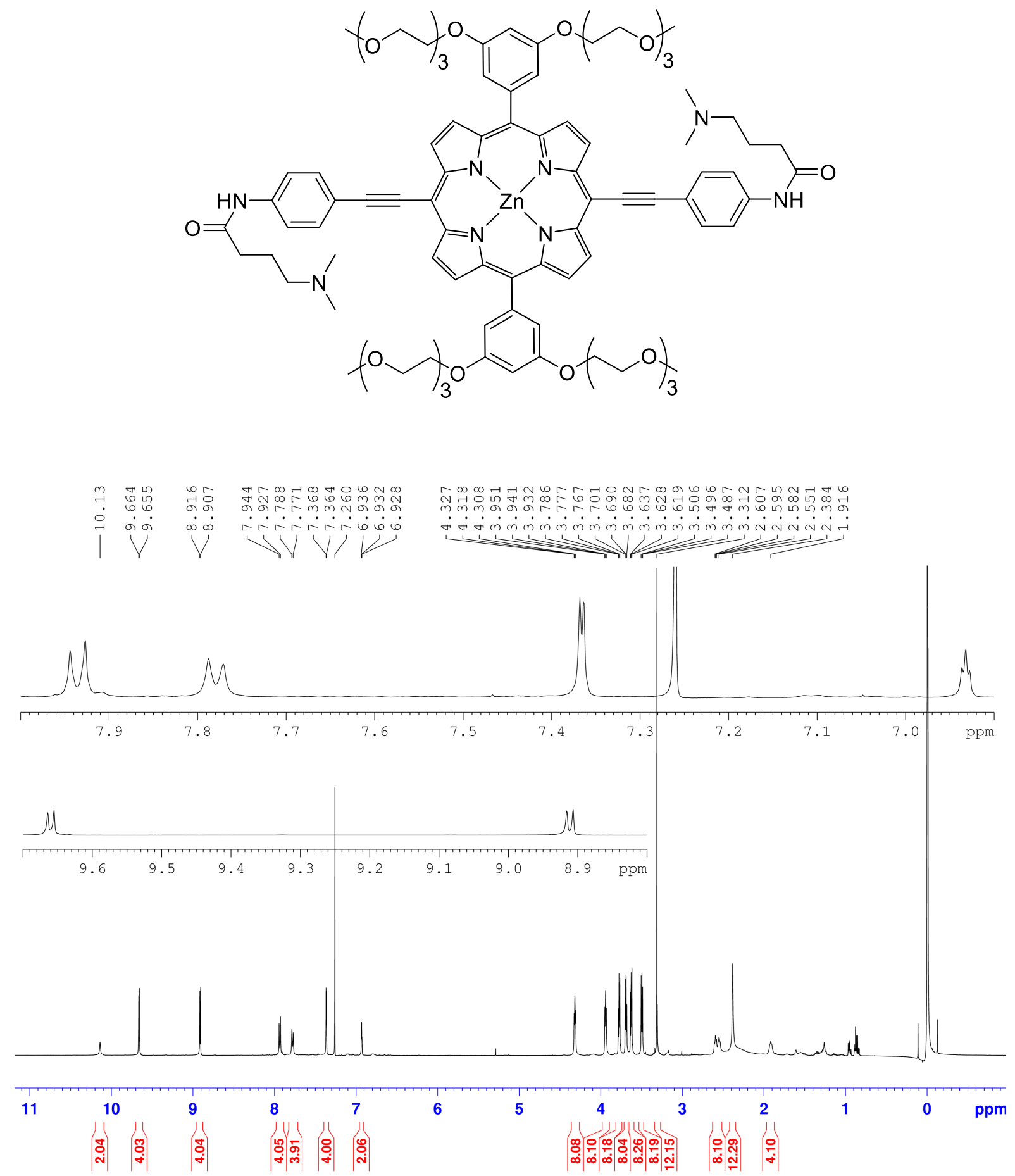

Figure S23. ${ }^{1} \mathrm{H}$ NMR spectrum of Compound 9. 

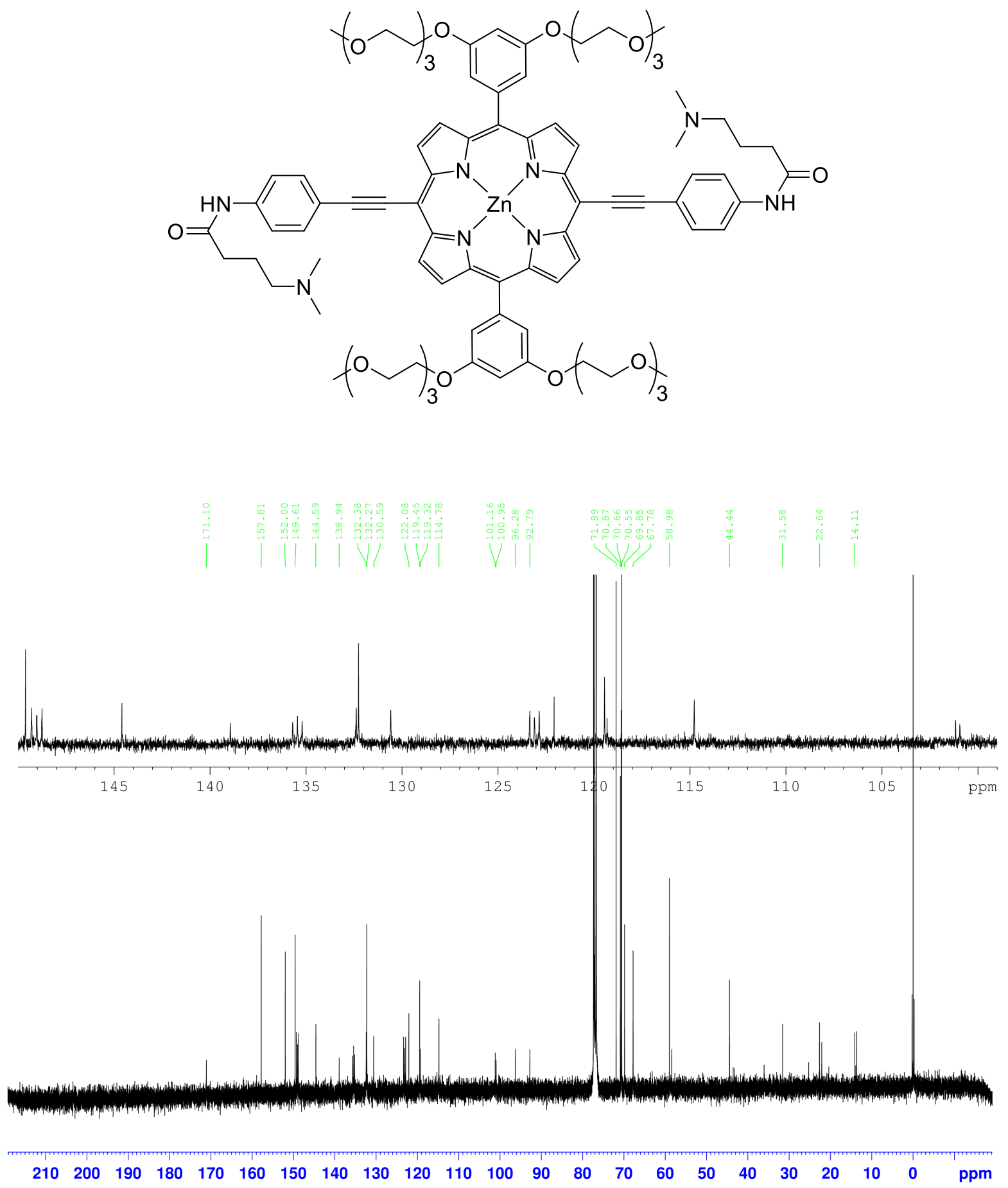

Figure S24. ${ }^{13} \mathrm{C}$ NMR spectrum of Compound 9. 


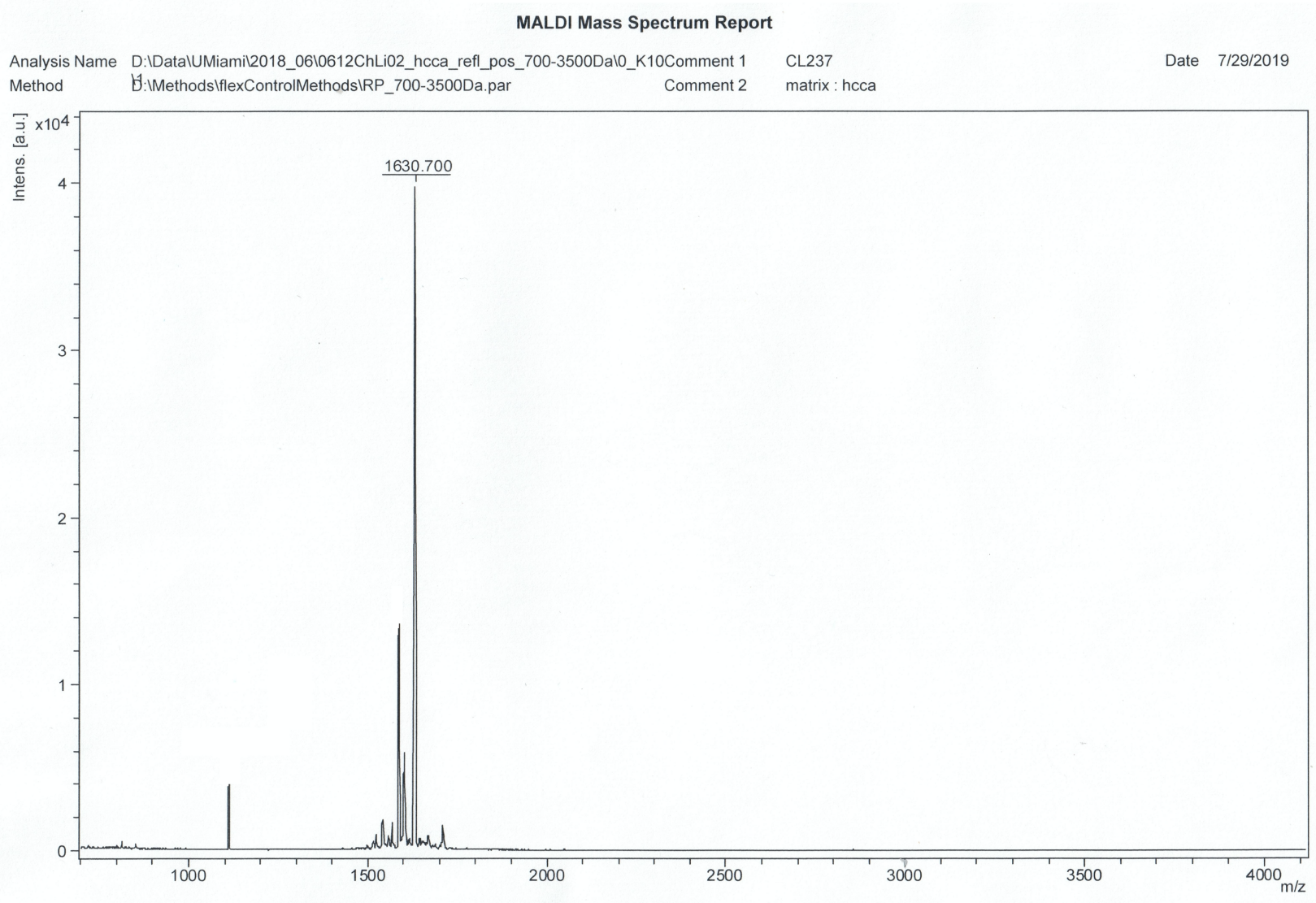

Figure S25. MALDI-MS of Compound 9. 


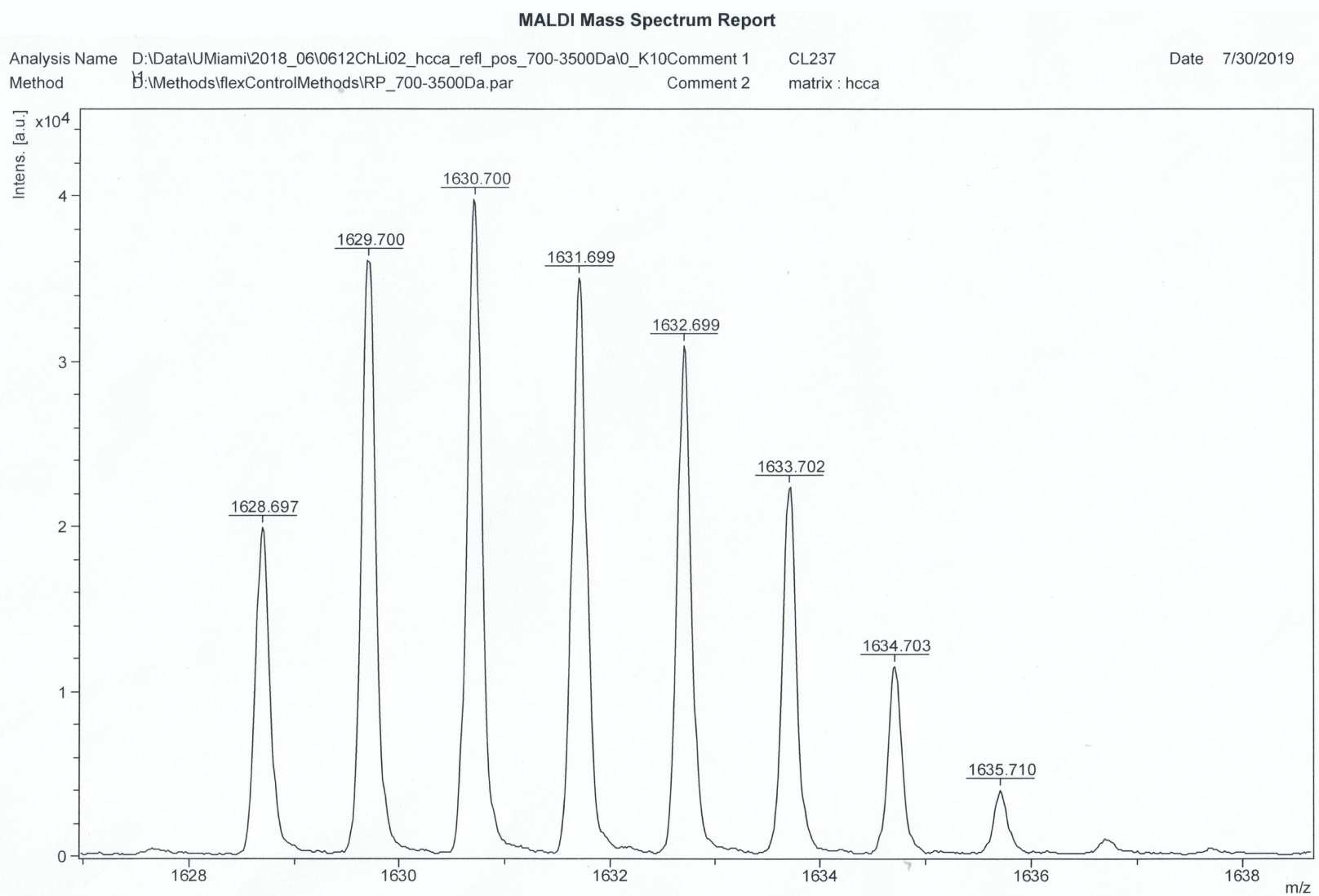

Figure S26. MALDI-MS of Compound 9 (zoomed-in peaks of interest). 

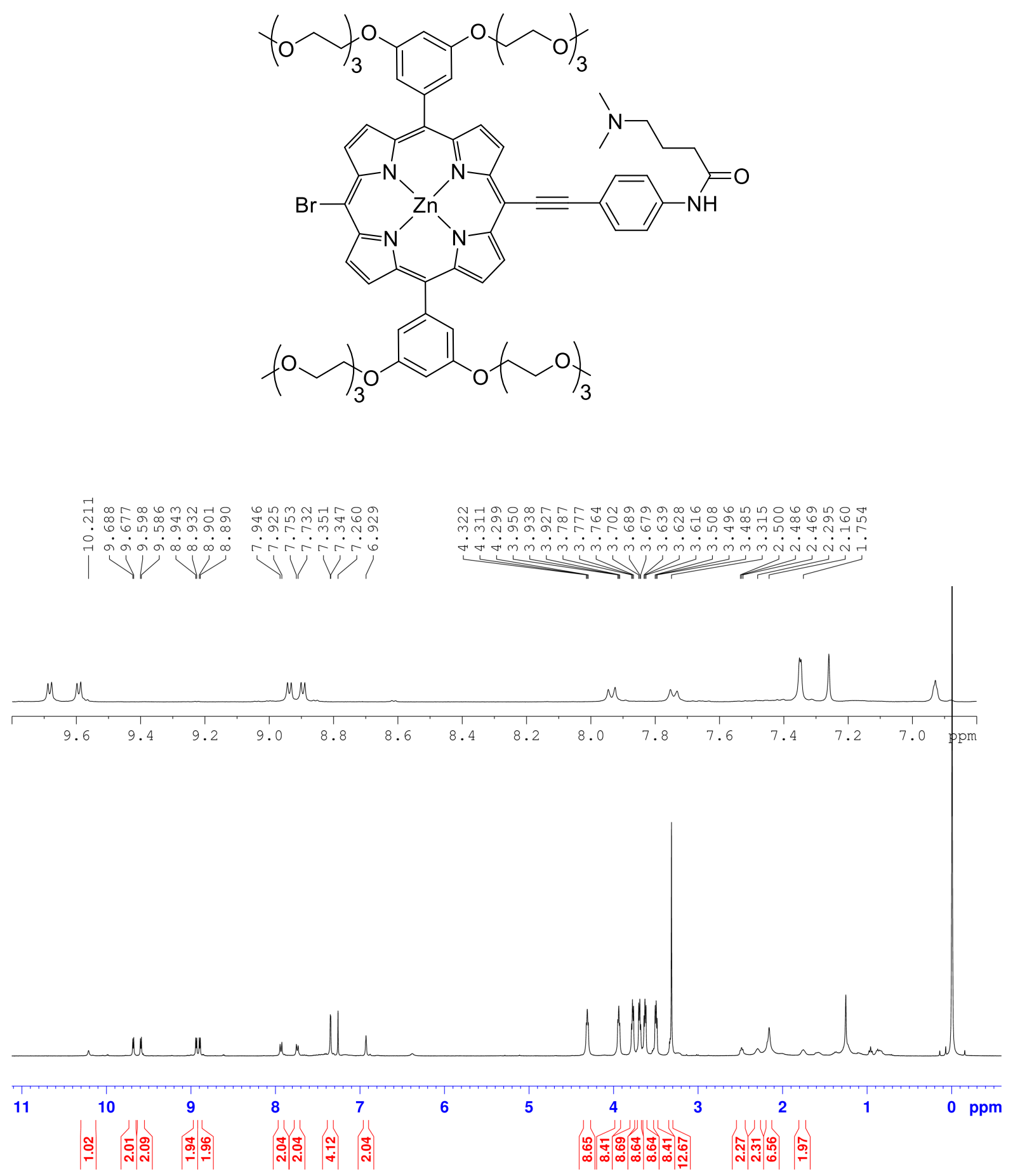

Figure S27. ${ }^{1} \mathrm{H}$ NMR spectrum of Compound $\mathbf{1 0 .}$ 

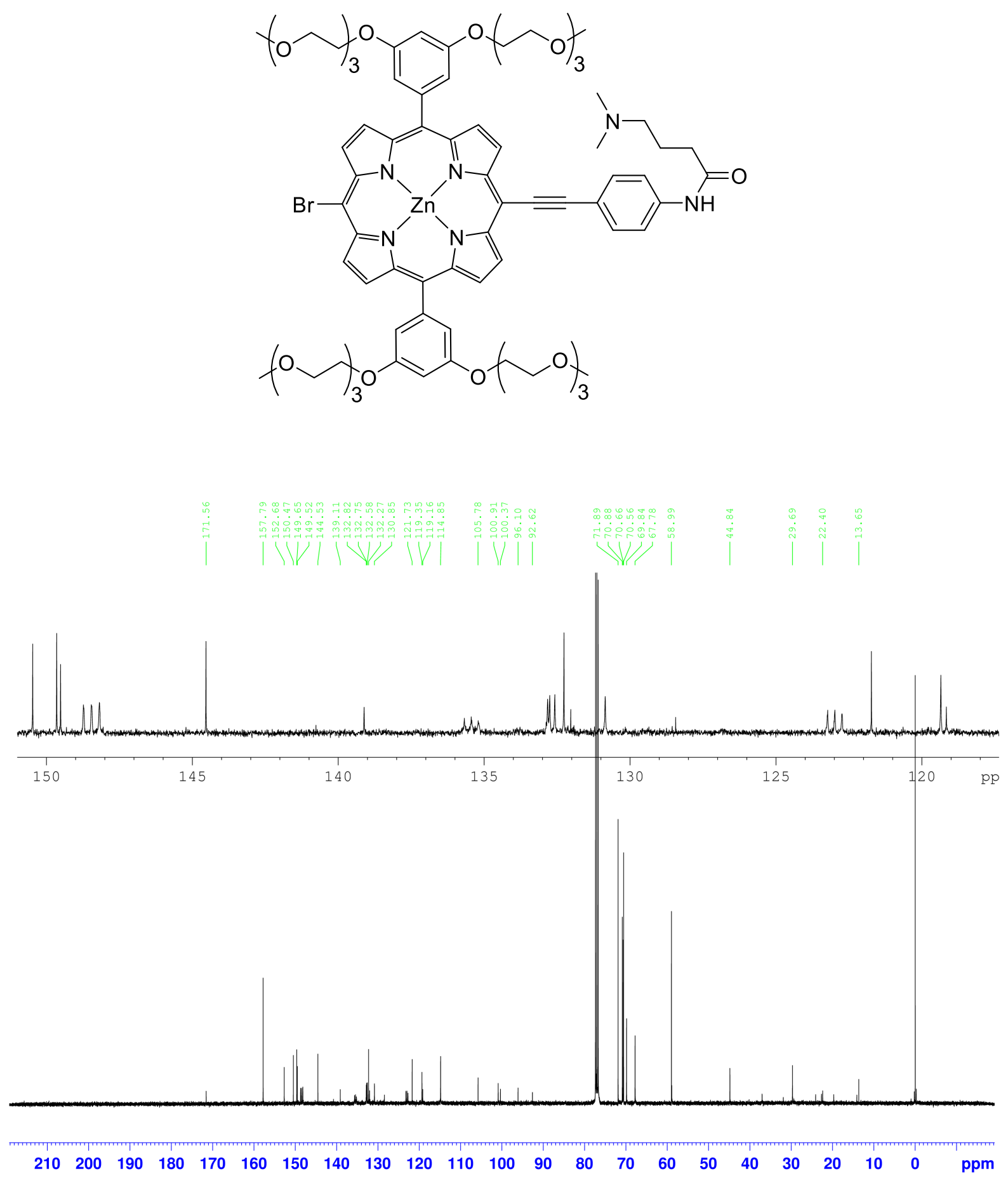

Figure S28. ${ }^{13} \mathrm{C}$ NMR spectrum of Compound $\mathbf{1 0}$. 
MALDI Mass Spectrum Report

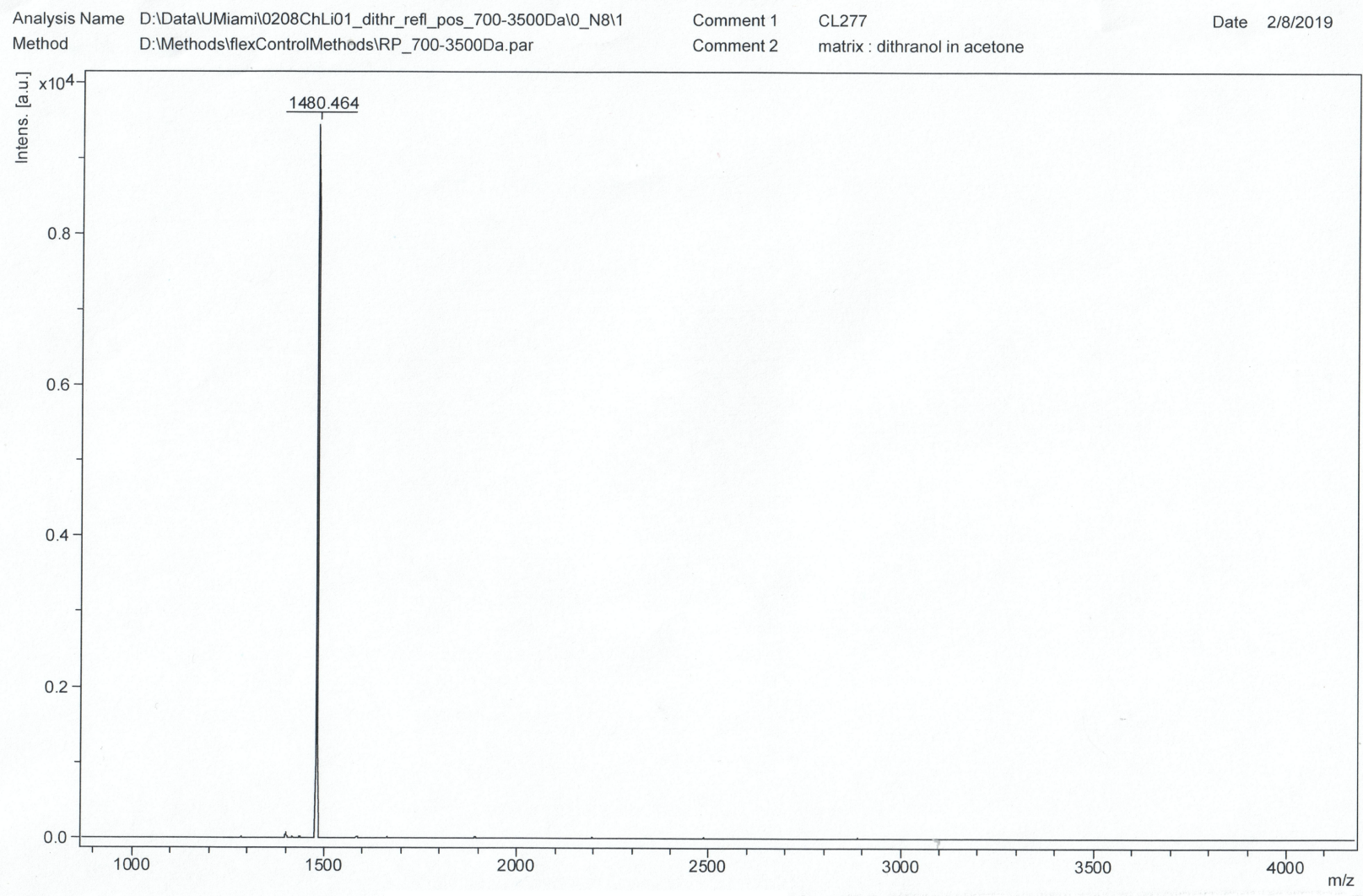

Figure S29. MALDI-MS of Compound 10. 


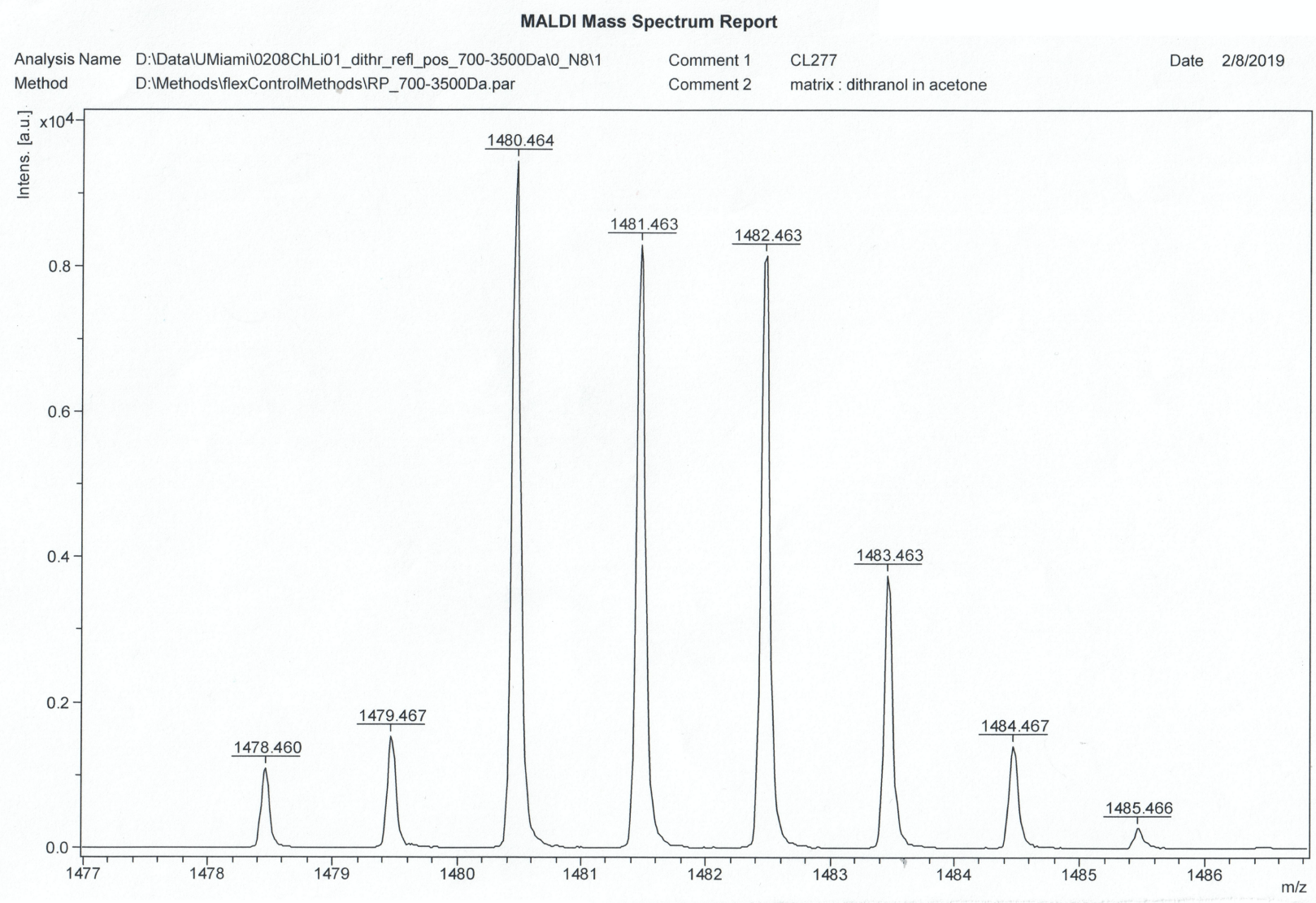

Figure S30. MALDI-MS of Compound 10 (zoomed-in peaks of interest). 

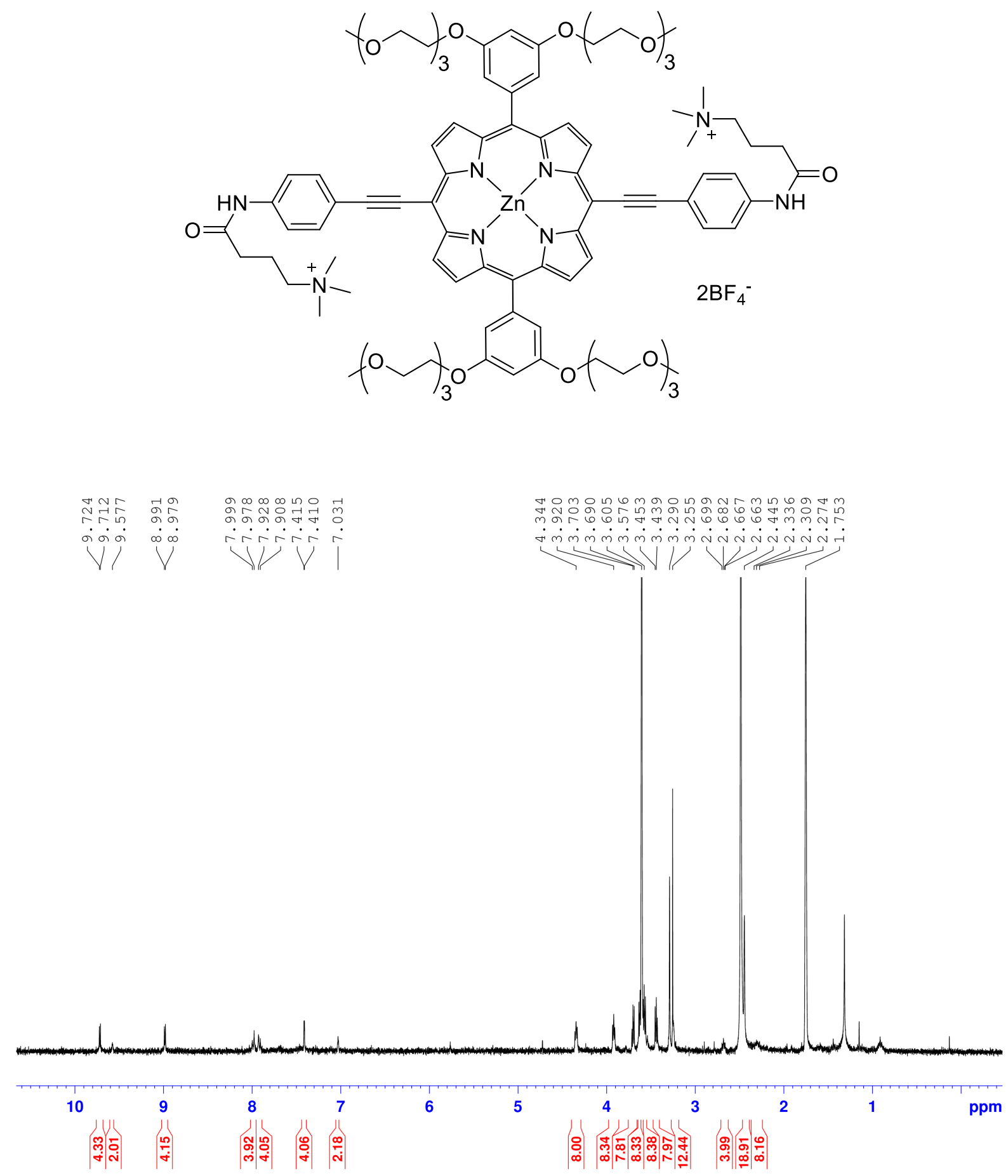

Figure S31. ${ }^{1} \mathrm{H}$ NMR spectrum of MPZnM. 


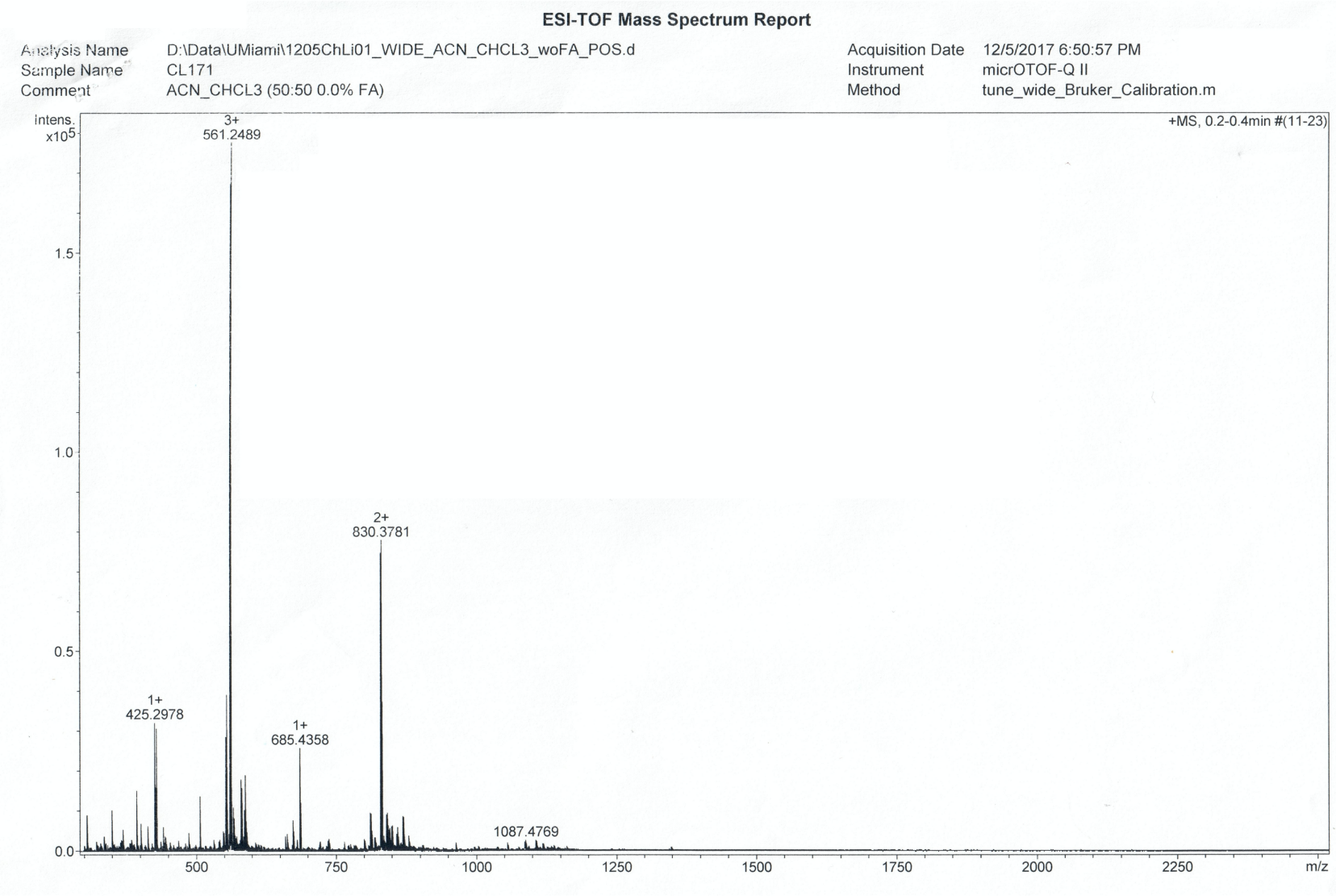

Figure S32. ESI-MS of MPZnM. 


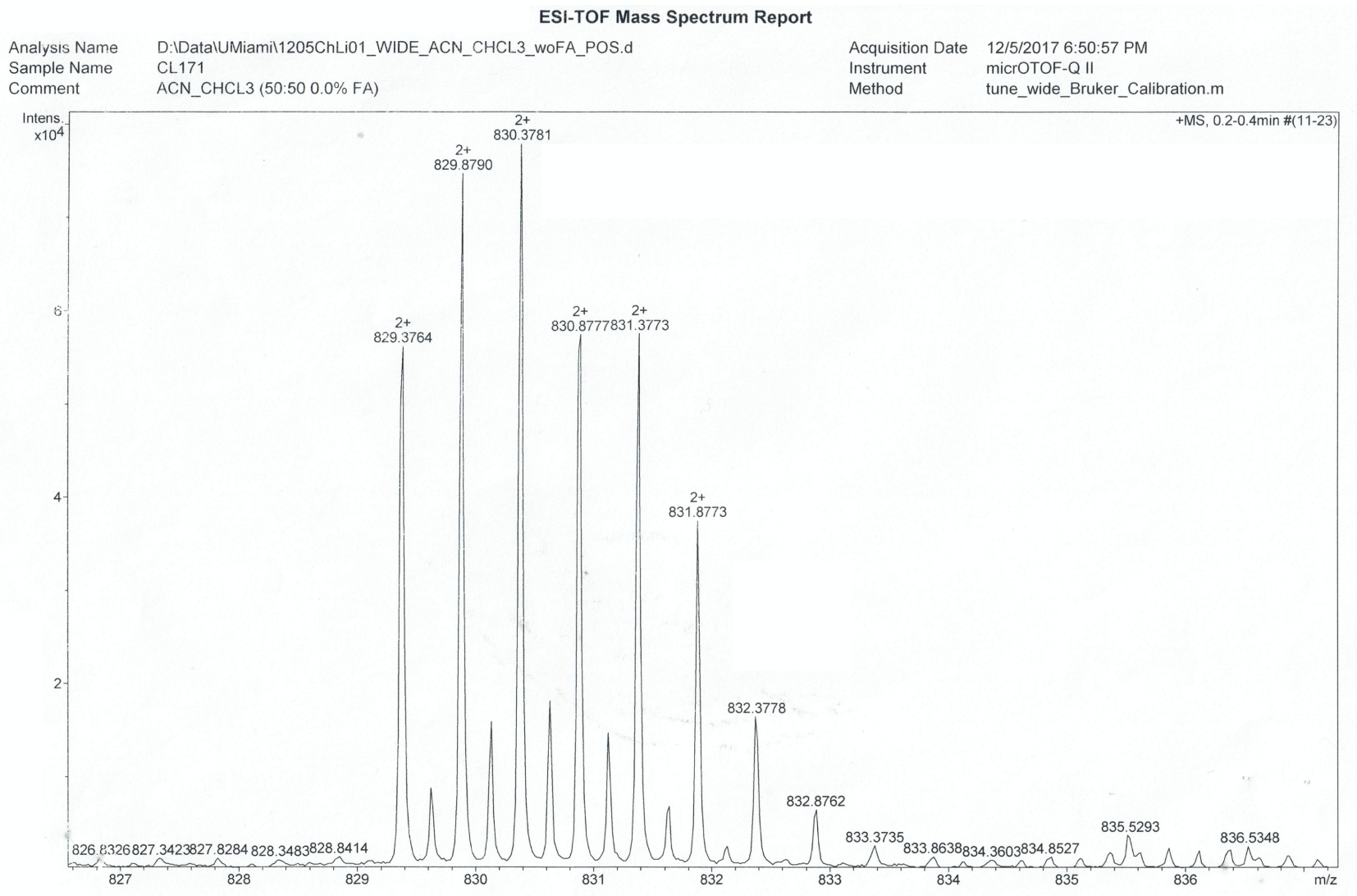

Figure S33. ESI-MS of MPZnM (zoomed-in peaks of interest). Note: the lower peaks partially overlapped with our main peaks correspond to $[2 \mathrm{M}]^{4+}$. 


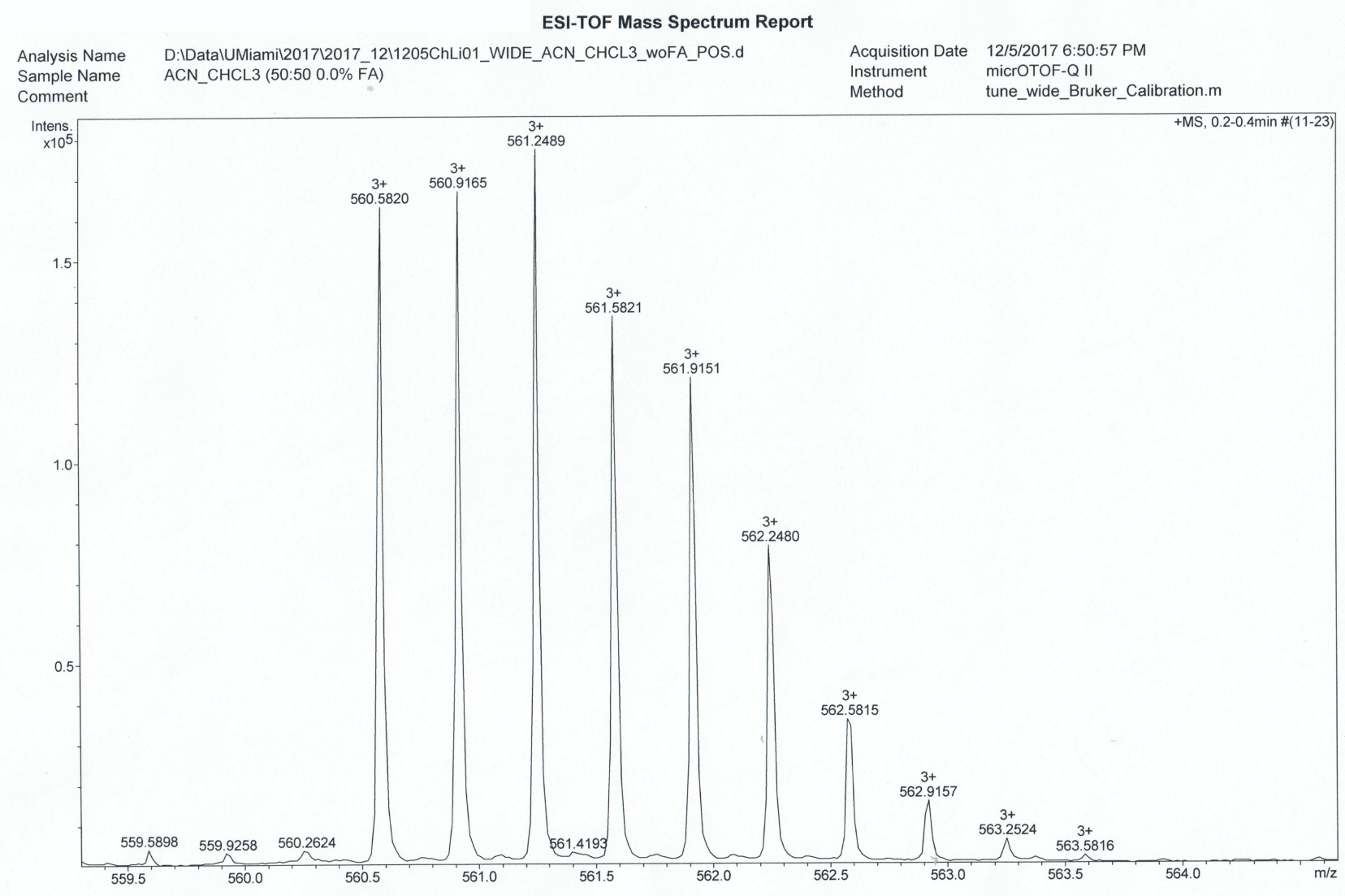

Figure S34. ESI-MS of MPZnM (zoomed-in peaks of interest). 

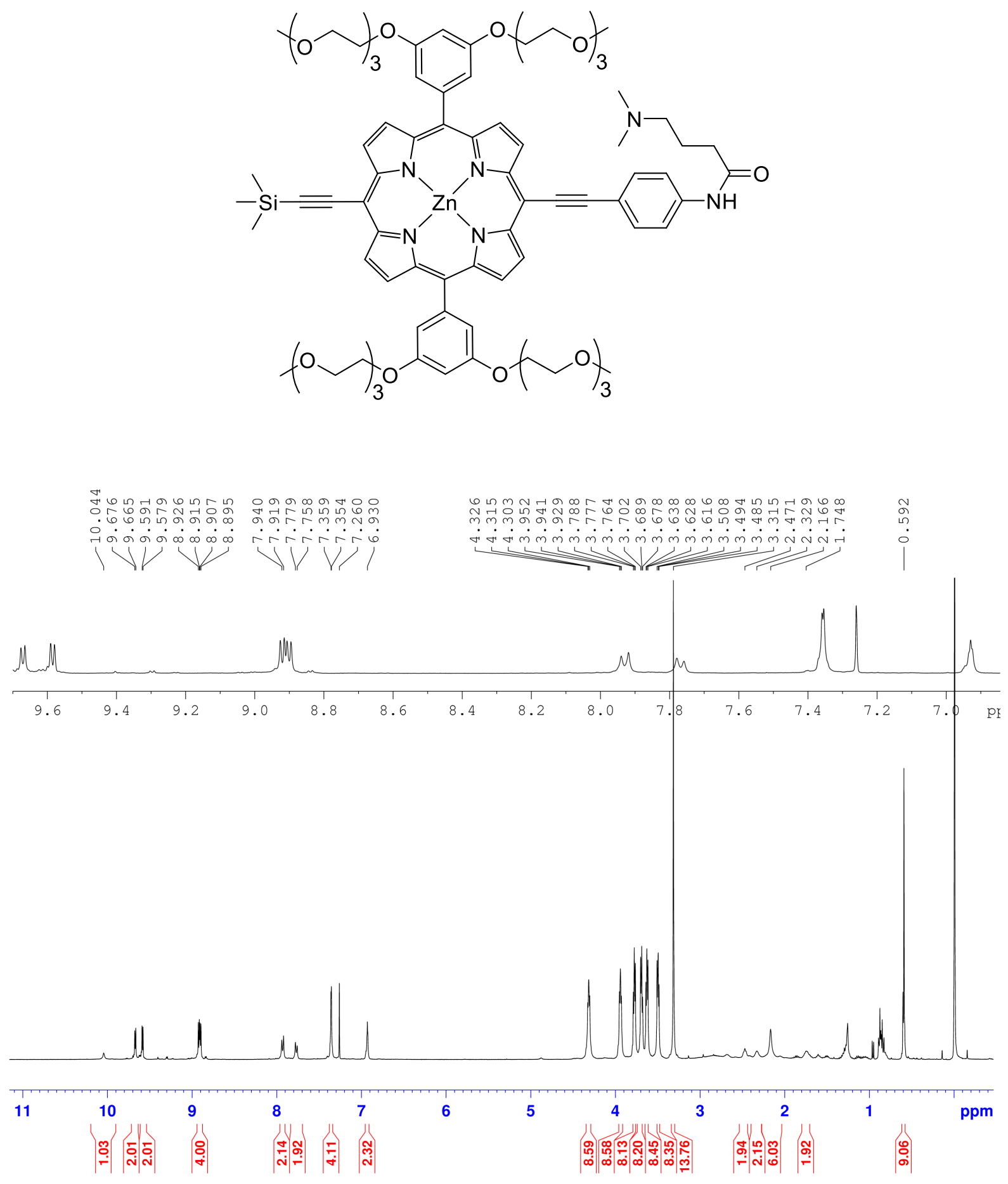

Figure S35. ${ }^{1} \mathrm{H}$ NMR spectrum of Compound 11. 

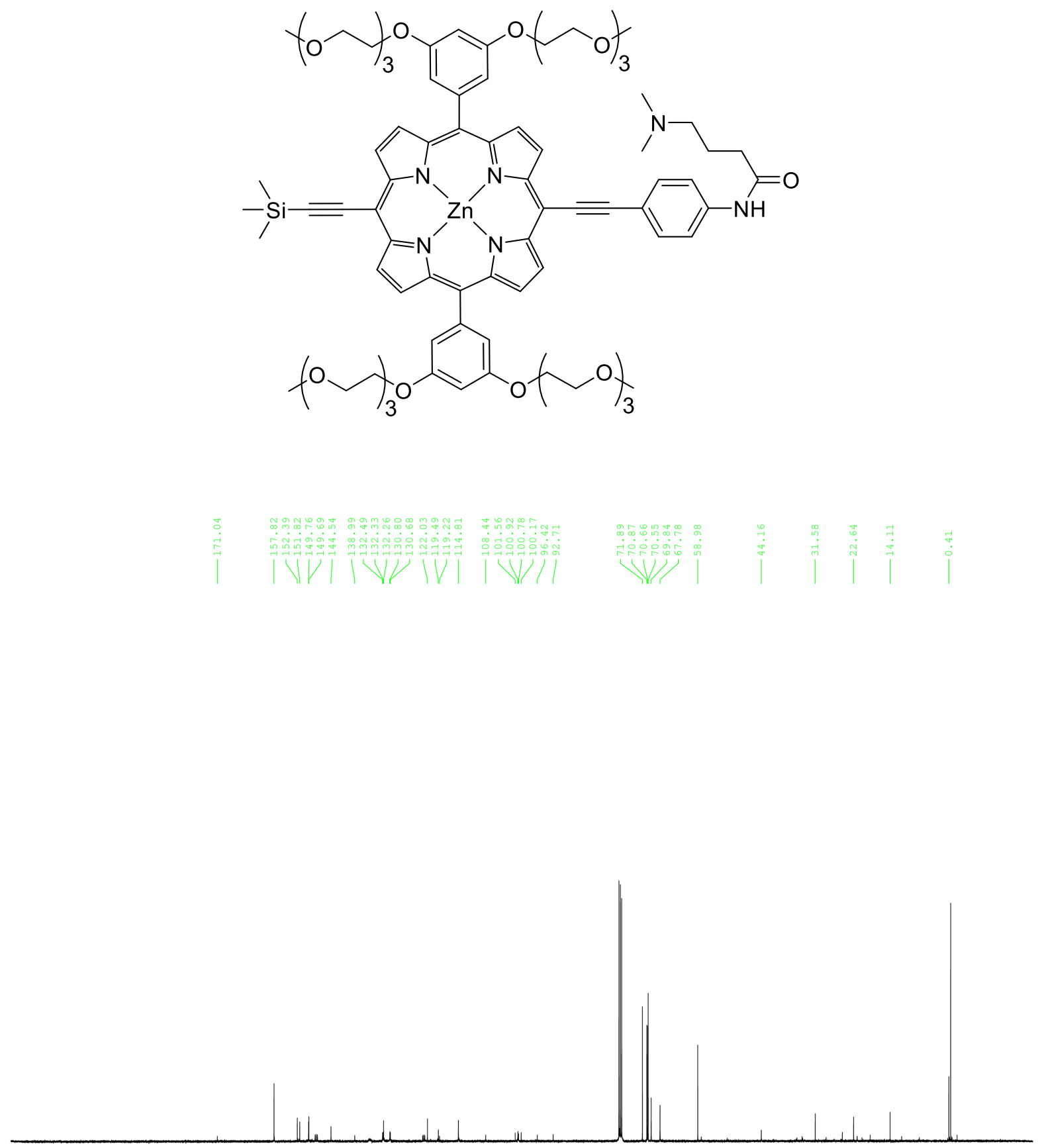

$\begin{array}{lllllllllllllllllllllll}210 & 200 & 190 & 180 & 170 & 160 & 150 & 140 & 130 & 120 & 110 & 100 & 90 & 80 & 70 & 60 & 50 & 40 & 30 & 20 & 10 & 0 & \mathrm{ppm}\end{array}$

Figure S36. ${ }^{13} \mathrm{C}$ NMR spectrum of Compound 11. 
MALDI Mass Spectrum Report

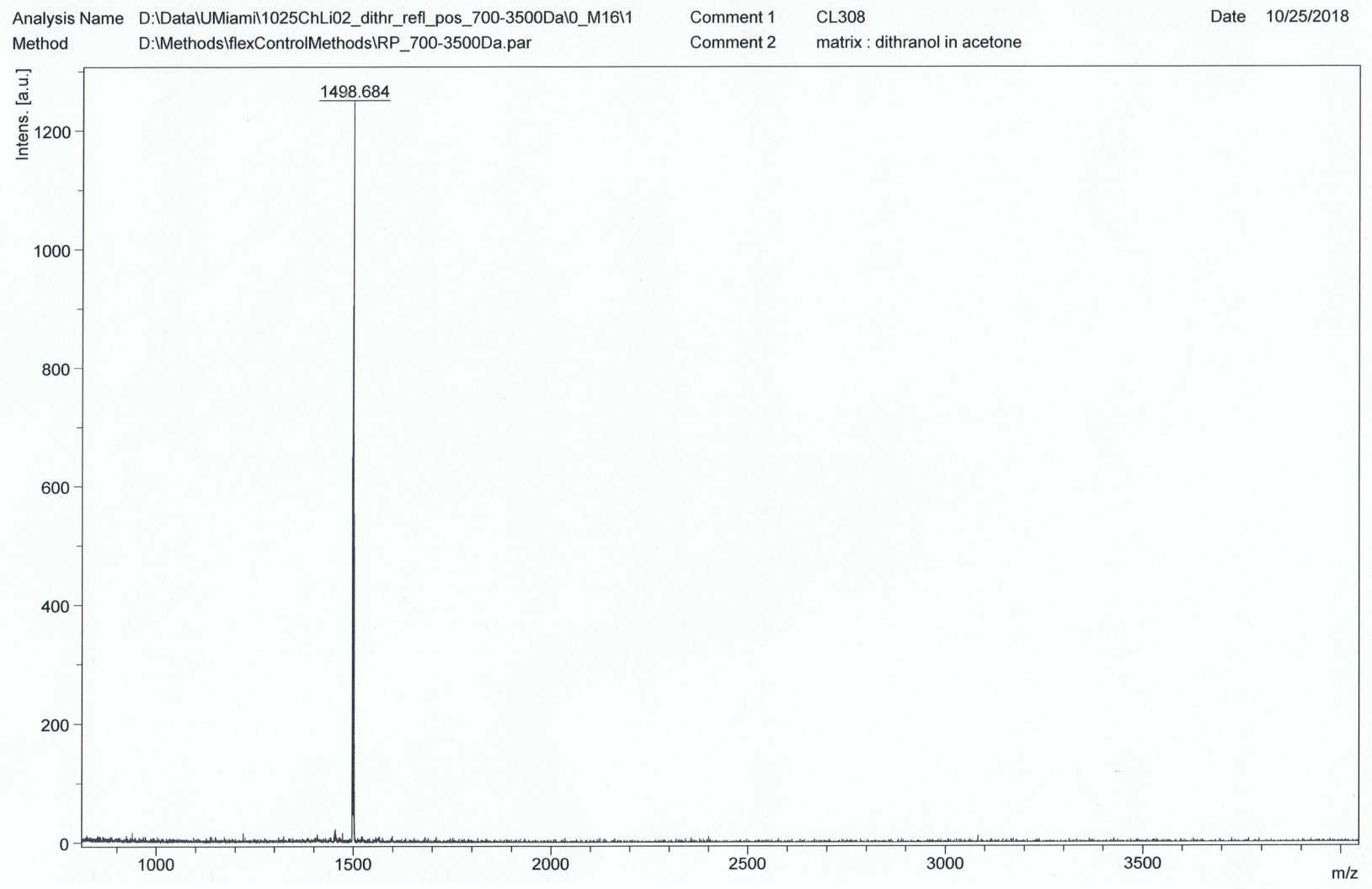

Figure S37. MALDI-MS of Compound 11. 


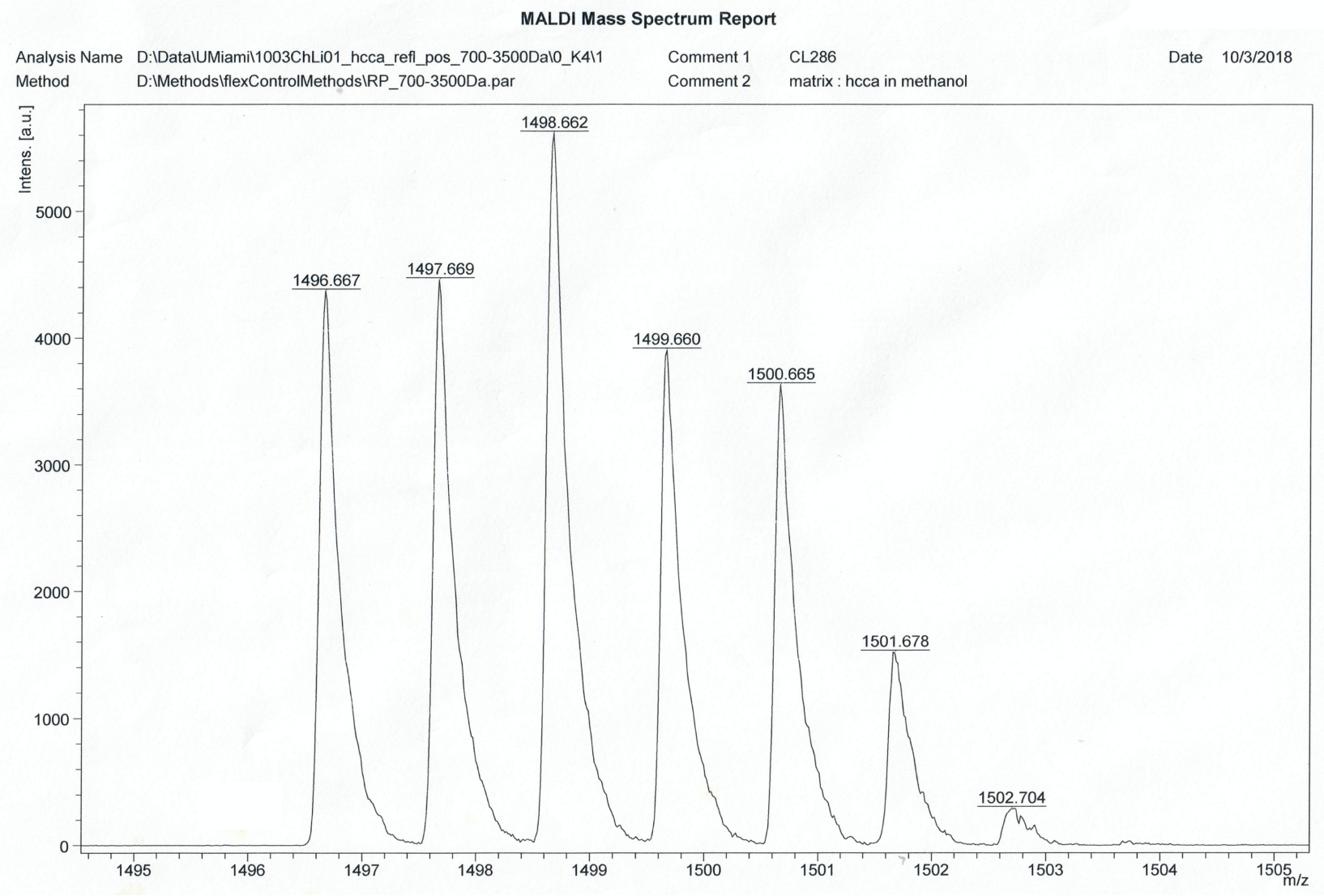

Figure S38. MALDI-MS of Compound 11 (zoomed-in peaks of interest). 
MALDI Mass Spectrum Report

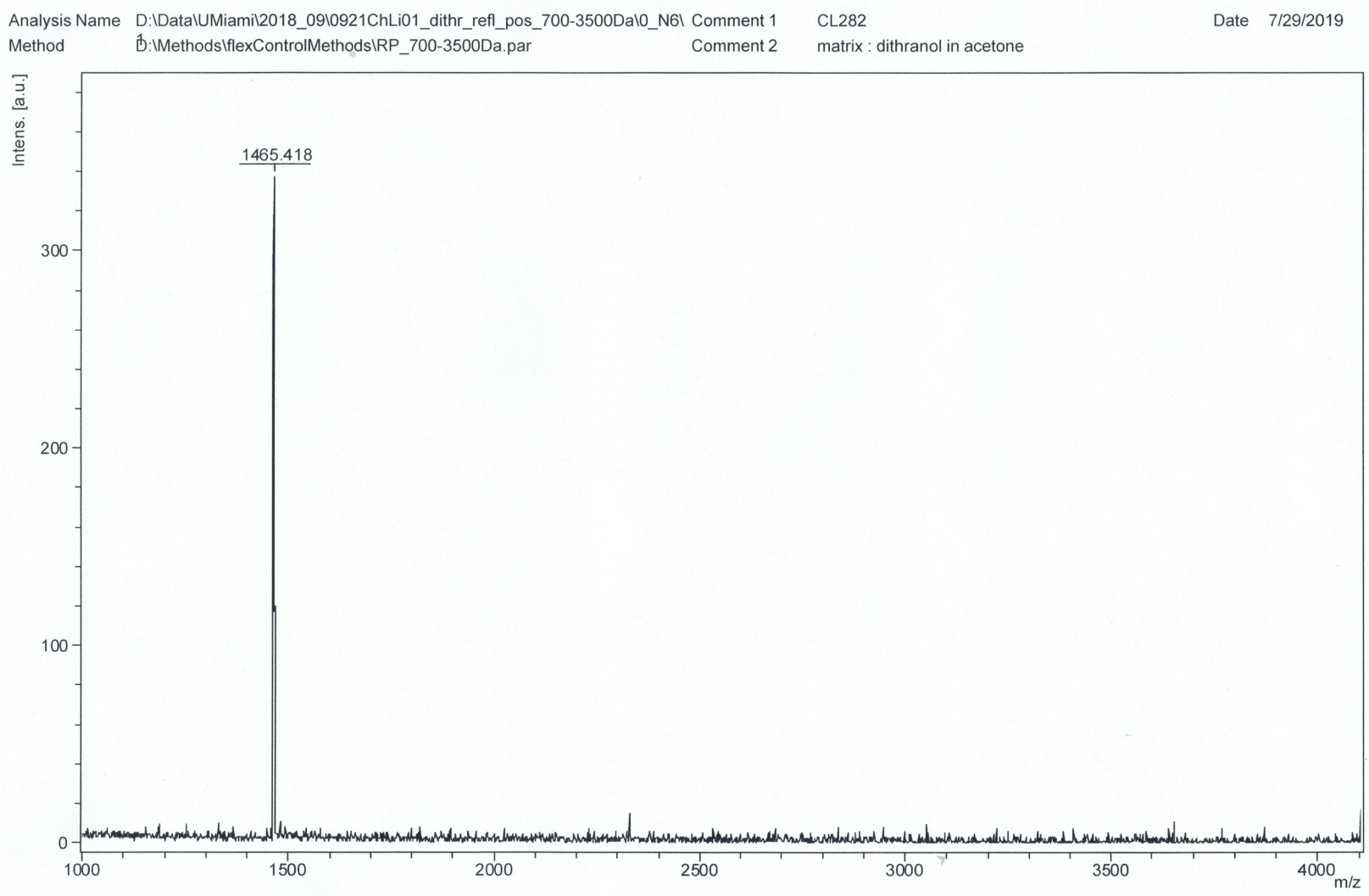

Figure S39. MALDI-MS of Compound 12. 


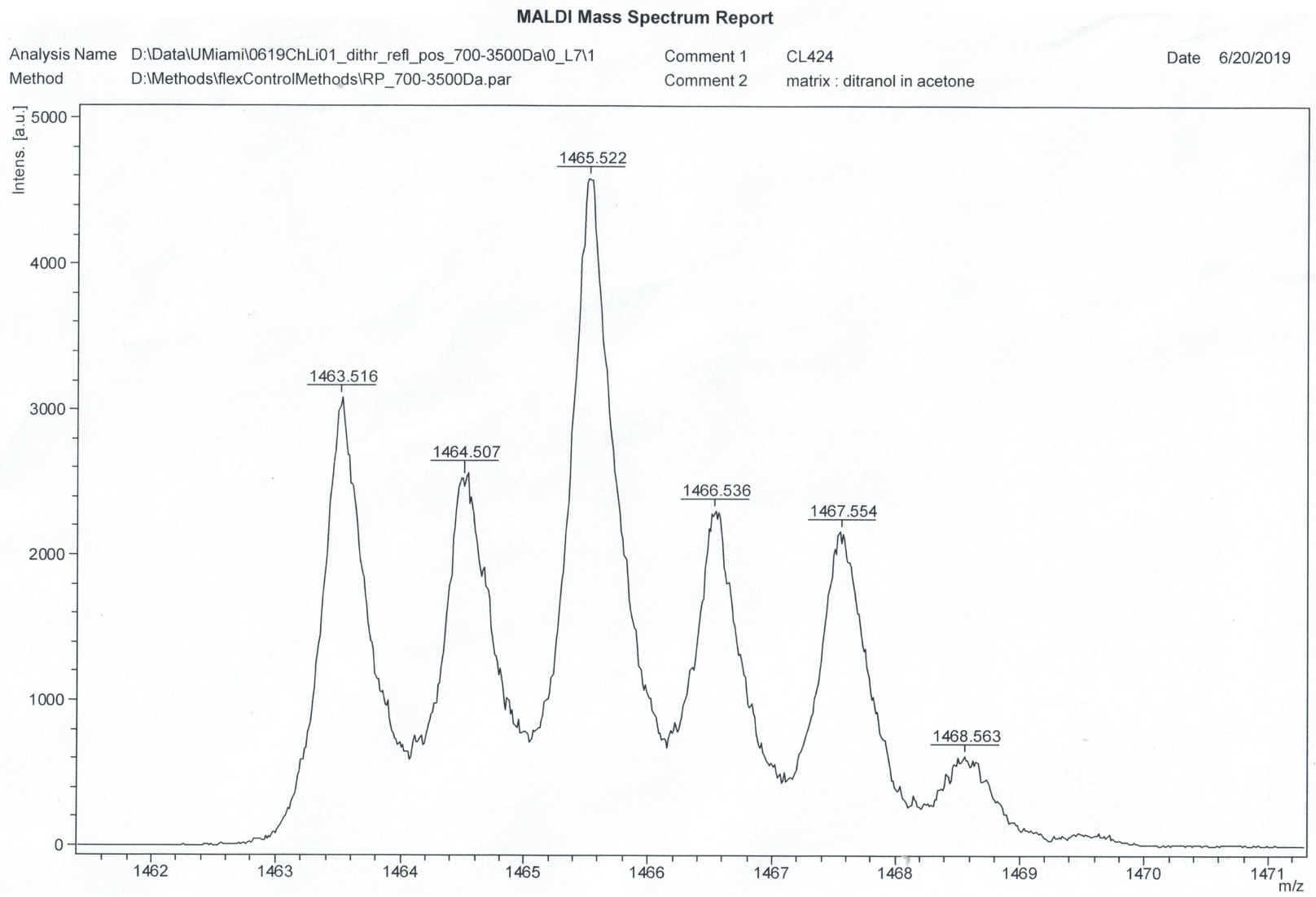

Figure S40. MALDI-MS of Compound 12 (zoomed-in peak of interest). 

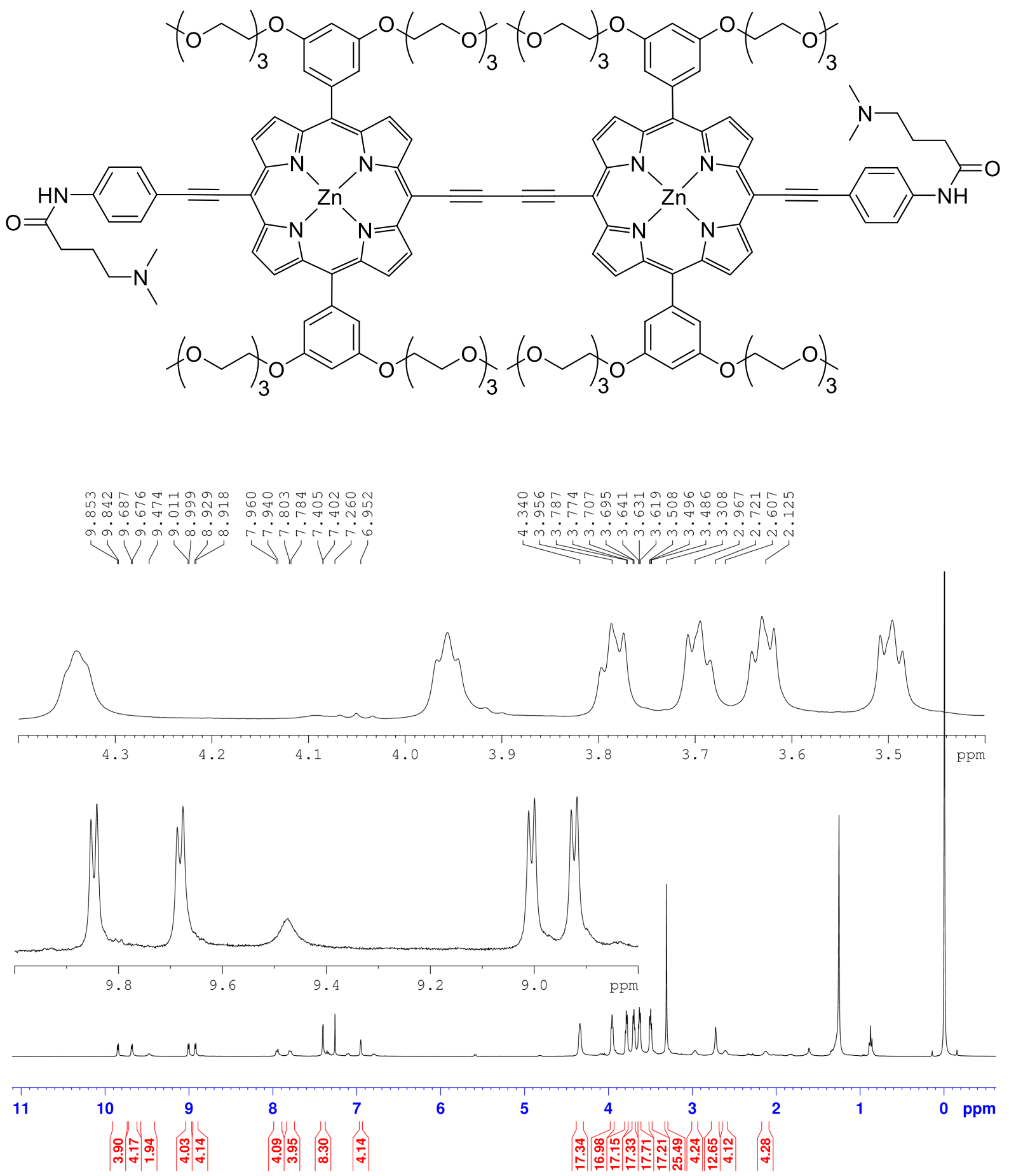

Figure S41. ${ }^{1} \mathrm{H}$ NMR spectrum of Compound 13. 

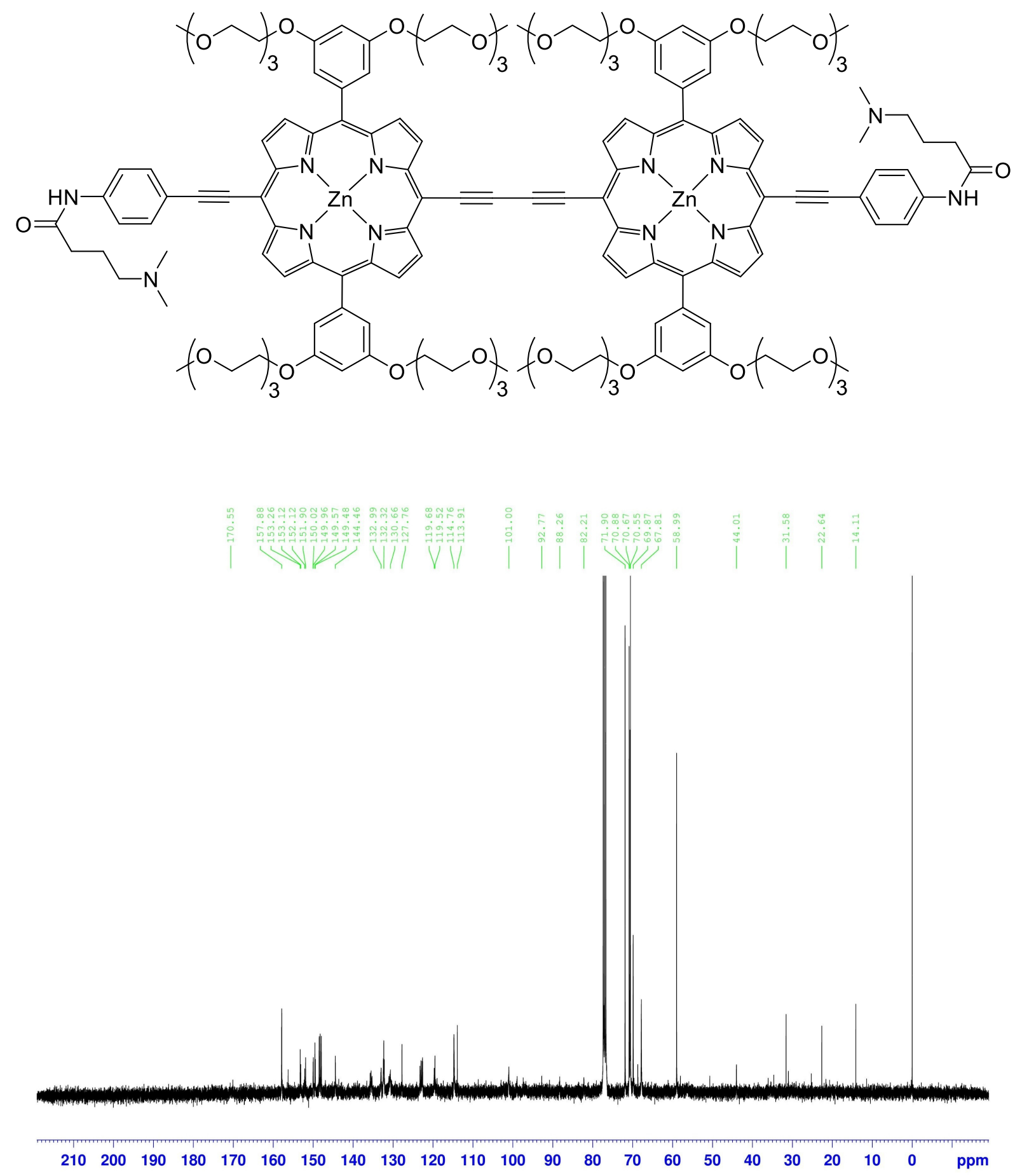

Figure S42. ${ }^{13} \mathrm{C}$ NMR spectrum of Compound 13. 
MALDI Mass Spectrum Report

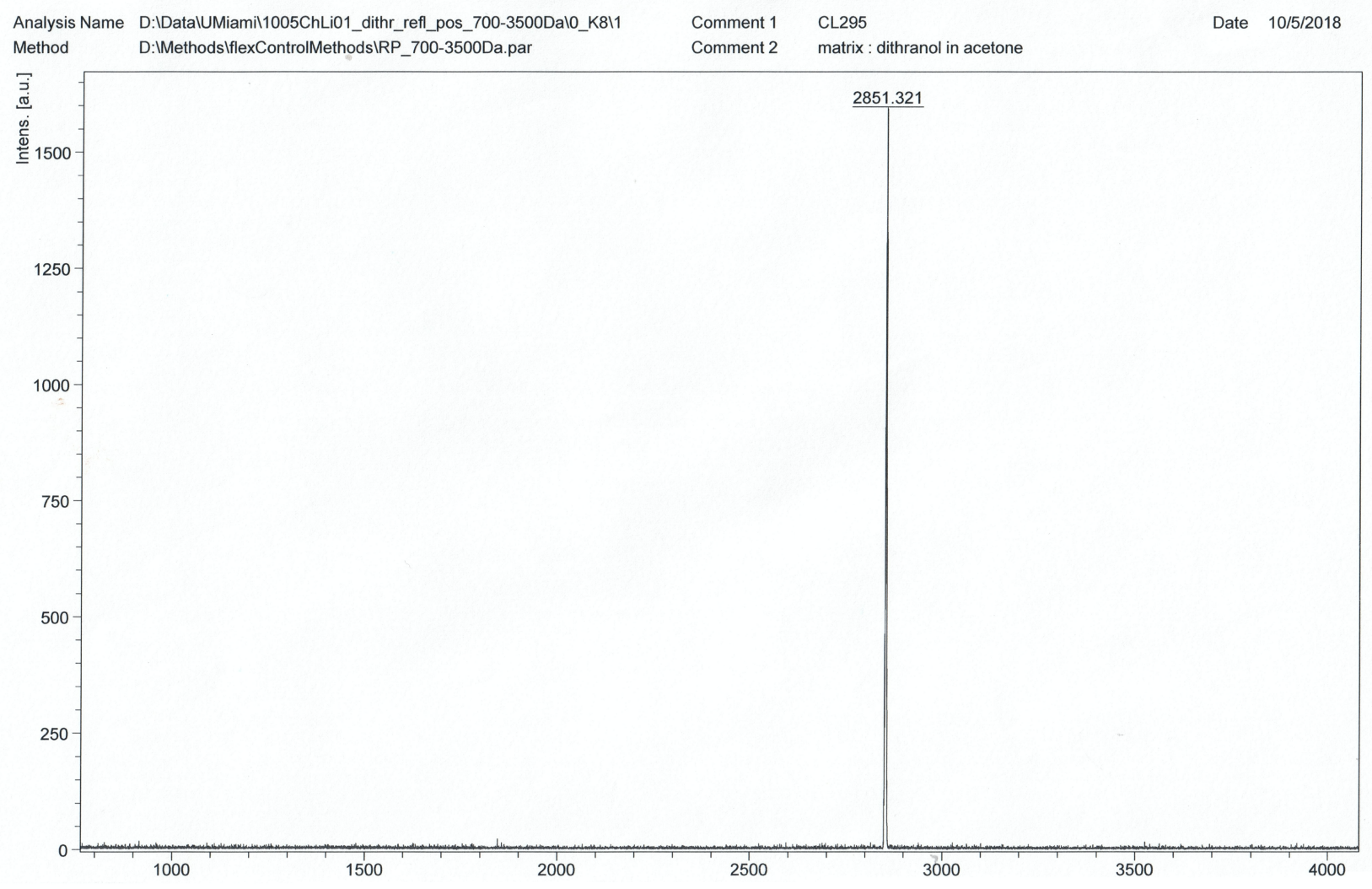

Figure S43. MALDI-MS of Compound 13. 


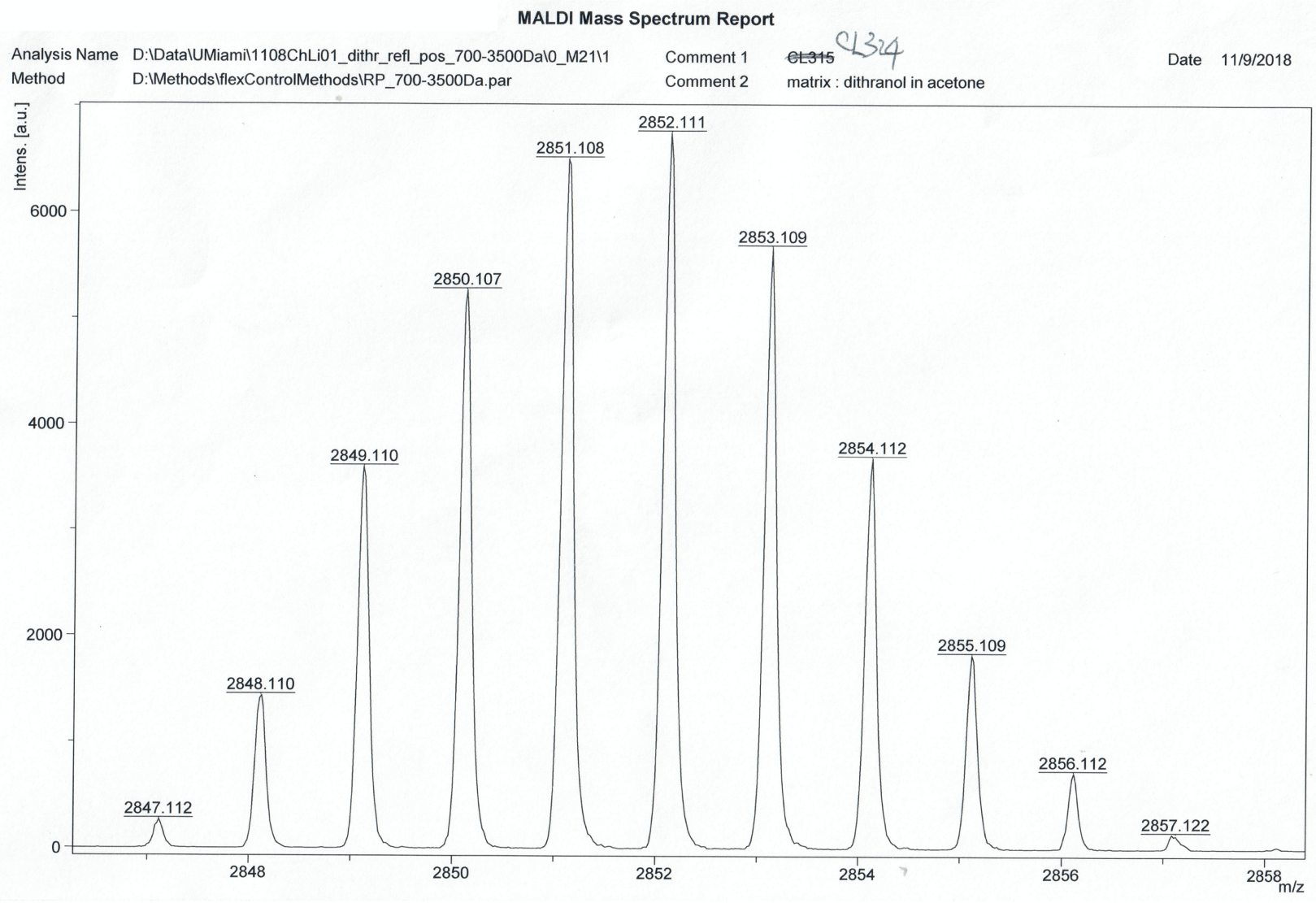

Figure S44. MALDI-MS of Compound 13 (zoomed-in peaks of interest). 

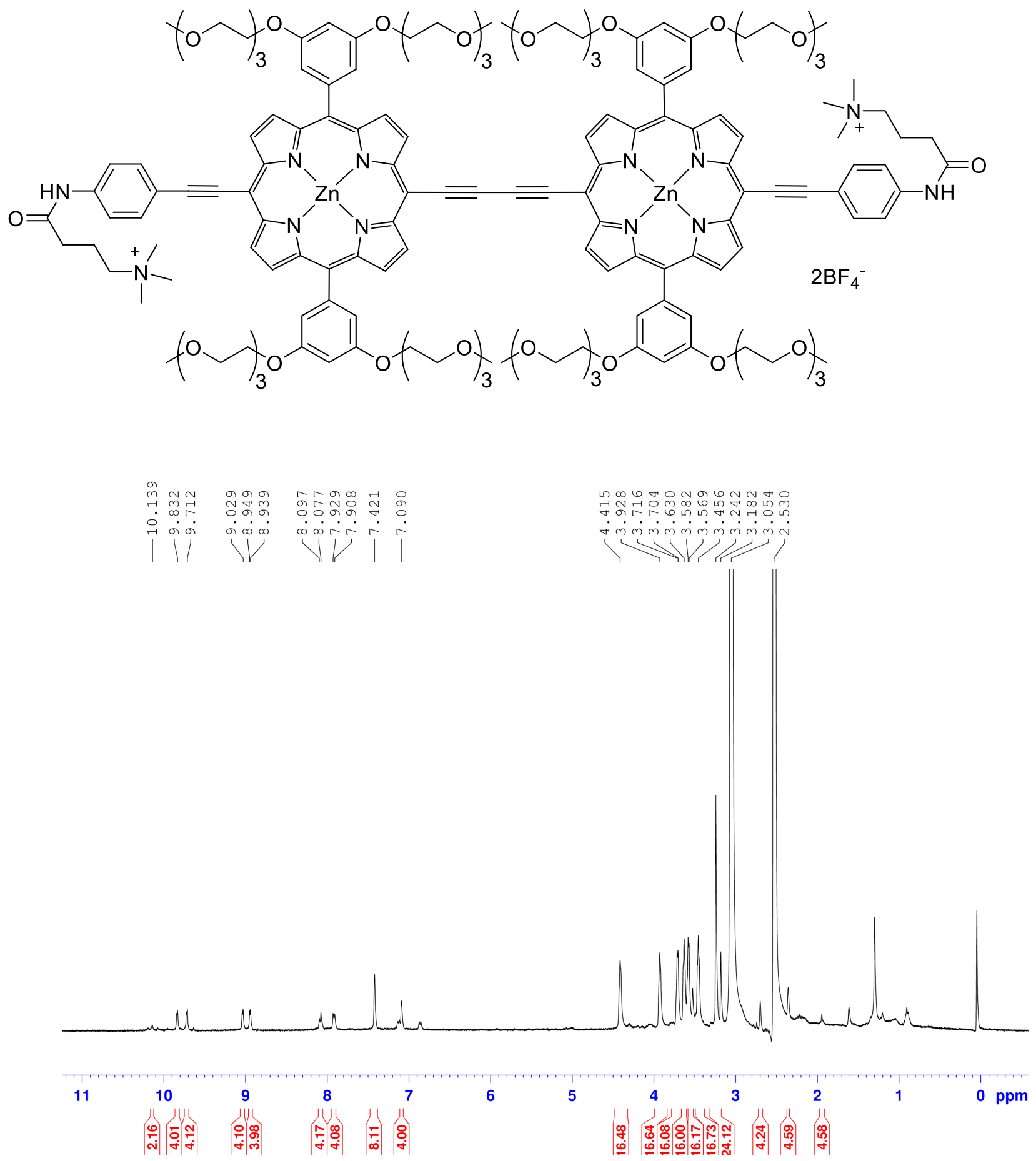

Figure S45. ${ }^{1} \mathrm{H}$ NMR spectrum of MPZnE $_{2} \mathbf{P Z n M}$. 
ESI-TOF Mass Spectrum Report

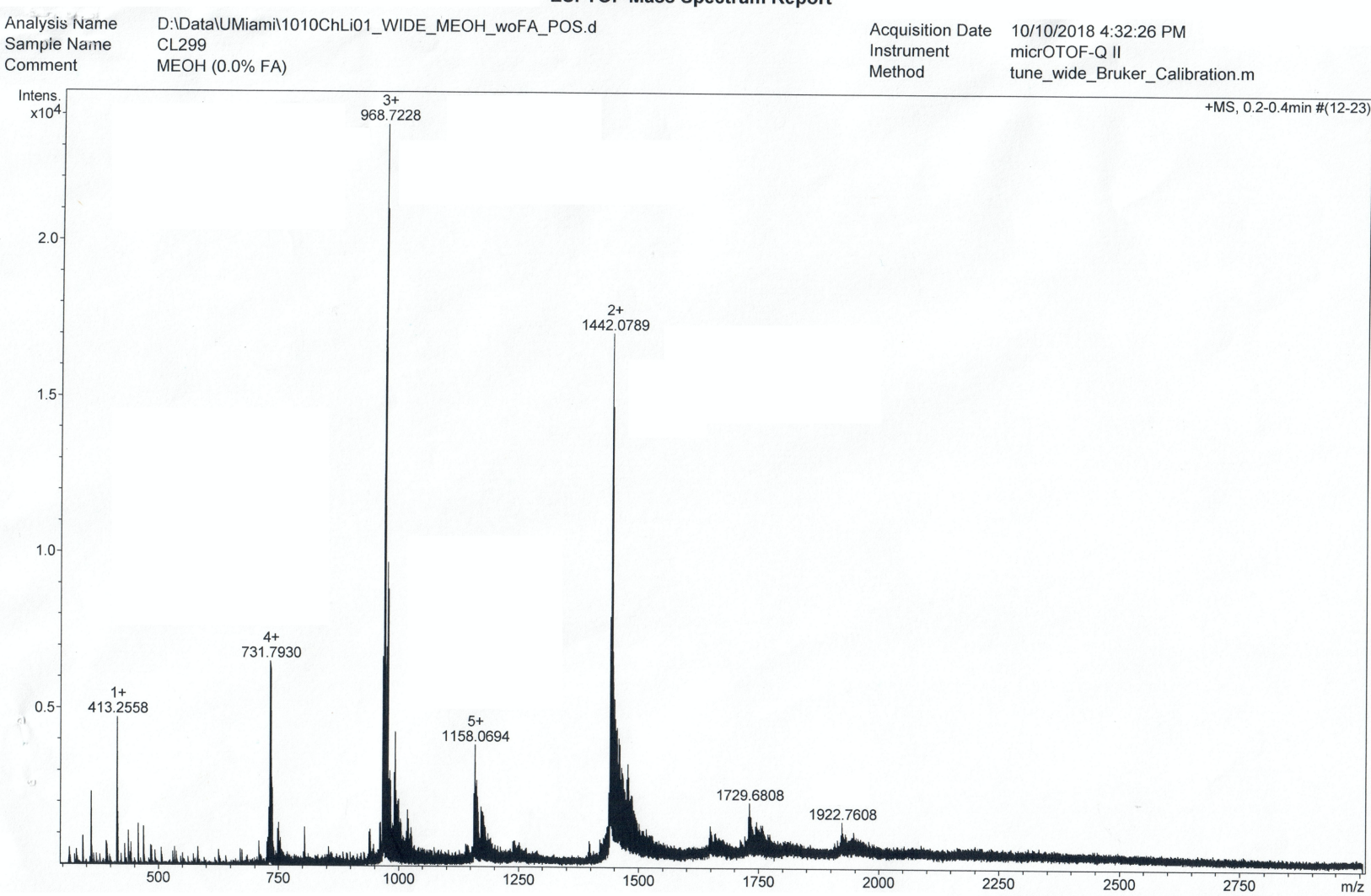

Figure S46. ESI-MS of $\mathrm{MPZnE}_{2} \mathrm{PZnM}$. 


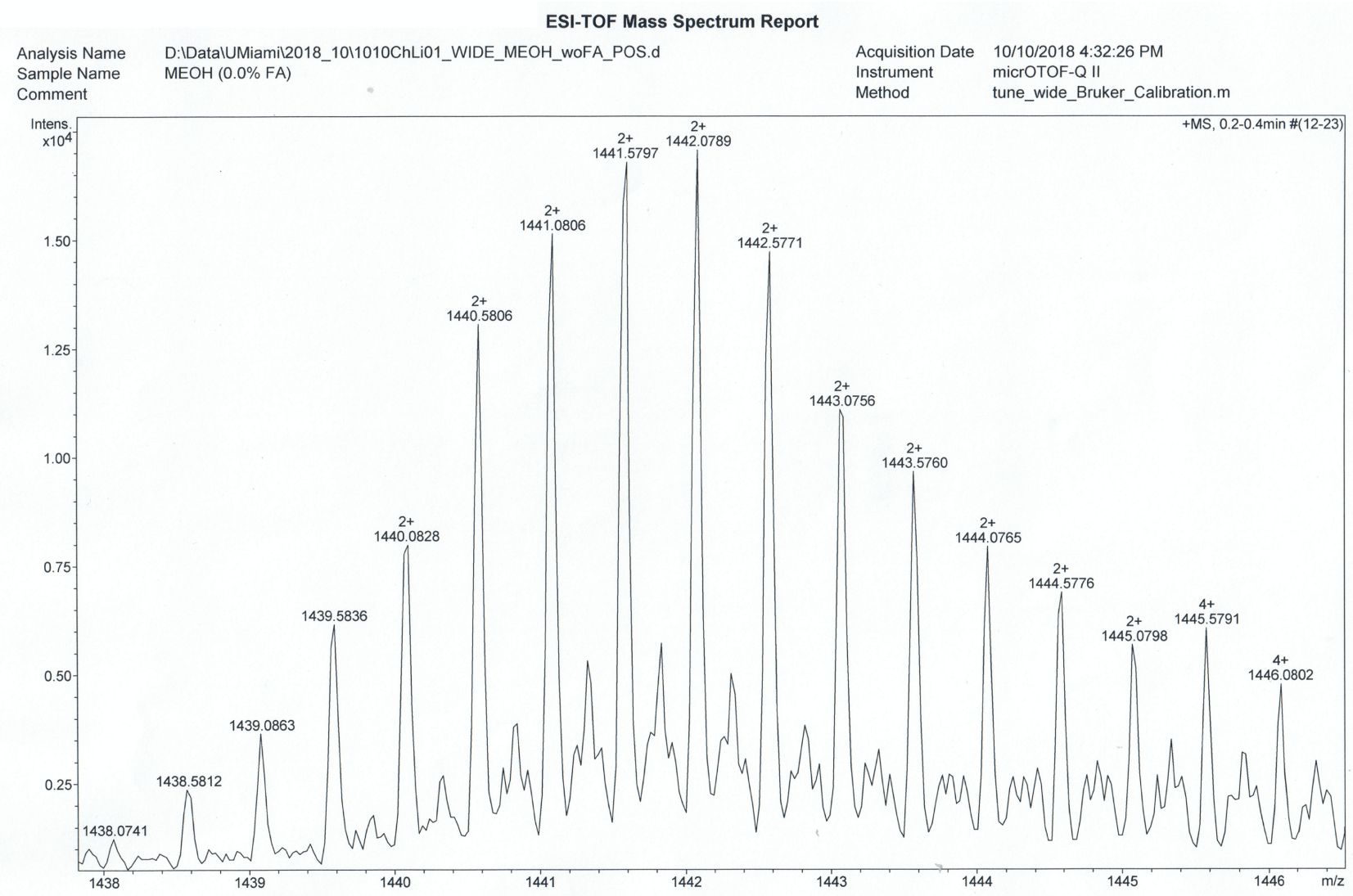

Figure S47. ESI-MS of MPZnE 2 PZnM (zoomed-in peaks of interest). Note: the lower peaks partially overlapped with our main peaks correspond to $[2 \mathrm{M}]^{4+}$ and $[3 \mathrm{M}]^{6+}$. 
ESI-TOF Mass Spectrum Report $\begin{array}{ll}\text { Analysis Name } & \text { D:IDatalUMiamil2018_1011010ChLi01_WIDE_MEOH_woFA_POS.d } \\ \text { Sample Name } & \text { MEOH }(0.0 \% \text { FA) }\end{array}$

Acquisition D
Instrument
Method 10/10/2018 4:32:26 PM micrOTOF-Q II tune_wide_Bruker_Calibration.m

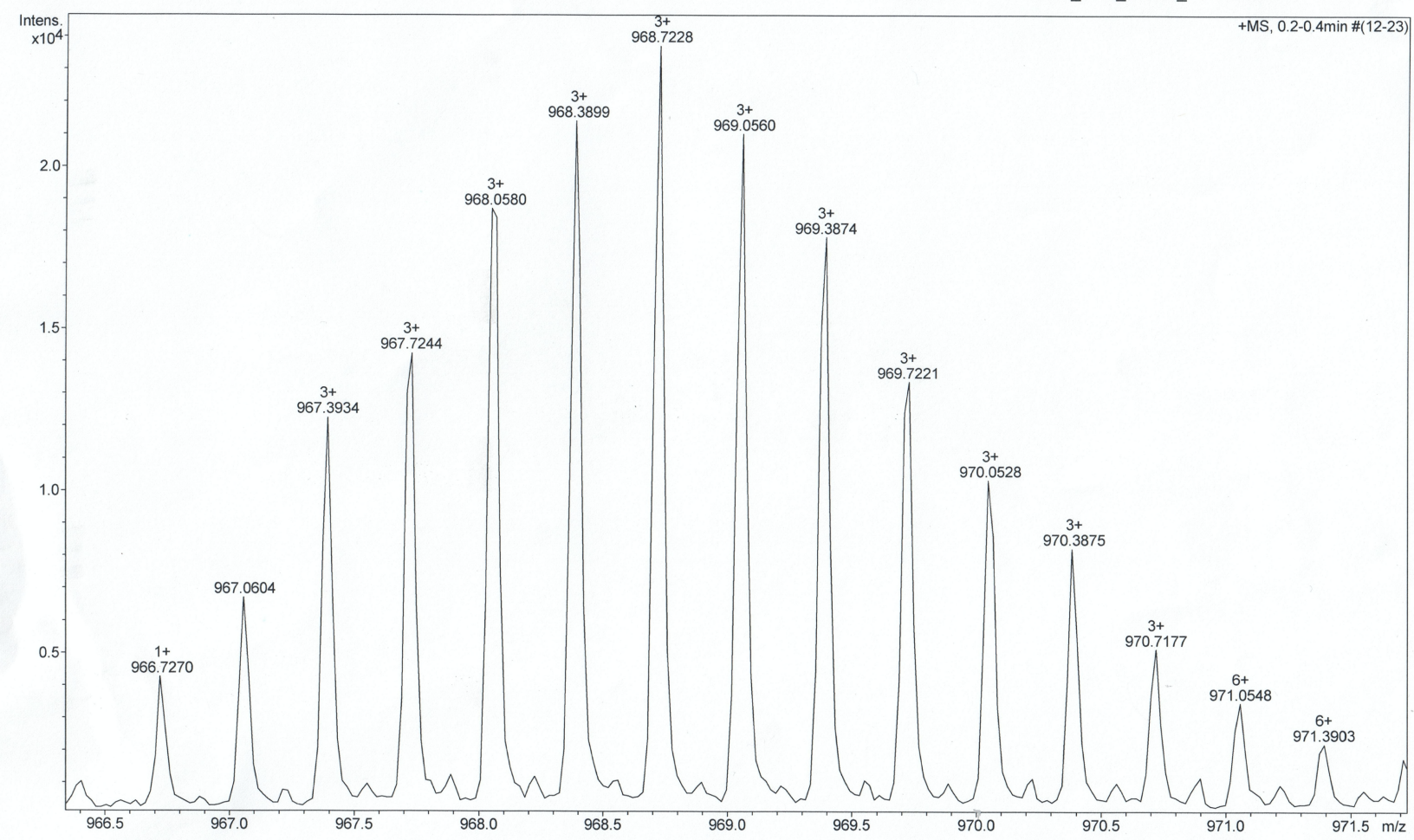

Figure S48. ESI-MS of $\mathbf{M P Z n E}_{2} \mathbf{P Z n M}$ (zoomed-in peaks of interest). 


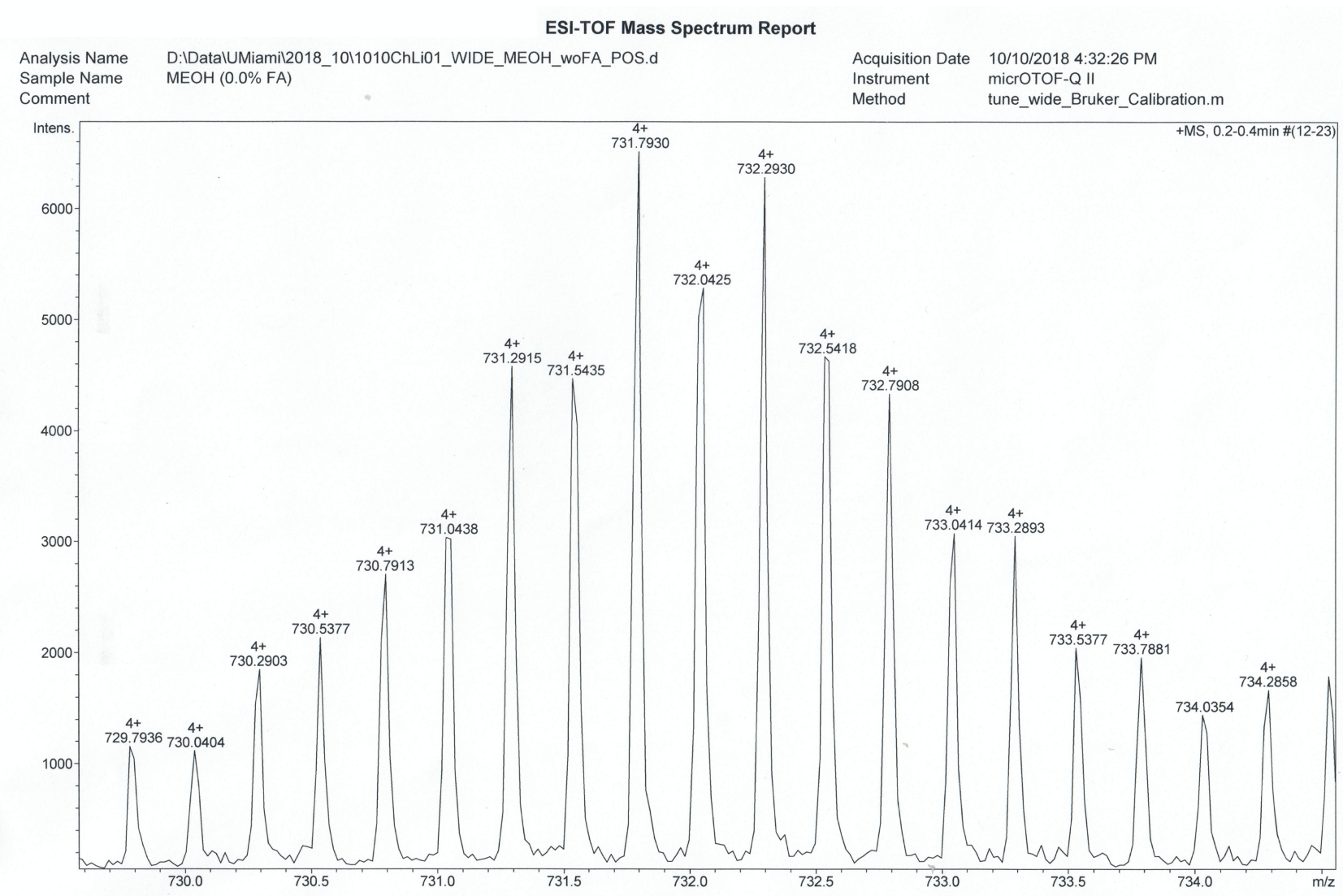

Figure S49. ESI-MS of $\mathrm{MPZnE}_{2} \mathbf{P Z n M}$ (zoomed-in peaks of interest). 


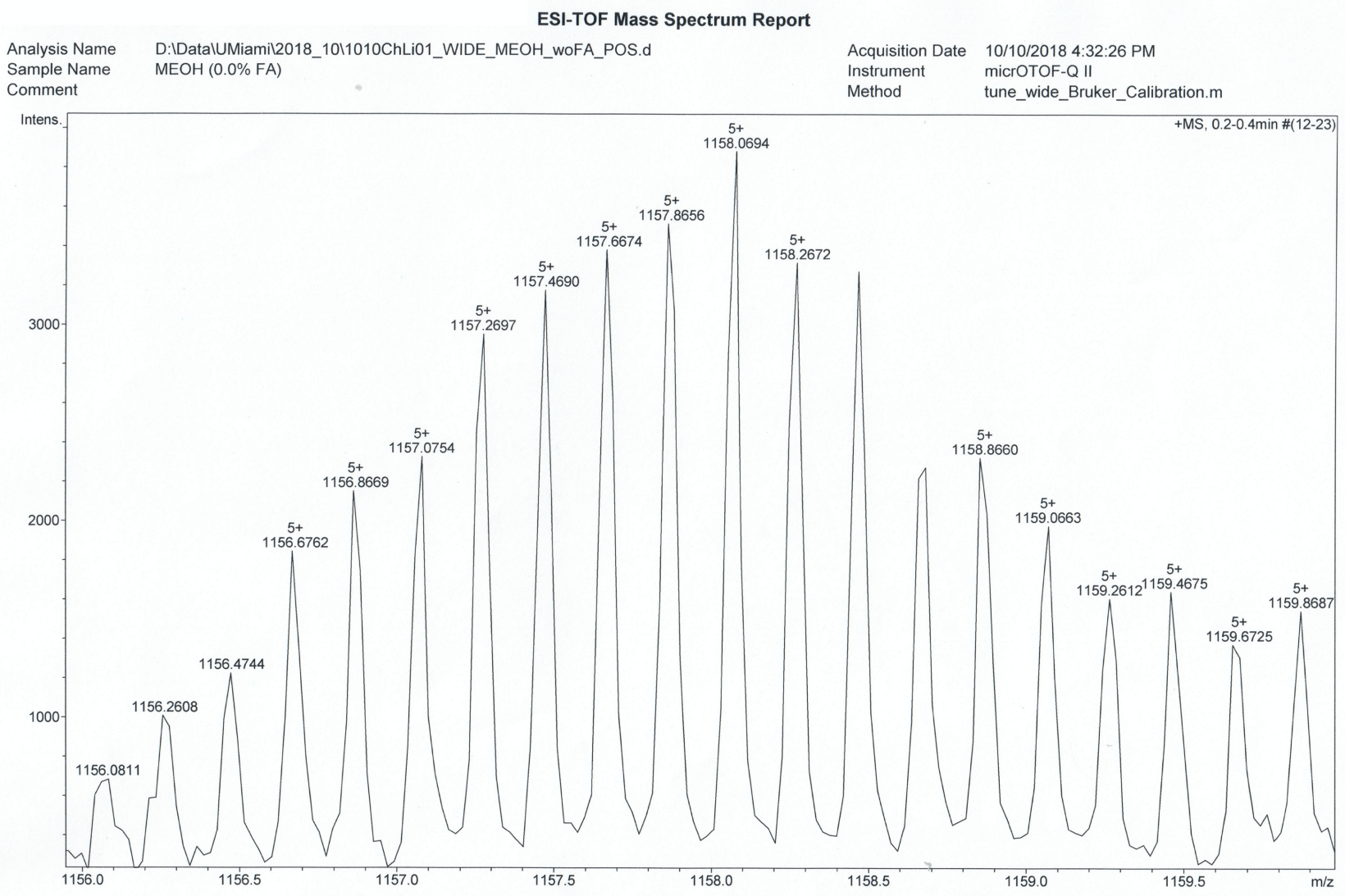

Figure S50. ESI-MS of $\mathrm{MPZnE}_{2} \mathbf{P Z n M}$ (zoomed-in peaks of interest). 


\section{References}

1. Frisch, M. J.; Trucks, G. W.; Schlegel, H. B.; Scuseria, G. E.; Robb, M. A.; Cheeseman, J. R.; Scalmani, G.; Barone, V.; Petersson, G. A.; Nakatsuji, H.; Li, X.; Caricato, M.; Marenich, A. V.; Bloino, J.; Janesko, B. G.; Gomperts, R.; Mennucci, B.; Hratchian, H. P.; Ortiz, J. V.; Izmaylov, A. F.; Sonnenberg, J. L.; Williams; Ding, F.; Lipparini, F.; Egidi, F.; Goings, J.; Peng, B.; Petrone, A.; Henderson, T.; Ranasinghe, D.; Zakrzewski, V. G.; Gao, J.; Rega, N.; Zheng, G.; Liang, W.; Hada, M.; Ehara, M.; Toyota, K.; Fukuda, R.; Hasegawa, J.; Ishida, M.; Nakajima, T.; Honda, Y.; Kitao, O.; Nakai, H.; Vreven, T.; Throssell, K.; Montgomery Jr., J. A.; Peralta, J. E.; Ogliaro, F.; Bearpark, M. J.; Heyd, J. J.; Brothers, E. N.; Kudin, K. N.; Staroverov, V. N.; Keith, T. A.; Kobayashi, R.; Normand, J.; Raghavachari, K.; Rendell, A. P.; Burant, J. C.; Iyengar, S. S.; Tomasi, J.; Cossi, M.; Millam, J. M.; Klene, M.; Adamo, C.; Cammi, R.; Ochterski, J. W.; Martin, R. L.; Morokuma, K.; Farkas, O.; Foresman, J. B.; Fox, D. J. Gaussian 09 Rev. D.01, Wallingford, CT, 2009.

2. Susumu, K.; Therien, M. J., Decoupling Optical and Potentiometric Band Gaps in m-Conjugated Materials. J. Am. Chem. Soc. 2002, 124 (29), 8550-8552.

3. Frail, P. R.; Susumu, K.; Huynh, M.; Fong, J.; Kikkawa, J. M.; Therien, M. J., Modulation of Dark Conductivity over a $1 \times 10-12$ to $1 \times 10-5 \mathrm{~S} / \mathrm{cm}$ Range Through Ancillary Group Modification in Amorphous Solids of Ethyne-Bridged (Porphinato)zinc(II) Oligomers. Chem. Mater. 2007, 19 (25), 60626064.

4. Winters, M. U.; Kärnbratt, J.; Eng, M.; Wilson, C. J.; Anderson, H. L.; Albinsson, B., Photophysics of a Butadiyne-Linked Porphyrin Dimer: Influence of Conformational Flexibility in the Ground and First Singlet Excited State. J. Phys. Chem. C 2007, 111 (19), 7192-7199.

5. Peeks, M. D.; Neuhaus, P.; Anderson, H. L., Experimental and computational evaluation of the barrier to torsional rotation in a butadiyne-linked porphyrin dimer. Phys. Chem. Chem. Phys. 2016, 18 (7), 5264-5274.

6. Bentea, L.; Watzky, M. A.; Finke, R. G., Sigmoidal Nucleation and Growth Curves Across Nature Fit by the Finke-Watzky Model of Slow Continuous Nucleation and Autocatalytic Growth: Explicit Formulas for the Lag and Growth Times Plus Other Key Insights. J. Phys. Chem. C 2017, 121 (9), 53025312.

7. Morris, A. M.; Watzky, M. A.; Finke, R. G., Protein aggregation kinetics, mechanism, and curvefitting: A review of the literature. Biochimica et Biophysica Acta (BBA) - Proteins and Proteomics 2009, 1794 (3), 375-397.

8. Watzky, M. A.; Finke, R. G., Transition Metal Nanocluster Formation Kinetic and Mechanistic Studies. A New Mechanism When Hydrogen Is the Reductant: Slow, Continuous Nucleation and Fast Autocatalytic Surface Growth. J. Am. Chem. Soc. 1997, 119 (43), 10382-10400. 